\title{
Guide to Tables of Elliptic Functions
}

by

Alan Fletcher

Editorial Note

\section{CONTENTS}

Preface

Part I: Guide to Tables

I-Tables concerning the modulus

II-Complete elliptic integrals of the first and second kinds

III-JACOBI's nome $q$

IV-Theta functions of zero argument

V-LAPLACE coefficients and related functions

VI-Combinations of $K$ and $E$ occurring in connection with currents in circles and coils

VII-Miscellaneous tables involving complete elliptic integrals and theta functions of zero argument

VIII-Incomplete elliptic integrals of the first and second kinds

IX-Elliptic integrals of the third kind

$\mathrm{X}$-Theta functions, Jacobian amplitude, second integral and zeta function

XI-Jacobian elliptic functions

XII-Weierstrassian functions

XIII-Dixon functions

Part II: Bibliography of Authors of Tables

Part III: Errors in Elliptic Tables

Note: In the various parts, differences are referred to as in FMR Index. In the description of a table, $\Delta$ means that first differences only are given; $\Delta^{2}$ means first and second differences, $\delta^{2}$ means second differences only, $\delta_{m^{2}}$ means modified second differences, $\Delta^{4}$ means first to fourth differences, $\delta^{4}$ means second and fourth differences, and so on.

\section{Editorial Note}

Of material which HARRy BATEman had prepared for his Subcommittee L-Report on Higher Mathematical Functions we have already published the part dealing with Bessel Functions (MTAC, no. 7, 1944). Since in varied research problems there seemed now to be an increasing demand for tabular information regarding Elliptic Functions, we invited Dr. FLETCHER, of the University of Liverpool, to prepare a Guide to this material as ahother part of our Section L-Report,-quite independent of anything H.B. had collected. The following comprehensive survey indicates not only all tables, but also all known errata, including many previously unpublished, discovered in Dr. FleTCHER's personal investigations. We are indeed grateful for this valuable aid in the promotion of scientific inquiry.

\section{Preface}

R. C. A.

In the title, "elliptic functions" is to be understood in a general sense, as including elliptic integrals and theta functions; in fact, existing tables, and therefore the present Guide, relate largely to elliptic integrals. "Tables" means numerical tables; extensive lists of formulae are given in several of the works quoted, but no account is given here of the enormous amounts of algebraical calculation which have been devoted to transformations 
of order higher than the third. The outlook is practical, and in sympathy with Lucien LEvy's dictum that "the most elementary properties of the elliptic functions are the most useful."

It will be observed that the Guide is divided into the following three parts: Part I, a descriptive Guide to all tables considered, referring, with constant obvious abbreviations, to material listed in the detailed bibliography of Part II ; and Part III, devoted to lists of errata in certain tables marked with an asterisk in Part II.

There is naturally in Part I an appreciable amount of duplication with FMR Index regarding material published before 1946; but in the present Part II much greater detail is offered, and Part III is almost entirely new.

Great care has been taken in Part III to indicate the nature of the verifications made and the status of the error lists given. A mere list of known errors, unaccompanied by any statement regarding its degree of completeness, is of limited use to the computer. Unless it can be asserted that the table in question contains no other gross errors, or at any rate no errors exceeding a definite size, he is still in the position of not having complete confidence in any entry. In several cases I have stated that a table is free from gross error (or free from any error); such a statement is more valuable than an imposing but uncharacterized list of errors. In a few cases where I have not examined a table, but merely communicate a few errors found by others, I have been careful to make clear the limited nature of the information given.

For information on the numerical calculation of elliptic integrals and functions, one may consult, among other references, L. V. KING, On the Direct Numerical Calculation of Elliptic Functions and Integrals, Cambridge, 1924, and a number of papers by S. C. vaN Veen in Akad. Wetens., Amsterdam, Proc., v. 44-45, 1941-42.

In performing about half the differencing which was done on the National accounting machine in the Mathematical Laboratory at Liverpool I had the invaluable assistance of Miss Olive E. Vanes. I also wish to thank various library officials, friends and colleagues, and the University of Liverpool, for encouragement and arrangement of facilities for carrying on my investigations; and Professor R. C. ARChibald for his encouragement and his care in editing the manuscript.

\section{PART I}

\section{Guide to Tables}

\section{Section I: TABLES Concerning the Modulus}

The description of tables of elliptic integrals and functions is complicated by the fact, which will become very noticeable, that various ways of specifying the modulus $k$ have been used, so that the various tables employ several different argument-systems. The older use of the modular angle $\sin ^{-1} k$ (which we shall denote by $\theta$, except, for a special reason, in Section IX) and the more recent use of $k^{2}$ are by far the most important for general mathematical purposes, since they facilitate tabulation of functions of the complementary modulus $k^{\prime}$ defined by $k^{\prime}=\sqrt{ }\left(1-k^{2}\right)=\cos \theta\left(k\right.$ and $k^{\prime}$ will almost always be real and between 0 and 1$)$; but other arguments $\left(k, k^{\prime}, \log k, \log k^{\prime 2}, \tan ^{2} \theta\right.$, etc.) are convenient for special purposes.

Several tables for conversion of system (tables of $\theta$ against $k^{2}, k^{2}$ against $\theta$, and $k$ against $k^{2}$ ) are given in HAYASHI 1, 2. These tables contain a number of errors. In most cases a computer, presumed to be using a calculating machine, will do best to perform his own squarings and extractions of square root, when a reliable table, such as BARLOw-Comrie, does not suffice; while the standard trigonometric and logarithmic tables are usually to be preferred, because of their great extent and accuracy, to any small table offered among elliptic tabulations.

Two tables for applying LANDEN's transformation will now be mentioned. The formulae for decreasing the modulus from $k$ to $k_{1}$, so making $K_{1}^{\prime} / K_{1}=2 K^{\prime} / K$, that is, doubling the 
period ratio, are

$$
k_{1}=\left(1-k^{\prime}\right) /\left(1+k^{\prime}\right)<k, \quad k_{1}{ }^{\prime}=2 \sqrt{ } k^{\prime} /\left(1+k^{\prime}\right)>k^{\prime} .
$$

$k_{1}{ }^{\prime 2}$ is tabulated to 7D with first differences for $k^{\prime 2}=0(.001) 1$ in NAGAoka \& SAKuraI 1 (p. 49). Successive applications of Landen's transformation provide a method of computing elliptic integrals, and 14D logarithms of the sequence of moduli and complementary moduli are given in LEGENDRE 3 (T.VI), 5 (T.VI) for $\theta=0\left(0^{\circ} .1\right) 15^{\circ}\left(0^{\circ} .5\right) 45^{\circ}$.

Elliptic calculations are frequently made by methods involving the evaluation of arithmetic-geometric means, usually between 1 and $k^{\prime}$. The process is a variant form of repeated Landen transformation. Usually only its end-result is of interest. But on account of their extent, it may be noticed that the first six sets of number triplets are given to 17D for $k^{2}=0(.01) 1$ in the unpublished NBSCL 2. See also the description of BartKy 1 in Section IX.

LEGENDRE 4 (p. 226) gives a table of modular angles in the cubic transformation. If the modular angles are $\theta$ and $\lambda(\theta<\lambda)$, and the corresponding quarter-periods are $K, K^{\prime}$, $\Lambda, \Lambda^{\prime}$, then $K^{\prime} / K=3 \Lambda^{\prime} / \Lambda$, provided that

$$
\begin{gathered}
p=\sin \left(M-30^{\circ}\right) / \cos M, \quad q=\cos \left(M-30^{\circ}\right) / \sin M, \quad 30^{\circ} \leqslant M \leqslant 60^{\circ}, \\
\sin ^{2} \theta=p^{3} q, \quad \sin ^{2} \lambda=p q^{2} .
\end{gathered}
$$

LEGENDRE 4 gives $\theta$ and $\lambda$ to $5 \mathrm{D}$ of $1^{\circ}$ for $M=30^{\circ}\left(1^{\circ}\right) 60^{\circ}$. At $M=45^{\circ}$ we have the wellknown case $\theta=15^{\circ}, \lambda=75^{\circ}$; moreover the second half of the table may be written down from the first, by changing $M, \theta, \lambda$ into $90^{\circ}-M, 90^{\circ}-\lambda, 90^{\circ}-\theta$ respectively. For a related table, see F. W. Newman 1, 2 in Section XI.

\section{Section II : Complete Elliptic Integrals of the First and Second Kinds}

The incomplete elliptic integrals of the first and second kinds will be denoted by, respectively,

$$
F(\phi)=\int_{0}^{\phi}\left(1-k^{2} \sin ^{2} \phi\right)^{-1} d \phi \quad \text { and } \quad E(\phi)=\int_{0}^{\phi}\left(1-k^{2} \sin ^{2} \phi\right)^{1} d \phi .
$$

These are functions of two variables, namely $\phi$ and $k$ (or $\sin ^{-1} k$, $k^{2}$, etc.). In this section we are concerned only with the corresponding complete integrals in which the upper limit is $\frac{1}{2} \pi$, which we shall denote as usual by

$$
K=\int_{0}^{3 \pi}\left(1-k^{2} \sin ^{2} \phi\right)^{-1} d \phi \quad \text { and } \quad E=\int_{0}^{t \pi}\left(1-k^{2} \sin ^{2} \phi\right)^{t} d \phi .
$$

These are functions of one variable, indicating the modulus, only, and are what is most of ten required in applications of elliptic integrals. Along with tables of $K, E$ and their logarithms, we consider tables of $2 K / \pi, 2 E / \pi$ and $\pi / 2 K$; the last of these is equal to $M$, the arithmetic-geometric mean of 1 and $k^{\prime}$. Sections III-VII will be concerned with further expressions involving $K, E$ and the corresponding functions $K^{\prime}, E^{\prime}$ of the complementary modulus.

As $k$ tends to unity, there is apt to be difficulty in interpolating a value of $K$ (which tends to infinity), and to a smaller extent one of $E$. Auxiliary tables for the calculation of $K$ and $E$ in such a case have been given by various authors. These are duly listed in $\mathbf{E}$ below. Attention is particularly drawn to the recent table of KAPLAN 1 (listed in $\mathbf{A}_{\mathbf{3}}$ below), which tabulates $K$ and $E$ to $10 \mathrm{D}$ with argument $\log k^{\prime 2}$. It is interesting to find that, with this argument, the second differences of $K$ become less than those of $E$. Towards the end of KAPLAN's table, in the region where interpolation in ordinary tables is practically impossible, interpolation is linear to 9D in both $K$ and $E$.

The lists at the end of this Section refer to tables in which $k^{2}$ is real. But diagrams for $K$ and $E$ when $k^{2}$ is complex are given in JAHNKE \& EMDE $1_{2}-1_{4}$.

The tables of CAMBI 1 tabulate complete integrals for moduli given by

$$
k^{2}=-e^{i x}=e^{-i y}, \quad k^{\prime 2}=1+e^{i x}=1-e^{-i y},
$$

where $y=\pi-x$. For $x=0(\pi / 20) \pi$, with additional arguments when necessary near 
$x=\pi\left(k^{2}=1\right)$, the tables give, to 7-10D, values of

$$
k^{\prime}, K, K^{\prime}, K / K^{\prime},-\log \left|q^{\prime}\right|, k^{\prime} K \text { and } e^{\text {tiv }}\left(1-E^{\prime} / K^{\prime}\right) \text {. }
$$

On the circle of tabulation, $q^{\prime}=e^{-\pi K / K^{\prime}}$ is purely imaginary. For fuller details, see RMT 565.

II-A $\mathrm{A}_{1} . K$ and $E$, argument $\theta$

15D, SPENCELEY $1, \theta=0\left(1^{\circ}\right) 90^{\circ}$

12D, LEGENDRE 3 (T.VIII), 5 (T.VIII), $7, \theta=0\left(1^{\circ}\right) 90^{\circ}, \Delta^{6}$ to $45^{\circ}$, then $\Delta$

12D, Moseley $1, \theta=0\left(1^{\circ}\right) 90^{\circ}$, from LeGENDRE

12D, $K$ only, F. W. Newman 2 (p. 29, 132), $\theta=0\left(1^{\circ}\right) 90^{\circ}$, from Legendre

9-10D, LEGENDRE 3 (T.IX), 5 (T.IX), 6, 7, 8, $\theta=0\left(1^{\circ}\right) 90^{\circ}\left(\phi=90^{\circ}\right.$ in double-entry tables)

9-10D, Hippisley $1, \theta=0\left(1^{\circ}\right) 10^{\circ}\left(5^{\circ}\right) 80^{\circ}\left(1^{\circ}\right) 90^{\circ}$

9D, S.A.E.W.E.B. 1 (p. 345$), \theta=0\left(2^{\circ} .5\right) 90^{\circ}$

7D, Boll 1 (p. 351), $\theta=0\left(1^{\circ}\right) 70^{\circ}\left(0^{\circ} .5\right) 80^{\circ}\left(0^{\circ} .2\right) 89^{\circ}\left(0^{\circ} .1\right) 90^{\circ}$

$7 \mathrm{D}, K$ only, LÁSKA $1, \theta=0\left(1^{\circ}\right) 90^{\circ}$

6D, Rosa \& CoHen 1 and Rosa \& Grover $1, \theta=0\left(1^{\circ}\right) 90^{\circ}, \Delta^{2}$

6D, GRAY $1_{2}, \theta=0\left(1^{\circ}\right) 90^{\circ}, \Delta$

$6 \mathrm{D}$, Russell $1, \theta=0\left(1^{\circ}\right) 90^{\circ}$

5D, KIEPERT $1, \theta=0\left(0^{\circ} .2\right) 90^{\circ}$

5D, Lévy 1 , HaNCock 1 , HaYAShi $2, \theta=0\left(1^{\circ}\right) 70^{\circ}\left(0^{\circ} .5\right) 80^{\circ}\left(0^{\circ} .2\right) 89^{\circ}\left(0^{\circ} .1\right) 90^{\circ}$

5D, DALE 1, FRICKE $1, \theta=0\left(1^{\circ}\right) 90^{\circ}$

$5 \mathrm{D}, K$ only, Dwight $2, \theta=86^{\circ}\left(1^{\prime}\right) 90^{\circ}, \Delta$

$4 \mathrm{D}$, SilBersteIN $1, \theta=0\left(1^{\circ}\right) 45^{\circ}\left(0^{\circ} .5\right) 80^{\circ}\left(0^{\circ} .2\right) 89^{\circ}\left(0^{\circ} .1\right) 90^{\circ}$

$4 \mathrm{D}$, Peirce 2, Burington 1 , Allen $1, \theta=0\left(1^{\circ}\right) 65^{\circ}\left(0^{\circ} .5\right) 80^{\circ}\left(0^{\circ} .2\right) 89^{\circ}\left(0^{\circ} .1\right) 90^{\circ}$

$4 \mathrm{D}$, Rosenbach, Whitman \& Moskovitz $1, \theta=0\left(1^{\circ}\right) 70^{\circ}\left(30^{\prime}\right) 80^{\circ}\left(12^{\prime}\right) 89^{\circ}\left(6^{\prime}\right) 89^{\circ} 30^{\prime}\left(3^{\prime}\right) 90^{\circ}$

$4 \mathrm{D}$, JAHNKe \& EMde 1 , GläenaP $1, \theta=0\left(1^{\circ}\right) 70^{\circ}\left(0^{\circ} .5\right) 80^{\circ}\left(0^{\circ} .2\right) 89^{\circ}\left(0^{\circ} .1\right) 90^{\circ}$

$4 \mathrm{D}$, LigowsKI $1, \theta=0\left(0^{\circ} .5\right) 89^{\circ} .5\left(0^{\circ} .1\right) 90^{\circ}$

4D, Hodgman 1, $\theta=0\left(1^{\circ}\right) 90^{\circ}$, also $K$ to $3 \mathrm{D}$ for $\theta=85^{\circ}\left(6^{\prime}\right) 89^{\circ}\left(2^{\prime}\right) 89^{\circ} 40^{\prime}\left(1^{\prime}\right) 90^{\circ}$

$4 \mathrm{D}$, Fowle 1 , Peirce 1 , HÜtTe $1, \theta=0\left(1^{\circ}\right) 90^{\circ}$

$3 \mathrm{D}, K$, Dwight $1, \theta=0\left(1^{\circ}\right) 50^{\circ}\left(30^{\prime}\right) 70^{\circ}\left(12^{\prime}\right) 82^{\circ}\left(6^{\prime}\right) 89^{\circ}\left(2^{\prime}\right) 89^{\circ} 40^{\prime}\left(1^{\prime}\right) 90^{\circ}, \Delta$

$3 \mathrm{D}, E$, Dwight $1, \theta=0\left(1^{\circ}\right) 90^{\circ}, \Delta$

3D, Montessus DE BaLlore 1, small tables

II-A2. $K$ and $E$, argument $k^{2}$

16D, $K$ only, NBSCL $2, k^{2}=0(.01) 1$

$12 \mathrm{D}, K$, HAYASHI $1, k^{2}=.835(.001) 1$

$10 \mathrm{D}, K$, HAYASHI $1, k^{2}=0(.001) .834, k^{2}=0\left(10^{-7}\right) 10^{-5}\left(10^{-5}\right) .00249$

$8 \mathrm{D}, K$, HAYASHI $1, k^{2}=.00250\left(10^{-5}\right) .003,1-k^{2}=0\left(10^{-7}\right) 10^{-5}\left(10^{-5}\right) .003$

$10 \mathrm{D}, E$, Hayashi $3, k^{2}=0(.001) 1$

9D, Milne-Thomson 2, $k^{2}=0(.01) 1, \Delta$

7D, SAMollova-政Hontova $1, k^{2}=0(.001) 1, \Delta$

7D, MiLne-Thomson $3, k^{2}=0(.01) 1$

6D, NAGAOKa \& SAKURAI $1, k^{2}=0(.001) 1, \Delta$

$5 \mathrm{D}$, HAYASHI $2, k^{2}=0(.001) 1$

$5 \mathrm{D}, E$, Dwight $3, k^{2}=0(.001) 1, I \Delta$

$4 \mathrm{D}, K$, Dwight $3, k^{2}=0(.001) .997\left(10^{-5}\right) .99999\left(10^{-7}\right) 1, I \Delta$ in most of range

$4 \mathrm{D}$, JAHNKE \& EMDE $1_{3}, 1_{4}, k^{2}=0(.01) 1, I \Delta$

II-A. $K$ and $E$, other arguments

12D, $K$, FLETCHER $3, k=0(.01) .7(.005) 1, \Delta^{n}$

12D, $E$, FLETCHER $3, k=0(.01) .9(.005) 1, \Delta^{n}$

$11 \mathrm{D}, E$ only, Schmidt 1 (p. 204), $k^{\prime}=0(.01) 1$

10D, KAPLAN $1, \log k^{\prime 2}=-1(.005)-2(.01)-6, \mu \delta^{2}$ or $\frac{1}{2} \mu \delta^{2}$

10D, FLETCHER $2, k=0(.01) 1$ 
7D, Rosa \& Cohen 1 and Rosa \& Grover $1, \tan \theta=0(.1) 1(.5) 3(1) 5(2.5) 12.5$

5D, $E$ only, Schlömilch $1, k^{\prime}=0(.01) 1$

$4 \mathrm{D}, 4 E$ only, JeLf́neK $1, k^{\prime}=0(.01) 1$

$4 \mathrm{D}, 2 E$ only, Moore $1, k^{\prime}=0(.01) 1$ [very inaccurate, see Part III]

$4 \mathrm{D}, E$, Cecconi $1, k=0(.01) 1$ [see also Section VII-4]

3D, $E$ only, WAYNE $1, k^{\prime}=0(.01) 1$

\section{II-B. $\log K$ and $\log E$}

12D, Legendre 3 (T.I), 5 (T.I), $8, \theta=0\left(0^{\circ} .1\right) 90^{\circ}, \Delta^{3}$ to $70^{\circ}$, then $\Delta^{4}$. (From 0 to $15^{\circ}$ and from $75^{\circ}$ to $90^{\circ}, 14 \mathrm{D}$ values, not very accurate, are given for the functions, but the differences throughout are those of the $12 \mathrm{D}$ values.)

8D, Rosa \& Cohen 1 and Rosa \& Grover $1, \theta=45^{\circ}\left(0^{\circ} .1\right) 90^{\circ}, \Delta^{2}$

$8 \mathrm{D}$, Russell $1, \theta=80^{\circ}\left(0^{\circ} .1\right) 90^{\circ}, \Delta^{2}$

7D, Bertrand 1 (p. 714), $\theta=0\left(0^{\circ} .5\right) 90^{\circ}, K$ and $E$ called $\omega$ and $\zeta$

$7 \mathrm{D}$, Greenhill 3, Potin $1, \theta=0\left(0^{\circ} .5\right) 90^{\circ}$

7D, LEgENDRE 1 (p. 118), $\theta=0\left(1^{\circ}\right) 90^{\circ}$

7D, Rosa \& Cohen 1 and Rosa \& Grover $1, \tan \theta=0(.1) 1(.5) 3(1) 5(2.5) 12.5$

$6 \mathrm{D}$, Hodgman $1, \theta=0\left(1^{\circ}\right) 90^{\circ}$, also $\log K$ to $5 \mathrm{D}$ for $\theta=85^{\circ}\left(6^{\prime}\right) 89^{\circ}\left(2^{\prime}\right) 89^{\circ} 40^{\prime}\left(1^{\prime}\right) 90^{\circ}$

6D, Fowle $1, \theta=0\left(1^{\circ}\right) 90^{\circ}$

5D, Bohlin 1 , Witkowski $1, \theta=0\left(0^{\circ} .1\right) 90^{\circ}$

$4 \mathrm{D}$, HoüEL $1, \theta=0\left(1^{\circ}\right) 100^{\circ}$

II-C. $2 K / \pi, 2 E / \pi, M=\frac{1}{2} \pi / K$ and their logarithms

$12 \mathrm{D}, 2 K / \pi, 2(K-E) / \pi$, KaPLAN $2, \tan ^{2} \theta=-.005(.005)+.160, \delta_{m}^{2}$

$6 \mathrm{D}, 2 K / \pi, 2 E / \pi$, HEUMAN $1, \theta=0\left(0^{\circ} .1\right) 90^{\circ}, \Delta$

$9 \mathrm{D}, 2 K / \pi$, also $(2 K / \pi)^{2}$, S.A.E.W.E.B. 1 (p. 345$), \theta=0\left(2^{\circ} .5\right) 90^{\circ}$

$14 \mathrm{D}, \log (2 \mathrm{~K} / \pi)$, LEGENDRE 3 (T.VI), 5 (T.VI), $\theta=0\left(0^{\circ} .1\right) 15^{\circ}\left(0^{\circ} .5\right) 45^{\circ}$

$4 \mathrm{D}, \log (2 K / \pi)$, HoüEL $1, \theta=0\left(1^{\circ}\right) 100^{\circ}$

$17 \mathrm{D}, M$, NBSCL $2, k^{2}=0(.01) 1$

11-15D, $M$, GAUSS 2 (p. 363), $k^{\prime}=.2, .6, .8$

12D, $M$, Fletcher $3, k=0(.01) .7(.005) 1, \Delta^{n}$

10D, $M$, Fletcher $2, k=0(.01) 1$

10D, $M\left(=1 / \vartheta_{3}{ }^{2}\right)$, MiLne-Thomson $2, k^{2}=0(.01) 1, \Delta$

$12 \mathrm{D}, M$, Hayashi $1, k^{2}=.835(.001) 1$

$8 \mathrm{D}, M$, HAYASHI $1, k^{2}=.997\left(10^{-5}\right) .99999\left(10^{-7}\right) 1$

$7 \mathrm{D}, M, \log M$, Gauss 2 (p. 403), $\theta=0\left(0^{\circ} .5\right) 90^{\circ}$

See also Section V.

II-D. $K^{\prime} / K, E / K$

10D, $K^{\prime} / K$, HAYASHI $1, k^{2}=0(.001) 1$

$8 \mathrm{D}, K^{\prime} / K, K / K^{\prime}$, HAYASHI $1, k^{2}=0\left(10^{-7}\right) 10^{-5}\left(10^{-5}\right) .003$

7D, $E / K$, Milne-Thomson $4, k^{2}=0(.1) 1$

II-E. A uxiliary tables, mainly for fairly large $k$

13-12D, $K_{1}, K_{2}, E_{1}, E_{2}$, AIREY $1, k^{\prime 2}=0(.00001) .00010, \delta^{2}, K=K_{1} \ln \left(4 / k^{\prime}\right)-K_{2}$, $E=E_{1} \ln \left(4 / k^{\prime}\right)+E_{2}$

12-11D, $K_{1}, K_{2}, E_{1}, E_{2}$, AIREY $1, k^{\prime 2}=0(.0001) .0010, \delta^{2}$

10D, $K_{1}, K_{2}$, AIREY 1, $k^{\prime 2}=0(.001) .170, \delta^{2}$

10D, $E_{1}, E_{2}$, AIREy $1, k^{\prime 2}=0(.001) .100, \delta^{2}$

$8 \mathrm{D}$, logarithms of $C, C^{\prime}, C_{1}, C_{1}^{\prime}, C_{2}$, WiTt $1, \theta=13^{\circ}\left(1^{\circ}\right) 36^{\circ}\left(30^{\prime}\right) 45^{\circ}\left(20^{\prime}\right) 50^{\circ}\left(10^{\prime}\right) 60^{\circ}, \Delta$, where $K=\sec \frac{1}{2} \theta \quad(\sec \theta)^{\frac{1}{t}} C, E=\cos ^{3} \frac{1}{2} \theta(\sec \theta)^{t} C_{1}, C^{\prime}=2 C / \pi, C_{1}^{\prime}=2 C_{1} / \pi$, $C_{2}=C-C_{1}$. More complicated functions for $\theta \geqslant 60^{\circ}$. See also Wirt 2

8D, $\log M$, Idelson $1, \theta=60^{\circ}\left(2^{\circ}\right) 64^{\circ}\left(1^{\circ}\right) 75^{\circ}$, where $2 K / \pi=\sec ^{2} \frac{1}{8} \psi\left(\sec \frac{1}{2} \theta\right)^{\frac{1}{2}}(\sec \theta)^{t} M$, $\cos \psi=(\cos \theta)^{\prime}$. More complicated function for $\theta>75^{\circ}$ 
$8 \mathrm{D}, \log (K / 2 \pi)+2 \log \left(1+\sqrt{ } k^{\prime}\right)$, RoBbins $2, k=.4(.01) \cdot 6(.001) .849$

$7 \mathrm{D}, \log \left[(4 K / \pi) \cos \frac{1}{2} \theta(\cos \theta)^{\mathrm{t}}\right]$, NewcomB 1 (p. 69), $k=.45(.01) .75$

$7-11 \mathrm{D}, K / \ln \left(4 / k^{\prime}\right)$, Dwight $2, \theta=86^{\circ}\left(1^{\prime}\right) 90^{\circ}, \Delta$

$7 \mathrm{D}, K / \log \left(4 / k^{\prime}\right)$, SAMoĺlova- Г̂KHONTOVA $1, k^{2}=.95(.001) 1, \Delta$

6D, $2 K / \pi-a \log (90-\theta), a=(2 / \pi) \ln 10=1.465871$, HeUMAN $1, \theta=65(0.1) 90, \Delta$

$5 \mathrm{D}$, first 8 coefficients in expansions of $K-\frac{1}{2} \pi+\ln k^{\prime}$ and $K^{\prime}+(2 K / \pi) \ln k-\ln 4$ in powers of $k^{2}$, TANNERY \& MOLK 1 (v. 3, p. 215)

$4 \mathrm{D}, K-\ln \left(4 / k^{\prime}\right), \ln \left(4 / k^{\prime}\right)$, JAHNKE \& EMDE $1_{3}, 1_{4}, k^{2}=.7(.01) 1, I \Delta$

$4 \mathrm{D}, \beta=\log K-\log \ln \left(4 / k^{\prime}\right)$, HoüEL 1 (p. 57$), \theta=50^{\circ}\left(1^{\circ}\right) 100^{\circ}$

$4 \mathrm{D}, 4 E / \pi\left(1+k^{\prime}\right)$, Boll 1 (p. 348), $\epsilon=\left(1-k^{\prime}\right) /\left(1+k^{\prime}\right)=0(.01) 1$

4D, $4 E / \pi\left(1+k^{\prime}\right)$, Boll 1 (p. 349), $k^{\prime}=0(.01) 1$

\section{Section III : JACOBI'S NOME $q$}

$q$ is defined as $e^{-\pi K^{\prime} / R}$. Thus $\ln q=-\pi K^{\prime} / K$, or $\log q=-\mu \pi K^{\prime} / K$, where $\mu \pi=\tau \log e$ $=1.364376353841841$, so that a table of $\log q$ is easily computed from a table of $K$, if $\theta$ or $k^{2}$ is the argument. Also

where

$$
\log \log (1 / q)=\log (\mu \pi)+\log K^{\prime}-\log K,
$$

$$
\log (\mu \pi)=0.1349341839946706,
$$

so that $\log \log (1 / q)$ is very easily computed from a table of $\log K$. It is not essential that a table of $\log q$ or of $\log \log (1 / q)$ should extend beyond $\theta=45^{\circ}$ or $k^{2}=\frac{1}{2}$, for if $q^{\prime}$ is the complementary nome $e^{-\pi K / K^{\prime}}$, we have

and

$$
\log q \log q^{\prime}=\mu^{2} \pi^{2}=1.861522834922757
$$

$$
\log \log (1 / q)+\log \log \left(1 / q^{\prime}\right)=2 \log (\mu \pi)=0.2698683679893413 .
$$

If $q=\Sigma a_{n} k^{2 n}$, the exact values of $a_{n}$ were calculated for $n=1(1) 12$ by F. Tisserand, published in Hermite $1_{1}$, and reproduced in Hermite $1_{2}$ and in TANNERy \& Molr 1 (v. 4, p. 121).

The most usual way of computing $q$, other than by using its definition as given above, is to put

when we have

$$
2 \epsilon=\left(1-\sqrt{ } k^{\prime}\right) /\left(1+\sqrt{ } k^{\prime}\right),
$$

$$
\epsilon=\left(q+q^{9}+q^{25}+\ldots\right) /\left(1+2 q^{4}+2 q^{16}+\ldots\right),
$$

which inverts (see WeIERSTRASS \& SCHWARz 1, p. 56) into

$$
q=\epsilon+2 \epsilon^{5}+15 \epsilon^{0}+150 \epsilon^{13}+\ldots
$$

The first 14 terms of the series are given in Lowan, Blanch \& Horenstein 1.

It should be noted that $q$ and $\epsilon$ are called $h$ and $\frac{1}{2} l$ respectively in WeIERstrass \& SchwARZ 1 and elsewhere. The small difference $q-\epsilon$ (called $\left.q-\frac{1}{2} l\right)$ is tabulated to 8D for $q=0(.01) .14$ in NAGAOKA 1 , and to $8 \mathrm{D}$ with $\Delta$ for $q=.02(.002) .1(.001) .15$ in NAGAOKA 2 ; the second table is reproduced in Rosa \& Grover 1. Nagaoka \& Sakurai 1 (p. 56) tabulates $\log 2 \epsilon$ (called $\log l$ ) to $7 \mathrm{D}$ with $\Delta$ for $k^{2}=0(.001) .5$.

For complex $k^{2}$, see CAMBI 1 in Section II; also the diagrams in Jahnke \& Emde 1. (p. 120), $1_{\gamma}-1_{4}$ (p. 46), giving $k^{2}$ as a function of $\tau$, where $q=e^{i \pi \tau}$.

III-A. $q$ and its powers

$16 \mathrm{~S}, q$, SPENCELEY $1, \theta=0\left(1^{\circ}\right) 90^{\circ}$

$14-15 \mathrm{D}, q$, HIPPISLEY $1, \theta=0\left(5^{\circ}\right) 80^{\circ}\left(1^{\circ}\right) 90^{\circ}$

$8 \mathrm{D}, q$, Glaisher $1, \theta=0\left(1^{\circ}\right) 90^{\circ}$

7-5D, $q$, LÁSKA $1, \theta=0\left(1^{\circ}\right) 90^{\circ}$

17D, $q^{n}$, NBSCL $2, n=\frac{1}{4}, \frac{1}{2}, 1(1) 4(2) 8,9,12,16,20,25, k^{2}=0(.01) 1$ 
10D, $q$, Milne-Thomson $1, k^{2}=0(.01) 1, \Delta$

$8 \mathrm{D}, q$, MrLne-Thomson $3, k^{2}=0(.01) 1$

$8 \mathrm{D}, q$, Samol̆lova-ГAkmontova $1, k^{2}=0(.001) 1, \Delta$

$8 \mathrm{D}, q$, HAYASHI $1, k^{2}=0(.001) .5$

$5 \mathrm{D}, q$, HAYASHI $2, k^{2}=0(.001) .5$

7D, $q$, Grover 6 (p. 251), $k^{2}=0(.005) .1, \Delta^{2}$

11D, $q^{25 / 4}$, HAYASHI $1, k^{2}=.3(.001) .5$

10D, $q^{4}, q^{9 / 4}$, HaYASHI $1, k^{2}=0(.001) .5$

$8 \mathrm{D}, q^{1 / 4}$, HAYASHI $1, k^{2}=0(.001) .5$

III-B. $\pm \log q$ and auxiliary functions

10D, $\log (1 / q)$, Plana $1, \theta=0\left(0^{\circ} .1\right) 45^{\circ}\left(1^{\circ}\right) 90^{\circ}$ [highly inaccurate, see Part III]

10D, $\log q$, INNES $2, \theta=0\left(1^{\circ}\right) 45^{\circ}$

10D, $\log \left(q \cot ^{2} \frac{1}{2} \theta\right)$, INNEs $2, \theta=0\left(1^{\circ}\right) 45^{\circ}, \log v^{4}$

$10 \mathrm{D}, \log (q / \epsilon)$, INNEs $2, \theta=0\left(1^{\circ}\right) 31^{\circ}\left(30^{\prime}\right) 40^{\circ}\left(10^{\prime}\right) 45^{\circ}$

$8 \mathrm{D}, \log q$, Meissel $1, \theta=0\left(1^{\prime}\right) 90^{\circ}$

$8 \mathrm{D}, \log q$, Glaisher $1, \theta=0\left(1^{\circ}\right) 90^{\circ}$

5D, $\log q$, JACOBI $1, \theta=0\left(0^{\circ} .1\right) 90^{\circ}, \Delta$

5D, $\log q$, Bertrand 1, Lévy 1 , Potin $1, \theta=0\left(5^{\prime}\right) 90^{\circ}$

5D, $\log q$, FrICKE $1, \theta=0\left(10^{\prime}\right) 90^{\circ}$

$5 \mathrm{D}, \log q, \mathrm{SChl}$ Ömilch 2, Silberstein $1, \theta=0\left(1^{\circ}\right) 90^{\circ}$

5D, $\log (1 / q)$, LÁsKA $1, \theta=0\left(1^{\circ}\right) 90^{\circ}$

$4 \mathrm{D}, \log q, \mathrm{JAHNKE} \&$ EMDE $1, \theta=0\left(5^{\prime}\right) 90^{\circ}$

$4 \mathrm{D}, \log q$, Bohlin 1, Glazenap $1, \theta=0\left(0^{\circ} .1\right) 90^{\circ}$

$4 \mathrm{D}, \log q$, HoǘL $1, \theta=0\left(1^{\circ}\right) 100^{\circ}$

$4 \mathrm{D}, \alpha=\log \left(16 q / k^{2}\right)$, HoüEL 1 (p. 57), $\theta=0\left(1^{0}\right) 50^{\circ}$

$3 \mathrm{D}, \log q$, MONTESSUS De BALlORE $1, \theta=0\left(1^{\circ}\right) 86^{\circ}\left(30^{\prime}\right) 89^{\circ}\left(20^{\prime}\right) 89^{\circ} 40^{\prime}, 89^{\circ} 55^{\prime}$

15D, $-\log q$, NBSCL $2, k^{2}=0(.01) 1$

$10 \mathrm{D}, \log q$, HAYASHI $1, k^{2}=0(.001) 1$

$8 \mathrm{D}, \log q$, HAYASHI $1, k^{2}=0\left(10^{-7}\right) 10^{-5}\left(10^{-5}\right) .003,1-k^{2}=$ same

7D, $\log q$, NAGaOKa \& SAKURAI $1, k^{2}=0(.001) 1, \Delta$

7D, $\log \left(q / k^{2}\right)$ and $\ln \left(k^{2} / q\right)$, NAGAOKA \& SAKURAI $1, k^{2}=0(.001) .05, \Delta$

$5 \mathrm{D}, \log q$, GROVER 6 (p. 251$), k^{2}=0(.005) .1, \Delta^{2}$

III-C. $\log \log (1 / q)$ and $\log \ln (1 / q)$

12D, $\log \log (1 / q)$, Verhulst $1, \theta=0\left(0^{\circ} .1\right) 45^{\circ}$. Computed by Loxhay. From 0 to $15^{\circ}$, values to 14 decimals are given, but they are inaccurate, as in LEGENDRE's table of $\log K$, on which they are based. See Part III

$10 \mathrm{D}, \log \log (1 / q)$, INNES $2, \theta=0\left(1^{\circ}\right) 45^{\circ}$, from Verhulst 1

7D, $\log \log (1 / q)$, Bertrand 1 , Potin $1, \theta=0\left(0^{\circ} .5\right) 90^{\circ}$

7D, log In $(1 / q)$, Nagaoka \& SAKurai $1, k^{2}=0(.001) 1, \Delta$

$5 \mathrm{D}, \log \ln (1 / q), \mathrm{GrOVER} 6$ (p. 251$), k^{2}=0(.005) .1, \Delta^{2}$

\section{Section IV. Theta Functions of Zero Argument}

The general notation for theta functions which we shall use is

$$
\begin{aligned}
& \vartheta_{1}(x)=2 q^{t}\left(\sin x-q^{2} \sin 3 x+q^{6} \sin 5 x-q^{12} \sin 7 x+\ldots\right), \\
& \vartheta_{2}(x)=2 q^{t}\left(\cos x+q^{2} \cos 3 x+q^{6} \cos 5 x+q^{12} \cos 7 x+\ldots\right), \\
& \vartheta_{3}(x)=1+2 q \cos 2 x+2 q^{4} \cos 4 x+2 q^{9} \cos 6 x+\ldots, \\
& \vartheta_{4}(x)=1-2 q \cos 2 x+2 q^{4} \cos 4 x-2 q^{9} \cos 6 x+\ldots,
\end{aligned}
$$

where, as in Section III above, $q=e^{-\pi K^{\prime}} / K$. This is the functional notation used, for example, in WhitTAKer \& WATSON, and we shall adhere to it in spite of the fact that definitions in which $x$ is replaced by $\pi v$ have been adopted in important tabulations. 
In this section we are concerned only with theta functions and their $x$-derivatives at $x=0$. Since $\vartheta_{1}(0)$ vanishes, $\vartheta_{1}{ }^{\prime}(0)$ is considered in its place, and we have

$$
\begin{aligned}
\vartheta_{1}{ }^{\prime} & =\vartheta_{1}{ }^{\prime}(0)=2 q^{3}\left(1-3 q^{2}+5 q^{6}-7 q^{12}+\ldots\right), \\
\vartheta_{2} & =\vartheta_{2}(0)=2 q^{3}\left(1+q^{2}+q^{6}+q^{12}+\ldots\right), \\
\vartheta_{3} & =\vartheta_{3}(0)=1+2 q+2 q^{4}+2 q^{9}+\ldots, \\
\vartheta_{1} & =\vartheta_{4}(0)=1-2 q+2 q^{4}-2 q^{9}+\ldots .
\end{aligned}
$$

On account of the difference of notation mentioned above, the $\vartheta_{1}{ }^{\prime}(0)$ of NAGAOKa \& SAKURAI and HAYASH is our $\pi \vartheta_{1}{ }^{\prime}$, and will be so described.

The four functions just defined are connected by JACOBI's identity $\vartheta_{1}^{\prime}=\vartheta_{2} \vartheta_{2} \vartheta_{4}$. Moreover, each is expressible in terms of $K$ (and moduli), as follows:

$$
\begin{aligned}
\vartheta_{1}^{\prime} & =\sqrt{ }\left(8 k k^{\prime} K^{3} / \pi^{3}\right), \quad \vartheta_{2}=\sqrt{ }(2 k K / \pi), \\
\vartheta_{3} & =\sqrt{ }(2 K / \pi)=\sqrt{ }(1 / M), \quad \vartheta_{4}=\sqrt{ }\left(2 k^{\prime} K / \pi\right) .
\end{aligned}
$$

If $M=1 / \vartheta_{3}^{2}=1-4 g_{1} q+4 g_{2} q^{2}-4 g_{3} q^{3}+\ldots$, the $g$ 's are all integral, and are given up to $g_{\Re}$ in GLAISHER 2.

NAGAOKA \& SAKURAI 1 and HAYASH 1 also tabulate quotients which, in our notation, are

$$
\pi^{2} \vartheta_{1}{ }^{\prime \prime \prime} / \vartheta_{1}{ }^{\prime}, \quad \pi^{2} \vartheta_{2}^{\prime \prime} / \vartheta_{2}, \quad \pi^{2} \vartheta_{3}{ }^{\prime \prime} / \vartheta_{3}, \quad \pi^{2} \vartheta_{4}^{\prime \prime} / \vartheta_{4} .
$$

In their notation, the $\pi^{2}$ factors are absent. Mainly in consequence of JACOBI's identity $\vartheta_{1}^{\prime}=\vartheta_{2} \vartheta_{3} \vartheta_{4}$, the first quotient is the sum of the other three. The expressions for $\vartheta_{1}{ }^{\prime \prime}, \vartheta_{2}{ }^{\prime \prime}$, $\vartheta_{3}^{\prime \prime}, \vartheta_{4}^{\prime \prime}$ are evidently

$$
\begin{aligned}
& \vartheta_{1}^{\prime \prime \prime}=-2 q^{\frac{1}{2}}\left(1-27 q^{2}+125 q^{6}-\ldots\right), \\
& \vartheta_{2}^{\prime \prime}=-2 q^{z}\left(1+9 q^{2}+25 q^{6}+\ldots\right) \text {, } \\
& \vartheta_{3}^{\prime \prime}=-8\left(q+4 q^{4}+9 q^{9}+\ldots\right) \text {, } \\
& \vartheta_{4}^{\prime \prime}=8\left(q-4 q^{4}+9 q^{9}-\ldots\right) \text {. }
\end{aligned}
$$

It should not be overlooked that the quotients mentioned are expressible in terms of $K$ and $E$ (and moduli), as follows:

$$
\begin{array}{ll}
\pi^{2} \vartheta_{1}^{\prime \prime \prime} / \vartheta_{1}{ }^{\prime}=4 K\left\{\left(2-k^{2}\right) K-3 E\right\}, & \pi^{2} \vartheta_{2}^{\prime \prime} / \vartheta_{2}=-4 K E, \\
\pi^{2} \vartheta_{3}^{\prime \prime} / \vartheta_{3}=-4 K\left(E-k^{\prime 2} K\right), & \pi^{2} \vartheta_{1}^{\prime \prime} / \vartheta_{1}=4 K(K-E) .
\end{array}
$$

Other notations for theta functions will be mentioned in Section X.

IV-A. $\vartheta_{1}^{\prime}, \vartheta_{2}, \vartheta_{3}, \vartheta_{4}$

15D, $\vartheta_{2} / \vartheta_{4}[=\mathrm{D}(90)], \vartheta_{4} / \vartheta_{3}$, SPENCELEY $1, \theta=0\left(1^{\circ}\right) 90^{\circ}$

10-12D, $\vartheta_{2}[=\mathrm{H}(K)], \vartheta_{4}[=\Theta(0)], \vartheta_{3} / \vartheta_{4}\left[=C(0)=1 / \sqrt{ } k^{\prime}\right]$, HIPPISLEY 1 , $\theta=0\left(5^{\circ}\right) 80^{\circ}\left(1^{\circ}\right) 90^{\circ}$

9D, $\log \vartheta_{3}$ [column $\log \Theta(\omega)$ ], BerTRAND 1 (p. 714), $\theta=0\left(0^{\circ} .5\right) 90^{\circ}$

9D, $\log \vartheta_{3}$ [column $\log \vartheta_{2}(0)$ ], Potin 1 (p. 832), $\theta=0\left(0^{\circ} .5\right) 90^{\circ}$

$8 \mathrm{D}, \pi \vartheta_{1^{\prime}}\left[\mathrm{col} . \vartheta_{1^{\prime}}(0)\right], \vartheta_{2}, \vartheta_{3}, \vartheta_{4}$ [col. $\left.\vartheta_{0}(0)\right]$, HAYASHI $1, k^{2}=0(.001) .5$

5D, $\pi \vartheta_{1}^{\prime}\left[\mathrm{col} . \vartheta_{1}^{\prime}(0)\right], \vartheta_{2}, \vartheta_{3}, \vartheta_{4}\left[\mathrm{col} . \vartheta_{0}(0)\right]$, HAYASHI $2, k^{2}=0(.001) .5$

$7 \mathrm{D}$, logs of these 4 functions, NAGAOKA \& SAKURAI $1, k^{2}=0(.001) .5, \Delta$

$7 \mathrm{D}, \log \left(\pi v_{1}^{\prime} / \sqrt{ } k\right)$, NAGAOKA \& SAKURAI $1, k^{2}=0(.001) .05, \Delta$

Use may also be made of the values for zero argument in the small double-entry tables of Hoüel 1 and JAHNKe \& Emde 1 (see Section X). It will be noticed that $\boldsymbol{\vartheta}_{3} / \vartheta_{4}$ (see SPEncELey 1 and Hippisley 1 above) is merely an algebraic function of the modulus.

IV-B. $\vartheta_{1}^{\prime \prime \prime}, \vartheta_{2}^{\prime \prime}, \vartheta_{3}^{\prime \prime}, \vartheta_{4}^{\prime \prime}$

8D, $\pi^{2} \vartheta_{1}^{\prime \prime \prime} / \vartheta_{1}^{\prime}, \pi^{2} \vartheta_{2}^{\prime \prime} / \vartheta_{2}, \pi^{2} \vartheta_{3}^{\prime \prime} / \vartheta_{3}, \pi^{2} \vartheta_{4}^{\prime \prime} / \vartheta_{4}$, HAYASH $1, k^{2}=0(.001) .5$

$7 \mathrm{D}, \operatorname{logs}$ of these 4 quotients, NAGAOKA \& SAKURAI 1, $k^{2}=0(.001) .5, \Delta$

$7 \mathrm{D}, \log \left(-\pi^{2} \vartheta_{3}{ }^{\prime \prime} / k^{2} \vartheta_{3}\right), \log \left(\pi^{2} \vartheta_{4}{ }^{\prime \prime} / k^{2} \vartheta_{4}\right)$, NAGAOKA \& SAKURAI $1, k^{2}=0(.001) .05, \Delta$ 


\section{Section V. Laplace Coefficients and Related Functions}

The Laplace coefficients $b_{\delta}^{(i)}$ occur in the expansion

$$
\left(1+\alpha^{2}-2 \alpha \cos x\right)^{-s}=\frac{1}{2} b_{s}{ }^{(0)}+\sum_{i=1}^{\infty} b_{\delta}^{(i)} \cos i x,
$$

where $s=\frac{1}{2}, \frac{3}{2}, \frac{5}{2}, \cdots$. The expansion is used in dynamical astronomy, where $\alpha$ is most of ten equal to the ratio of the mean distances of two planets from the Sun. The coefficients, and their derivatives with respect to $\alpha$, are all linear functions of the complete elliptic integrals of the first and second kinds with modulus $k=\alpha$; in particular,

$$
b_{\mathbf{3}}{ }^{(0)}=4 K / \pi, \quad b_{1}^{(1)}=4(K-E) / \pi k .
$$

The principal tables multiply the Laplace coefficients by various integral powers of $\alpha$ and $\sqrt{ }\left(1-\alpha^{2}\right)$ before tabulation, or use variant forms of the functions. The argument is usually $\alpha, \log \alpha$ or $\alpha^{2} /\left(1-\alpha^{2}\right)$, that is, in the notation of our other sections, $k, \log k$ or $\tan ^{2} \theta$.

A full description of the various tables entails some algebraical complication; for details one may consult p. 333-335 of FMR Index. When all derivatives of all Laplace coefficients are considered, the functions may be regarded as somewhat general hypergeometric functions rather than merely as standard forms of elliptic integrals. Consequently only a few brief indications are given here.

Tables with argument $\alpha$. The most extensive tables are in RunkLe 1 (on errors, see Witt 2). Brown \& Brouwer 1 has minor tables with argument $\alpha$. See also Robbins 2 (and InNes 5), Fletcher 1, Witt 2, Noren \& RAAB 1, ANDOYer 1, and Legendre 2 (p. 289), 5 (p. 551).

Tables with argument $\log \alpha$. MASAL 1 and GyLDEN 1 are extensive. The integrals tabulated in MASAL 1, namely

$$
\beta_{n}(s)=(2 / \pi) \int_{0}^{3 \pi}\left(1-\alpha^{2} \sin ^{2} \phi\right)^{-i s} \sin ^{2 n} \phi d \phi,
$$

are perhaps more germane to this Guide than most functions discussed in the present section.

Tables with argument $\alpha^{2} /\left(1-\alpha^{2}\right)$. This is the argument of the major tables in the important BROWN \& BROUWER 1.

Coefficients used in calculating Laplace coefficients. See RUNKLE 1, LeVERRIER 1, Newcomb 1, Wellmann 1, Brown 1, 2, Williams 1, Witt 2, Brown \& Brouwer 1, and Brown \& SHOOK 1 .

\section{Section VI. Combinations of $K$ and $E$ occurring in Connection with Currents in Circles and Colls}

Below are listed a number of standard tables, many of which may be regarded as source tables, of four main kinds designed for electrical use. Some of them have doubtless been copied into various electrical text-books and hand-books, but no attempt has been made to extend the lists below to include all these.

The function $f_{1}[=M / 4 \pi \sqrt{ }(A a)$, in a common notation $]$ occurs in connection with the mutual inductance of two circles with a common axis; $f_{2}$ in connection with the attraction between currents in such circles. The function $f_{3}$ (of ten called $K$ ) occurs in connection with the self-inductance of cylindrical solenoids, as NAGAOKA's correction factor for finite length; in this case $\tan \theta$ is the ratio of diameter to length of the solenoid, and $f_{3}$ tends to unity for long coils (small $\theta$ ). As the signs will be found to be wrong or misleading in a number of places in the literature, it may be added that $f_{1}, f_{2}$ and $f_{3}$ are all positive when defined as below.

SPIELREIN's function $f(\alpha)=f_{4}$ occurs in connection with the self-inductance of flat coils. If the windings lie in a plane between two concentric circles of radii $a, A$, and the number of turns, $N$, is large, each turn being approximately circular, the self-inductance in absolute electromagnetic units is $N^{2} A f(\alpha)$, where $\alpha=a / A<1$. It will be observed that $f(\alpha)$ involves integrals of $K$ and $E$ with respect to the modulus $k$, so that it is essentially 
more complicated than the other three functions, but it is convenient to include it here on account of the electrical relatedness. It may be noted that

$$
\int_{0}^{1} K d k=2 G, \quad \int_{0}^{1} E d k=G+\frac{1}{2},
$$

where $G$ is Catalan's constant,

$$
G=\frac{1}{2} \int_{0}^{4 \pi} \phi \operatorname{cosec} \phi d \phi=1^{-2}-3^{-2}+5^{-2}-7^{-2}+\cdots=0.915965594177219 .
$$

so that $f(0)=\frac{8}{3} \pi(2 G-1)=6.9695704257$.

Grover 1, 6 (p. 252) give tables relating to the maximum attraction between currents in two circles with a common axis, and the distance between the planes of the circles which produces this maximum.

Further references will be found in Rosa \& GROVER 1, in Grover 6, and in the extensive bibliography of HAK 1 (687 items, p. 232-246).

VI-A $1 . f_{1}=(2 / k-k) K-2 E / k$

7D, $\log f_{1}$, MaXwell $1, \theta=60^{\circ}\left(0^{\circ} .1\right) 90^{\circ}$, reprinted in Mascart \& Joubert 1, A. Gray $1_{1}$, and FowLE $1_{1}$, and (partly corrected by comparison with Rosa et al.) in A. GRAY $1_{2}$

7D, $\log f_{1}$, RosA \& CoHen 1 and Rosa \& GRover $1, \theta=60^{\circ}\left(0^{\circ} .1\right) 90^{\circ}, \Delta$, recomputation of MAXWELL 1

5D, $f_{1}$, JAHNKe $\&$ EMde $1_{1}$ (p. 77$), \theta=60^{\circ}\left(0^{\circ} .1\right) 90^{\circ}$, antilogs of MAXwell 1

4-6D, $4 \pi f_{1}$, PIDDUCK 1, $\theta=5^{\circ}\left(6^{\prime}\right) 89^{\circ}\left(1^{\prime}\right) 89^{\circ} 54^{\prime}$

About 6S, $4 \pi f_{1}, \log \left(4 \pi f_{1}\right)$, NAGAOKA \& SAKURAI 2 (p. 140), $k^{2}=0(.001) 1, \Delta^{2}$

About $6 \mathrm{~S}, 4 \pi f_{1} / 1000, \log \left(4 \pi f_{1} / 1000\right)$, GROVER $5, k^{2}=0(.005) 1, \Delta^{n}$, also auxiliary tables

$4 \mathrm{~S}, 2 \pi k f_{1}$, CURTIS \& SParks $1, k^{2}=0(.01) 1, \Delta$, also auxiliary tables

4-5S, $4 \pi f_{1} / 1000, \log \left(4 \pi f_{1} / 1000\right)$, Grover 6 (p. 79), $k^{\prime 2}=0(.01) 1, \Delta$, also auxiliary tables

About $4 \mathrm{~S}, 4 \pi f_{1} / 1000$, Bureau of Standards 1 , Terman 1 (p. 69), $k^{\prime}=.01(.001) .016(.002) .05(.01) .95(.002) 1$

$8 \mathrm{D}$, $\epsilon$ and $\log (1+\epsilon)$, NAGAOKA $2, q=.02(.002) .1(.001) .15, \Delta$ for $\log (1+\epsilon)$, where $f_{1}=4 \pi q !(1+\epsilon)$. Also two further auxiliary functions with $q^{\prime}$ as argument. All reproduced in Rosa \& Grover 1. Brief tables of the same kind in NAGaOKa 1. NAGAOKA 5 tabulates $\log (1+\epsilon)$ to $7 \mathrm{D}$ with $\Delta$ for $h=0(.001) .2$, where $h=q_{1}=q^{2}$, $q$ and $q_{1}$ corresponding to $k$ and LANDEN's modulus $k_{1}$, see Section I. Brief table of the same kind in NaGaOKa 3. ( $\epsilon$ is not to be confused with the $\epsilon$ of Section III, which is denoted by $\frac{1}{2} l$ in NAGAOKA.)

VI-A. $f_{2}=k\left\{\left(2-k^{2}\right) E /\left(1-k^{2}\right)-2 K\right\}=\sin \theta\left\{\left(1+\sec ^{2} \theta\right) E-2 K\right\}$

$8 \mathrm{D}, \log f_{2}$, Rosa, DoRsey \& MiLler $1, \theta=55^{\circ}\left(0^{\circ} .1\right) 70^{\circ}, \Delta^{2}$, recomputation of RAYLEIGH \& SIDGWICK 1

7D, $\log f_{2}$, RAYLEIGH \& SidGwick $1, \theta=55^{\circ}\left(0^{\circ} .1\right) 69^{\circ} .9$, reprinted in MASCART \& JouberT $1_{3}$ About 5S, $f_{2}$, JAHNKe \& EMde $1_{1}$ (p. 79), $\theta=55^{\circ}\left(0^{\circ} .1\right) 69^{\circ} .9$, antilogs of RAYLEIGH \& SidgWICK 1

About 6S, $\pi f_{2}, \log \left(\pi f_{2}\right)$, NAGAOKA \& SAKURAI 2 (p. 161), $k^{2}=0(.001) 1, \Delta^{2}$

$5 \mathrm{D}, \log \left(\pi f_{2}\right)$, NAGAOKA $4, q=.02(.002) .1(.001) \cdot 15, \Delta$

About $4 \mathrm{~S}, \pi f_{2}$, Grover 6 (p. 250), $k^{2}=0(.01) 1, \Delta^{2}$, abridged from Nagaoka \& Sakurai 2

VI-A $f_{3} f_{3}=(4 / 3 \pi)\left[\left(K \cos ^{2} \theta-E \cos 2 \theta\right) \sin ^{-2} \theta \cos ^{-1} \theta-\tan \theta\right]$

$6 \mathrm{D}, f_{3}, \log \left(\pi^{2} f_{3}\right)$, NAGAOKA \& SAKURAI $2, k^{2}=0(.001) 1, \tan \theta=0(.001) 1$, $\cot \theta=0(.001) 1, \Delta^{2}$

6D, $f_{3}$, HAK 1 (p. 16), $\tan \theta=0(.001) .002(.002) .01(.01) 1, \cot \theta=0(.001) .002(.002) .01(.01) 1$

$6 \mathrm{D}, f_{3}, \log f_{3}$, NAGAOKA $2, \theta=0\left(1^{\circ}\right) 90^{\circ}, \Delta^{2}$

6D, $f_{2}$, Rosa \& GRover 1 (T.XX), $\theta=0\left(1^{\circ}\right) 90^{\circ}, \Delta^{2}$, from NAGAOKa 2

$6 \mathrm{D}, f_{3}$, NAGAOKA $2, \tan \theta=0(.01) 1(.05) 2(.1) 5(.5) 10, \Delta$ 
6D, $f_{2}$, RosA \& Grover 1 (T.XXI), $\tan \theta=0(.01) 1(.05) 2(.1) 5(.5) 10, \Delta^{2}$ to 5 , then $\Delta^{3}$, from NAGAOKA 2 with correction

6D, $f_{3}$, GROVER 6 (p. 144), $\cot \theta=0(.01) 1, \tan \theta=0(.01) 1, \Delta^{2}$

5D, $f_{3}$, Grover 3, $\tan \theta=0(.01) 1(.05) 2(.1) 5(.5) 10(1) 20$ (var.)400, $\Delta$

4D, $f_{2}$, BUREAU OF STANDARDS $1, \tan \theta=0(.05) 2(.1) 5(.2) 8(.5) 10(1) 20$ (var. $) 100, \Delta$

5D, $2 \pi^{2} f_{2} \tan \theta$, Rosa \& Cohen 1 (T.IV), Rosa \& GRover 1 (T.IV), $\tan \theta=.2(.1) 1(.2) 4$

4D, $2 \pi^{3} f_{3} \tan \theta$, RUSSELL $1, \tan \theta=.2(.1) 1(.2) 4$

$4 \mathrm{D}, \frac{1}{2} \pi f_{3} \tan \theta$, EMDE 1, $\tan \theta=0(.01) 1, \cot \theta=0(.01) 1$

4-5S, $\pi^{2} f_{3} \tan \theta, \pi^{2} f_{3} \tan ^{2} \theta$, JAHNKE \& EMDE $1_{2}-1_{4}$, Boll 1 (p. 344), $\tan \theta=0(.01) 1$, $\cot \theta=0(.01) 1$

2-3D, $\pi^{2} f_{3}$ (col. $k$ ), $\pi^{2} f_{3} \tan \theta$ (col. $F$ ), Grover 4,6 (p. 152), $\tan \theta=0(.01) 1, \cot \theta=0(.01) 1$

VI-A $f_{4}=16 \pi /\left[3(1-\alpha)^{2}\right] \int_{\alpha}^{1}\left(1-\alpha^{3} k^{-3}\right)(K-E) d k$

6-7S, $f(\alpha)=f_{4}$, Spielrein 1, Grover 2 (p. 570), $\alpha=0(.05) .9,1$

$4 \mathrm{~S}, f(\alpha)=f_{4}$, SPIELREIN $1, \alpha=0, .05(.01) .95, .99,1$

4S, $Q=(1-\alpha)^{2} f_{4}$, BUTTERWORTH $1, r_{1} / r_{2}=\alpha=0(.05) 1$

$5 \mathrm{~S}, \Phi=f_{4} /(1+\alpha)$, HAK 1 (p. 18), $\gamma=\alpha=0(.05) .9$

4-5S, $\Phi=f_{4} /(1+\alpha)$, HAK $_{1}$ (p. 18), $\rho=(1-\alpha) /(1+\alpha)=0(.05) 1$

5S, $P=2 f_{4} /(1+\alpha)$, Grover 6 (p. 113), $c / 2 a=(1-\alpha) /(1+\alpha)=0(.01) 1, \Delta$

\section{Section VII. Miscellaneous Tables Involving Complete Elliptic Integrals and Theta Functions of Zero Argument}

1. LEGENDRE functions $P_{n}(x), Q_{n}(x)$ of half-odd-integral order $n$ may be expressed in terms of complete elliptic integrals of the first and second kinds. BATEMAN ${ }^{1}$ gives a treatment of the case $x \geqslant 1$, which arises in solving LAPLACE's equation in toroidal coordinates. For references to early work, see BAteman ${ }^{1}$ and Airey 1 . Some authors (including Airey 1 and LEVY \& FoRSDYKE 1) use a variant notation for toroidal functions, in that they write $Q_{0}, Q_{1}, Q_{2}, \cdots$ in place of $Q_{-\mathbf{k}}, Q_{\mathbf{1}}, Q_{\mathbf{1}}, \cdots$, in order to avoid fractional suffixes; but we shall adhere to the usual Legendre function notation. Some formulae for low $n$ have recently been stated explicitly by MILLER ${ }^{2}$, for both cases, $-1 \leqslant x \leqslant 1$ and $x \geqslant 1$.

When $|x| \leqslant 1$, put $x=\cos \theta$. Then the elliptic modulus being given by

$$
k^{2}=\frac{1}{2}(1-x)=\sin ^{2} \frac{1}{2} \theta, \quad k^{\prime 2}=\frac{1}{2}(1+x)=\cos ^{2} \frac{1}{2} \theta,
$$

we have, for instance,

and (see MILLER²)

$$
P_{-1}(x)=2 K / \pi, \quad P_{i}(x)=2(2 E-K) / \pi,
$$

$$
Q_{-j}(x)=K^{\prime} \mp i K, \quad Q_{\mathfrak{t}}(x)=2 E^{\prime}-K^{\prime} \pm i(2 E-K) .
$$

Further $P$ 's and $Q$ 's may be obtained from the usual recurrence relation. No tables, except of course for $P_{-j}$ and $Q_{-i}$, are known, but they could evidently be very easily formed, with argument $\theta$, from the tables of LEGENDRE or Heuman 1.

When $x \geqslant 1$, put $x=\cosh \sigma$. Then the elliptic modulus being given by

$$
k^{2}=2 /(x+1)=\operatorname{sech}^{2} \frac{1}{2} \sigma, \quad k^{\prime 2}=(x-1) /(x+1)=\tanh ^{2} \frac{1}{2} \sigma,
$$

we have, for instance,

$$
\begin{array}{ll}
P_{-3}(x)=2 k K^{\prime} / \pi, & P_{3}(x)=2\left(2 E^{\prime}-k^{2} K^{\prime}\right) / k \pi, \\
Q_{-1}(x)=k K, & Q_{\mathfrak{k}}(x)=\left\{\left(2-k^{2}\right) K-2 E\right\} / k .
\end{array}
$$

The values of $Q_{n}(x), Q_{n}{ }^{\prime}(x), Q_{n}{ }^{\prime \prime}(x)$ are given to $6 \mathrm{D}$ or $7 \mathrm{~S}$ for $n=-\frac{1}{2}(1)+2 \frac{1}{2}$, $\sin ^{-1} k=83^{\circ}, 80^{\circ}\left(5^{\circ}\right) 65^{\circ}\left(10^{\circ}\right) 25^{\circ}$ in LEVY \& FORSDYKe 1 . The values of $P_{n}(x), P_{n}^{\prime}(x)$, $Q_{n}(x), Q_{n}^{\prime}(x)$, as well as corresponding associated Legendre functions and their first derivatives, are given to about $6 \mathrm{~S}$ for $n=-\frac{1}{2}(1)+4 \frac{1}{2}, x=1(.1) 10$ in NBSCL 1. $P_{n}(\cosh \sigma)$, $P_{n}^{\prime}(\cosh \sigma), Q_{n}(\cosh \sigma), Q_{n}^{\prime}(\cosh \sigma)$ are tabulated to $4 \mathrm{D}$ for $n=-\frac{1}{2}(1)+\frac{3}{2}, \sigma=0(.1) 3$ in Fouquer 1. 
2. F. W. Newman 1 has a number of tables in which the argument is $\rho=\pi K^{\prime} / 2 K$, so that $q=e^{-2 \rho}, \rho=\frac{1}{2} \ln (1 / q)$. For the first of these tables, see Section XI. The remainder are as follows:

p. $129,16 \mathrm{D}, \frac{1}{\ln } \ln \left(1 / k^{\prime}\right), \rho=1(.1) 6.3$

p. $130,16 \mathrm{D}, \frac{1}{2} \ln (2 K / \pi)=\ln \vartheta_{3}, \rho=1(.1) 6.3$

p. $131,16 \mathrm{D}, \frac{1}{2}(2 K / \pi-1), \rho=1(.1) 6.1$

p. 132, 16D, $\ln Q, \rho=1(.1) 4.6$, where $Q^{-1}=\left(1-q^{2}\right)\left(1-q^{4}\right)\left(1-q^{6}\right) \cdots=\left(\vartheta_{1}^{\prime} / 2 q^{\frac{1}{t}}\right)^{t}$

p. $133,16 \mathrm{D}, \frac{1}{2}\left(1-2 k^{\prime} K / \pi\right), \rho=1(.1) 6.3$

p. $134,16 \mathrm{D}, k K / \pi, \rho=1(.1) 6$

p. $135,18 \mathrm{D}, e^{-\rho}, \rho=.1(.1) 37$

The last table barely falls within the scope of this Guide, but is included to complete the description of NEwMAN's $\rho$-tables, and is relevant to the remainder of these. It is taken from Newman's original publication. ${ }^{3}$ About $16 \mathrm{D}$ are correct.

3 . It is well known that, on putting $q=e^{-4 t}$, each term of the defining expansions of the four theta functions satisfies $\partial^{2} f / \partial x^{2}=\partial f / \partial t$, the diffusion or heat conductivity equation. The theta functions themselves are not usually the appropriate combinations of such terms in physical problems. But integrals of theta functions of zero argument have been tabulated in connection with a number of diffusion problems. For example,

$$
\frac{4}{\pi^{2}} \int_{0}^{t} \vartheta_{2} d t=1-\frac{8}{\pi^{2}}\left(e^{-t}+\frac{1}{9} e^{-9 t}+\frac{1}{25} e^{-25 t}+\cdots\right),
$$

and the expression on the right is tabulated as the "simple diffusion function" in McKAY 1 to $4 \mathrm{D}$ for $t=0(.01) 3.59$. Similarly a table in Olson \& Schultz 1 involves $\int_{0}^{t} \vartheta_{1}^{\prime} d t$, some in Sherwood 1 involve $\mathcal{S}_{0}^{t} \vartheta_{2} d t$ and $\mathcal{S}_{0}^{t}\left(\mathcal{S}_{0}^{t} \vartheta_{2} d t\right) d t$, some in A. B. Newman 1 involve first integrals (with respect to $t$ ) of $\vartheta_{2}$ and $\vartheta_{3}$, some in A. B. NEwMAN 2 involve first and second integrals of $\vartheta_{2}$ and $\vartheta_{3}$, and some in A. B. Newman 3 involve first and second integrals of $\vartheta_{3}$ and $\vartheta_{4}$. These tables have various arguments $\left(t / \pi^{2}, 4 t / \pi^{2}, 4 t\right)$, and particulars will be omitted here (some will be found in FMR Index, p. 323). There appears to be need for a consolidated table of first and second integrals of theta functions of zero argument with respect to $t$ or some simple multiple of $t$. It may be noted that F. W. Newman's $\rho$ is $2 t$.

4. Eмде 2 proposes new normal forms of complete elliptic integrals, namely, quantities $D, B, C$ defined by

$$
\begin{aligned}
& D=(K-E) / k^{2}, \\
& B=K-D=\left(E-k^{\prime 2} K\right) / k^{2}, \\
& C=(D-B) / k^{2}=\left[\left(2-k^{2}\right) K-2 E\right] / k^{4} .
\end{aligned}
$$

In the notation of Section VI, $C=f_{1} / k^{3}$. EmDE 2 tabulates $D, B, C$ to $4-5 D$ with $I \Delta$ for $k^{2}=0(.01) 1$. For $D$ and $C$ the auxiliary functions

$$
\begin{aligned}
& d=D+1-\ln \left(4 / k^{\prime}\right) \\
& c=C+2-\ln \left(4 / k^{\prime}\right)
\end{aligned}
$$

are tabulated to 3-4D with $I \Delta$ for $k^{2}=.7(.01) 1$. These five tables are reproduced in JAHNKE \& EMde $1_{3}, 1_{4}$. Cecconi 1 gives $\left(E-k^{\prime 2} K\right) / k^{2}$, which he calls $G$, to $4 \mathrm{D}$ for $k=0(.01) 1$; see also Section II-A $\mathbf{3}$.

5. Hill 1 tabulates to $8 \mathrm{D}$ with $\Delta^{2}$ for $\theta=0\left(0^{\circ} .1\right) 50^{\circ}$ the logarithms of three quantities $\Re, \mathfrak{R}^{\prime}$ and $\mathfrak{R}$ which may be identified as follows:

$$
\begin{aligned}
\pi k^{\prime 2} \Re & =2 E, \\
k^{4} k^{\prime 2} E \mathfrak{R}^{\prime} & =2\left(1-k^{2} k^{\prime 2}\right) E-k^{\prime 2}\left(1+k^{\prime 2}\right) K, \\
k^{2} k^{\prime 2} E \Re & =\left(1+k^{2}\right) E-k^{\prime 2} K .
\end{aligned}
$$

6. Smekal 1 has a table of quantities $K, Q(K), Q(1 / K), 1 / K$ with argument $\alpha$. This notation is so inconvenient for present purposes that the tabulated functions will be denoted instead by $k, Q, Q^{*}, 1 / k$. The primary argument of the table is

$$
\alpha=45^{\circ}\left(3^{\prime}\right) 44^{\circ} 30^{\prime}\left(6^{\prime}\right) 40^{\circ}\left(15^{\prime}\right) 35^{\circ}\left(30^{\prime}\right) 5^{\circ} \text {. }
$$


$k$ is tabulated to $5 \mathrm{D}$, the other functions to about $4 \mathrm{D}$, all but $1 / k$ having first differences. The definitions in terms of $\alpha$ are

$$
k=\tan ^{2} \alpha, \quad Q=\pi^{-1} \sin ^{2} \alpha(K-E \sec 2 \alpha), \quad Q^{*}=\pi^{-1} \cos ^{2} \alpha(K+E \sec 2 \alpha),
$$

where $K$ and $E$ have modular angle $2 \alpha$. But $k$ is the reduced modulus derived from $\sin 2 \alpha$ by Landen's transformation (Section I), and in terms of this subsidiary argument we have

$$
\begin{aligned}
& Q=-2 k^{2} d K /(\pi d k)=-2 k\left(E-k^{\prime 2} K\right) /\left(\pi k^{\prime 2}\right), \\
& Q^{*}=2 d(k K) /(\pi d k)=2 E /\left(\pi k^{\prime 2}\right),
\end{aligned}
$$

where $K$ and $E$ now have modulus $k$. Thus $Q$ is related to EMDE's $B$ and $Q^{*}$ is identical with Hill's $\Omega$ (see 4 and 5 above). Replacing $k$ now by the symbol $\alpha$ usual in planetary theory (not SMEkaL's $\alpha$ ), the identifications are

$$
Q=-\frac{1}{2} \alpha^{2} b_{0}{ }^{\prime}, \quad Q^{*}=\frac{1}{2}\left(b_{0}+\alpha b_{0}{ }^{\prime}\right),
$$

where $\frac{1}{2} b_{0}$ is the constant term in the Fourier expansion of $\left(1+\alpha^{2}-2 \alpha \cos x\right)^{-1}$, and $b_{0}{ }^{\prime}=d b_{0} / d \alpha$. The symbol $\alpha$ just introduced in place of SMEKAL's $K$ is appropriate, because the latter is the ratio of the radii of two circular orbits (compare Section V).

7. Coefficients in the Fourier expansions of two Jacobian functions (see Sections $\mathrm{X}$ and $\mathrm{XI}$ ) are tabulated in Glaisher 1. If

we have

$$
\left.\begin{array}{l}
2 \sin u \operatorname{cn} u=\Sigma A_{n} \sin 2 n x \\
2 \text { am } u-2 x=\Sigma B_{n} \sin 2 n x
\end{array}\right\} x=\pi u / 2 K
$$

$$
A_{n}=n\left(\frac{\pi}{k K}\right)^{2} \frac{4 q^{n}}{1+q^{2 n}}, \quad B_{n}=\frac{1}{n} \frac{4 q^{n}}{1+q^{2 n}} .
$$

GLAISHER 1 gives $A_{1}, B_{1}$, about $7 \mathrm{D}, \theta=0\left(1^{\circ}\right) 89^{\circ} ; \log A_{1}, \log B_{1}$, about $8 D, \theta=0\left(1^{\circ}\right) 89^{\circ}$; $A_{2}, B_{2}, A_{3}, B_{3}, 7 \mathrm{D}, \theta=0\left(5^{\circ}\right) 85^{\circ}$.

8. SHook 1 tabulates the arithmetic-geometric mean of 1 and $x$ to $4 \mathrm{~S}$ for $x=1(.1) 20(1) 100$.

9. Devison 1 tabulates (p. 334) $\frac{1}{2} \gamma(t)=\tan ^{-1}\left(K^{\prime} / K\right)$ to $3 \mathrm{D}$ of a radian for

$t=k^{2}=0(.00001) .0001(.0001) .0005(.0002) .0015, .002(.001) .010, .013, .016$, $.020(.005) .05(.01) .10(.02) .2(.1) .5$.

This small table is then used for the evaluation by numerical quadrature of integrals such as $\int_{0}^{1} \frac{\gamma(t) d t}{t-\lambda} \cdot$ See $M T A C$, v. 2, p. 268, 1947.

10. See also Great Britain, Admiralty Computing Service 1.

1 H. Bateman, Partial Differential Equations of Mathematical Physics, Cambridge, 1932 and New York, 1944, p. 461.

J J. C. P. Miller, Math. Gazette, v. 30, 1946, p. 240.

s F. W. Newman, Camb. Phil. Soc., Trans., v. 13, pt. 3, 1883, p. 145-241.

\section{Section VIII. Incomplete Elliptic Integrals of the First AND SECOND Kinds}

Almost all tables of $F(\phi)$ and $E(\phi)$ are derived ultimately from the great Table IX of LEGENDRE (it is to be noted that SAMOILOVA-ГAKHONTOVA states that her tables were constructed by interpolation in LEGENDRE). The chief exception is the independently-computed table of $E(\phi)$ by ScHMIDT, which gives more values to more decimals than LEGENDRE's table of $E(\phi)$, but has the unorthodox arguments $k^{\prime}$ and $\sin \phi$; the values are arcs of ellipses with semi-axes $a=1, b=k^{\prime}$ between the points $\left(0, k^{\prime}\right)$ and $\left(\sin \phi, k^{\prime} \cos \phi\right)$. HoüEL's second table under $B$ below is also probably independent of LEGENDRE. No attempt has been made to seek out all abbreviations of LEGENDRE's table, which is now easily accessible through the three facsimile reproductions of Porin, Emde and Pearson.

For the second integral with argument of Jacobian type, see Section X. 
KAPLAN 2 has recently given important auxiliary tables for the computation of $F(\phi)$ and $E(\phi)$ when both $\theta$ and $\phi$ are near $90^{\circ}$, so that interpolation in LEGENDRE is difficult or impossible. KAPLAN puts

$$
\begin{aligned}
& r=k^{\prime} / k=\cot \theta, \quad x=\cos \phi \\
& K-F(\phi)=(2 / \pi) K^{\prime} \sinh ^{-1}(x / r)+x\left(r^{2}+x^{2}\right)^{3} f \\
& E-E(\phi)=(2 / \pi)\left(K^{\prime}-E^{\prime}\right) \sinh ^{-1}(x / r)+x\left(r^{2}+x^{2}\right)^{3} e
\end{aligned}
$$

and tabulates the auxiliary functions $f$ and $e$ to $10 \mathrm{D}$ for $x^{2}=-.005(.005)+.160$ and $r^{2}=-.005(.005)+.160$, the negative arguments -.005 being included to facilitate interpolation.

As an example of one of the more extended applications of the incomplete integrals to the formation of tables of physical interest, see OsBORN 1.

VIII-A. $F(\phi)$ and $E(\phi)$

12D, LegendRE 3 (T.II), 5 (T.II), $\theta=45^{\circ}, \phi=0\left(0^{\circ} .5\right) 90^{\circ}, \Delta^{4}$ or $\Delta^{5}$

12D, LegendRe 3 (T.VIII), 5 (T.VIII), 7, $\theta=0\left(1^{\circ}\right) 90^{\circ}, \phi=45^{\circ}, \Delta^{6}$ or $\Delta^{6}$

10D, LEGENDRE 3 (p. 84), 5 (p. 77), $\theta=89^{\circ}, \phi=0\left(0^{\circ} .5\right) 90^{\circ}, \Delta$

9-10D, LEGENDRE 3 (T.IX), 5 (T.IX), 6, 7, 8, $\theta=0\left(1^{\circ}\right) 90^{\circ}, \phi=0\left(1^{\circ}\right) 90^{\circ}$

10D, KaPLAN $2, \theta=70^{\circ}\left(5^{\circ}\right) 85^{\circ}, \phi=70^{\circ}\left(5^{\circ}\right) 85^{\circ}$

5D, Levy 1, Bohlin 1, Dale 1, Hancock 1, Hayashi $2, \theta=0\left(5^{\circ}\right) 90^{\circ}, \phi=0\left(1^{\circ}\right) 90^{\circ}$

$5 \mathrm{D}, F(\phi)$, FrICKE $1, \theta=0\left(5^{\circ}\right) 90^{\circ}, \phi=0\left(1^{\circ}\right) 90^{\circ}$

5D, $E(\phi)$, FrICKE $1, \theta=0\left(10^{\circ}\right) 90^{\circ}, \phi=0\left(2^{\circ}\right) 90^{\circ}$

5D, Boll 1 (p. 352), $\theta=0\left(3^{\circ}\right) 90^{\circ}, \phi=0\left(3^{\circ}\right) 90^{\circ}$

5D, KIEPERT $1, \theta=0\left(5^{\circ}\right) 90^{\circ}, \phi=0\left(5^{\circ}\right) 90^{\circ}$

SD, Bertrand $1, \theta=0\left(15^{\circ}\right) 90^{\circ}$, also $10^{\circ}, 80^{\circ}, 89^{\circ}, \phi=0$ (var. $65^{\circ}\left(1^{\circ}\right) 90^{\circ}$

5D, LÁsKA $1, \theta=0\left(15^{\circ}\right) 90^{\circ}$, also $10^{\circ}, 80^{\circ}, \phi=0\left(1^{\circ}\right) 5^{\circ}\left(5^{\circ}\right) 85^{\circ}\left(1^{\circ}\right) 90^{\circ}$

5D, $F(\phi)$ only, GreEnHILl $3, \theta=45^{\circ}, \phi=0\left(0^{\circ} .5\right) 90^{\circ}$

4D, GlazenaP $1, \theta=0\left(5^{\circ}\right) 90^{\circ}, \phi=0\left(1^{\circ}\right) 90^{\circ}$; also $F(\phi), \theta=87^{\circ}, 89^{\circ}, \phi=0\left(1^{\circ}\right) 90^{\circ}$

4D, JAHNKE \& EMDE $1, \theta=0\left(5^{\circ}\right) 90^{\circ}, \phi=0\left(1^{\circ}\right) 90^{\circ}$, also $F(\phi), \theta=89^{\circ}, \phi=0$ (var.) $65^{\circ}\left(1^{\circ}\right) 90^{\circ} ; F(\phi)$ has $5 \mathrm{D}$ for $\phi=0\left(1^{\circ}\right) 5^{\circ}$

4D, Silberstein $1, \theta=0\left(5^{\circ}\right) 90^{\circ}, \phi=0\left(1^{\circ}\right) 90^{\circ} ; F(\phi)$ has $5 \mathrm{D}$ for $\phi=0\left(1^{\circ}\right) 5^{\circ}$

$4 \mathrm{D}$, Rosenbach, Whitman \& Moskovitz $1, \theta=5^{\circ}\left(5^{\circ}\right) 90^{\circ}, \phi=0\left(1^{\circ}\right) 90^{\circ}$

$4 \mathrm{D}$, Peirce $1_{2}-1_{5}, \theta=0\left(15^{\circ}\right) 90^{\circ}$, also $10^{\circ}, 80^{\circ}, \phi=0\left(1^{\circ}\right) 5^{\circ}\left(5^{\circ}\right) 85^{\circ}\left(1^{\circ}\right) 90^{\circ}$

4D, Ligowski 1 , HÜTTE $1, \theta=0\left(10^{\circ}\right) 90^{\circ}, \phi=0\left(10^{\circ}\right) 90^{\circ}$

$3 \mathrm{D}$, Montessus de Ballore $1, \theta=0\left(15^{\circ}\right) 90^{\circ}, \phi=0\left(5^{\circ}\right) 90^{\circ}$

3D, Byerly 1, Campbell $1, \theta=0\left(6^{\circ}\right) 30^{\circ}, 37^{\circ}, 45^{\circ}, 53^{\circ}, 64^{\circ}, 90^{\circ}, \phi=0\left(5^{\circ}\right) 90^{\circ}$

$4 \mathrm{D}$, HoÜEL $1, \theta=0\left(10^{\circ}\right) 100^{\circ}, \phi=0\left(10^{\circ}\right) 100^{\circ}$

5D, SAmolllova-rakhontova $1, k^{2}=0(.01) 1, \phi=0\left(1^{\circ}\right) 90^{\circ}, I \Delta$ in $k^{2}, \Delta$ in $\phi$

4D, $F(\phi)$ only, Reno $1, k^{2}=0(.01) 1, \phi=0\left(1^{\circ}\right) 90^{\circ}$

3D, GRIFFIN $1, k=0(.1) .9, .95, .99,1, \phi=0\left(10^{\circ}\right) 90^{\circ}$

$11 \mathrm{D}, E(\phi)$ only, SchmidT $1, k^{\prime}=0(.01) 1, \sin \phi=0(.01) 1, \Delta^{2}$; also $10 \mathrm{D}$, $\sin \phi=.990(.001) .999, k^{\prime}=.80(.01) .99, \Delta^{5}$ in $k^{\prime}$

VIII-B. $\log F(\phi)$ and $\log E(\phi)$

$4 \mathrm{D}$, HoüEL $1, \theta=0\left(10^{\circ}\right) 100^{\circ}, \phi=0\left(10^{\circ}\right) 100^{\circ}$

$4 \mathrm{D}, \log F(\phi)$ only, HoüEL $1, \theta=90^{\circ}\left(1^{\circ}\right) 100^{\circ}, \phi=90^{\circ}\left(1^{\circ}\right) 100^{\circ}$

VIII-C. $F(\phi) / K$

$4 \mathrm{D}$, HoüEL $1, \theta=0\left(10^{\circ}\right) 100^{\circ}, \phi=0\left(10^{\circ}\right) 100^{\circ}$

VIII-D. Other combinations

6D, $[K-F(\phi)] / \sqrt{ } 2$, MACGREGor $1, \theta=45^{\circ}$ (lemniscate case), $\phi=0\left(0^{\circ} .5\right) 90^{\circ}$

3D, $\int_{x}^{\infty}\left(1+y^{4}\right)^{-i} d y$, BORN 1 (p. 432), $x=0(.1) 1,1 / x=0(.1) 1$; the integral equals $K-\frac{1}{2} F\left(2 \tan ^{-1} x\right)$ with $\theta=45^{\circ}$ 
2D, $P(\alpha)=\int_{0}^{\alpha} \sin ^{t} t d t=2 \int_{\frac{1}{2} \pi-\xi \alpha}^{\frac{1}{2} \pi}\left(1-2 \sin ^{2} u\right)^{\frac{1}{b}} d u$, FREEMAN $1, \alpha=0\left(5^{\circ}\right) 180^{\circ}$. Also functions involving $P(\alpha)$. To reduce integrand to standard form with $k^{2}=\frac{1}{2}$, put $\sin u=2^{-t} \sin \phi$.

\section{Section IX. Ellliptic Integrals of THE ThiRd Kind}

The incomplete elliptic integral of the third kind, say

$$
\int_{0}^{\phi} \frac{1}{1-p \sin ^{2} \phi} \frac{d \phi}{\sqrt{ }\left(1-k^{2} \sin ^{2} \phi\right)},
$$

is apparently a function of three variables, $k, p$ and $\phi$.

But in the "hyperbolic" cases, in which $0<p<k^{2}$ or $p>1$, the integral may be expressed in terms of theta and Jacobian zeta functions of real arguments, so that it can be evaluated by means of double-entry tables.

In the "circular" cases, which tend to be more important in practice (the spherical pendulum provides an elementary dynamical example), we have $k^{2}<p<1$ or $p<0$, and the arguments of the theta and zeta functions become complex. The circular integral has apparently not been tabulated as a function of three variables.

But the complete integral with upper limit of integration $\frac{1}{2} \pi$ can in all cases be expressed in terms of complete and incomplete integrals of the first and second kinds. In the circular case $k^{2}<p<1$ (to which the case $p<0$ may be reduced), the complete integral has been tabulated in Heuman 1. The actual function tabulated is

$$
\Delta_{0}(\alpha, \beta)=\frac{2}{\pi} \int_{0}^{\pi / 2} \frac{\cos ^{2} \alpha \sin \beta \cos \beta \sqrt{ }\left(1-\cos ^{2} \alpha \sin ^{2} \beta\right)}{\cos ^{2} \alpha \cos ^{2} \beta+\sin ^{2} \alpha \cos ^{2} \phi} \frac{d \phi}{\sqrt{ }\left(1-\sin ^{2} \alpha \sin ^{2} \phi\right)},
$$

so that $\alpha$ is the modular angle and $p=\sin ^{2} \alpha /\left(\sin ^{2} \alpha+\cos ^{2} \alpha \cos ^{2} \beta\right)$. The expression in terms of first and second integrals is

$$
\frac{1}{2} \pi \Lambda_{0}(\alpha, \beta)=K E^{\prime}(\beta)-(K-E) F^{\prime}(\beta),
$$

where $K$ and $E$ have modulus $\sin \alpha$, and primes are used to denote that $F^{\prime}(\beta)$ and $E^{\prime}(\beta)$ have modulus $\cos \alpha$. Heuman 1 gives $\Lambda_{0}(\alpha, \beta)$ to 6 decimals without differences for $\alpha=0\left(1^{\circ}\right) 90^{\circ}$, $\beta=0\left(1^{\circ}\right) 90^{\circ}$, with a supplementary 6-decimal table for $\alpha=0\left(0^{\circ} .1\right) 5^{\circ} .9, \beta=80^{\circ}\left(1^{\circ}\right) 89^{\circ}$.

I know of no other table of a standard form of third elliptic integral. A rather special inversion of HeUMAN's table is given in connection with the quantum mechanics of a freely rotating rigid body in G. W. KING 1, 2, 3; for a detailed account, see RMT 467, 544.

BARTKY 1 discusses the numerical calculation of a general form of complete elliptic integral by use of arithmetic-geometric means. Defining these by

$$
m_{i}=\frac{1}{2}\left(m_{i-1}+n_{i-1}\right), \quad n_{i}=\left(m_{i-1} n_{i-1}\right)^{3}, \quad m_{0}=m, \quad n_{0}=n .
$$

he shows that, if the difference between $m_{3}$ and $n_{3}$ may be neglected, that is, if $m_{3}$ gives a sufficiently accurate approximation to the mean $M=m_{\infty}=n_{\infty}$, then

$$
\int_{0}^{\pi / 2} \frac{F(R) d \phi}{R}=\frac{\pi}{8 m_{2}}\left\{\frac{1}{2} F(m)+\frac{1}{2} F(n)+F\left(n_{1}\right)+F\left(m^{\prime}\right)+F\left(n^{\prime}\right)\right\} .
$$

where

and

$$
R^{2}=m^{2} \cos ^{2} \phi+n^{2} \sin ^{2} \phi
$$

$$
m^{\prime}=n_{2}+\left(n_{2}^{2}-n_{1}^{2}\right)^{3}, \quad n^{\prime}=n_{2}-\left(n_{2}^{2}-n_{1}^{2}\right)^{3} \text {. }
$$

Taking $m=1, n=k^{\prime}$, which gives $R$ the Legendre normal form $\left(1-k^{2} \sin ^{2} \phi\right)^{3}$, he tabulates $m_{3}, n_{1}, m^{\prime}, n^{\prime}$ to $4 D$ for $k^{\prime}=.10(.01) .49$ and to $5 D$ for $k^{\prime}=.50(.01) 1$. As a special case, to calculate

take

$$
\int_{0}^{\pi / 2} \frac{1}{1-p \sin ^{2} \phi} \frac{d \phi}{\left(1-k^{2} \sin ^{2} \phi\right)^{1}}
$$

$$
F(R)=k^{2}\left(k^{2}-p+p R^{2}\right)^{-1} .
$$


Nyström 1 discusses the practical calculation, by graphical and planimetric methods, of the normal form

$$
\Pi(k, \lambda, \phi)=\int_{0}^{\phi} \frac{\sqrt{ }\left(1-k^{2} \sin ^{2} \psi\right)}{1+\lambda^{2} \sin ^{2} \psi} d \psi=\int_{0}^{\phi} \frac{\sqrt{ }\left(\cos ^{2} \psi+k^{\prime 2} \sin ^{2} \psi\right)}{\cos ^{2} \psi+\lambda^{\prime 2} \sin ^{2} \psi} d \psi,
$$

where $\lambda^{\prime 2}=\lambda^{2}+1>0$. This is a circular case. NYSTRÖM 1 gives no elliptic table, though he provides an approximate nomogram relating $k^{\prime}, \lambda^{\prime}$ and the complete integral $\Pi\left(k, \lambda, \frac{1}{2} \pi\right)$ in the ranges $0 \leqslant k^{\prime} \leqslant 1,0 \leqslant \lambda^{\prime} \leqslant 10$. But he gives double-entry tables and diagrams of the elementary functions

$$
\begin{aligned}
& x(\lambda, \psi)=3.6 \pi^{-1} \tan ^{-1}\left(\lambda^{\prime} \tan \psi\right), \\
& y(k, \psi)=\sqrt{ }\left(\cos ^{2} \psi+k^{\prime 2} \sin ^{2} \psi\right), \\
& z(k, \psi)=k^{\prime}+\left(1-k^{\prime}\right) \cos \psi-y(k, \psi),
\end{aligned}
$$

the tables being for $\lambda^{\prime}=0(.1) 1(1) 10, k^{\prime}=0(.1) .9, \psi=0\left(5^{\circ}\right) 90^{\circ}$. These enable one to evaluate $\Pi(k, \lambda, \phi)$, since it is proportional to the Stieltjes integral

$$
\int_{0}^{\phi} y(k, \psi) d x(\lambda, \psi) \text {. }
$$

Use of the auxiliary function $z$ in place of $y$ gives increased accuracy, since $z$ is in general much smaller than $y$, and the remaining contribution to $I$ is an elementary integral.

TALLQVIST 1, 2 tabulate respectively magnetic potential (solid angle) due to a circular current, and gravitational potential due to a uniform circular disc. Both may be expressed either as infinite series involving Legendre functions, or in terms of elliptic integrals, including those of the third kind.

A very complicated integral expressible in terms of the third elliptic integral is tabulated for seismological purposes in CONFORTO \& VIOLA 1.

\section{Section X. Theta Functions, Jacobian Amplitude, Second Integral and Zeta Function}

We shall use the four theta functions already defined in Section IV, in which tables of theta functions of zero argument have been listed. The connection with Jacobi's earlier notation is, if $M=\pi / 2 K$, and $x=M u=\pi u / 2 K$,

$$
\begin{array}{lll}
\vartheta_{1}(x)=\vartheta_{1}(M u)=\mathrm{H}(u), & \vartheta_{2}(x)=\vartheta_{1}\left(\frac{1}{2} \pi-x\right)=\mathrm{H}(K-u), \\
\vartheta_{4}(x)=\vartheta_{4}(M u)=\Theta(u), & \vartheta_{3}(x)=\vartheta_{4}\left(\frac{1}{2} \pi-x\right)=\Theta(K-u) .
\end{array}
$$

All tables of theta functions employ, substantially, the argument $x$; that is, they divide the quadrant (for $x$ ) or the quarter-period $K$ (for $u$ ) into a number (say 90 or 100) of equal parts. But Milne-Thomson's tables of Jacobian elliptic and zeta functions have argument $u$ at an interval (.01) which is incommensurable with $K$ for the tabular moduli.

The few tables of the amplitude $\phi=$ am $u$, defined by $u=F(\phi)$, also have $x$ or $u / K$ as argument.

To avoid confusion, we follow GUDERMann and other writers in defining

$$
\text { el } u=\int_{0}^{u} \operatorname{dn}^{2} u d u=\int_{0}^{\phi} \sqrt{ }\left(1-k^{2} \sin ^{2} \phi\right) d \phi=E(\phi),
$$

el $u$ being denoted more of ten by $E(u)$ in the literature. A quantity of ten tabulated instead of el $u$ is the Jacobian zeta function, or periodic part of el $u$, defined by

$$
\mathrm{Z}(u)=\mathrm{zn} u=\operatorname{el} u-E u / K .
$$

The Glaisher and Greenhill notations will be explained in connection with the descriptions of the corresponding tables.

HoüEL 1 tabulates to $4 \mathrm{D}$ the common logarithms of $\vartheta_{n}(x)$ and $\vartheta_{n}{ }^{\prime}(x) / \vartheta_{n}(x), n=1(1) 4$, for $\theta=0\left(10^{\circ}\right) 90^{\circ}, x=0\left(10^{\circ}\right) 100^{\circ}$. Natural values deduced (with correction) from these logarithms are given to $4 \mathrm{~S}$ in JAHNKE \& EMDE 1 . (In both tables, our $\vartheta_{4}$ is denoted simply by $\vartheta$.) 
Rosenhead 1 tabulates, for $\theta=9^{\circ}, n=1(1) 4$,

$$
\begin{aligned}
& \vartheta_{n}(x), \quad \pi d \vartheta_{n}(x) / d x, \quad \text { to } 3-4 \mathrm{D} \text { for } x / \pi=0(.05) .5 \text {, } \\
& \vartheta_{n}(i y), \quad \pi d \vartheta_{n}(i y) / d(i y), \quad \text { to } 4 \mathrm{D} \text { for } y / \pi=0(.05) 1 \text {. }
\end{aligned}
$$

The Glaisher manuscript (Glaisher 3, now in the possession of the BAASMTC) relates to the theta functions

$$
\begin{array}{ll}
\Theta_{1}(x)=\vartheta_{3} \vartheta_{1}(x) / \vartheta_{2}=\vartheta_{1}(x) / \sqrt{ } k, & \Theta_{2}(x)=\vartheta_{4} \vartheta_{2}(x) / \vartheta_{2}=\vartheta_{2}(x) \sqrt{ }\left(k^{\prime} / k\right), \\
\Theta_{3}(x)=\vartheta_{4} \vartheta_{3}(x) / \vartheta_{3}=\vartheta_{3}(x) \sqrt{ } k^{\prime}, & \Theta_{4}(x)=\vartheta_{4}(x) .
\end{array}
$$

The four functions were computed in 1872-75 for the BAAS under GLAISHER's superintendence. They were tabulated to $8 \mathrm{D}$, both naturally and logarithmically, for $\theta=0\left(1^{\circ}\right) 89^{\circ}$, $x=0\left(1^{\circ}\right) 90^{\circ}$. The tables were completely set up in type (356 pages), but were not published, and no printed copy appears to have survived. See BAAS Reports of 1873 (p. 171) and 1930 (p. 250), Mess. Math., v. 6, p. 111-112, 1876, and MTAC, v. 3, p. 92, 1948.

In 1911 GREENHILl brought forward (BAASMTC 1) a scheme for the rearrangement of the elliptic tables. He suggested that tables be made of four theta functions defined by

$$
A(r)=\vartheta_{1}(x) / \vartheta_{2}, \quad B(r)=\vartheta_{2}(x) / \vartheta_{2}, \quad C(r)=\vartheta_{3}(x) / \vartheta_{4}, \quad D(r)=\vartheta_{4}(x) / \vartheta_{4},
$$

where $x=r^{\circ}$. These have the property, which both the ordinary and the GLAISHER forms lack, that the division-values arising at bisection, trisection, etc. of the quadrant or quarterperiod are algebraic functions of the modulus; values for $x=0\left(3^{\circ}\right) 90^{\circ}$ may, as in the case of the trigonometric functions, be expressed by surd formulae. They also have the advantage over GLAISHER's forms of retaining simple relationships between functions of complementary arguments, since

$$
B(r)=A(90-r), \quad C(r)=D(90-r) .
$$

GRRENHILl suggested a semi-quadrantal tabular arrangement, giving, at one opening for each modulus,

$$
\boldsymbol{u}=r K / 90=F(\phi), \quad \phi=\operatorname{am} u, \quad E(r)=\mathrm{zn} u, \quad D(r), \quad A(r)
$$

for $r=0(1) 90$. (The notation $E(r)$ for the zeta function $\mathrm{Z}(u)=\mathrm{zn} u$ is unfortunate.) The experimental tables of this kind for $\theta=15^{\circ}, 45^{\circ}, 75^{\circ}$ in BAASMTC 2,4 are practically superseded by the corresponding definitive tables in HipPISLEY 1 or SPENCELEY 1, described below. Only in the improved table, calculated by HippisLey, for $\theta=45^{\circ}$ (BAASMTC 4) is appreciably more information given ( $\phi$ to $0^{\circ} .001$ instead of to $1^{\prime}$ ) than in HippisLey's Smithsonian tables. There are, however, tables of the same kind in BAASMTC 2, 3, 4 for the "singular" moduli for which

$$
K / K^{\prime}=1 / \sqrt{ } 2, \sqrt{ } 2,2,3 / \sqrt{ } 2,2 \sqrt{ } 2,3,2 \sqrt{ } 3,4,3 \sqrt{ } 2,5,3 \sqrt{ } 3 .
$$

Details of the transformations employed are given. These tables are rather rough, but not without interest, since some of the modular angles exceed $89^{\circ}$, and such cases contribute appreciably to three noteworthy graphs of $D(r), A(r)$ and $E(r)$ in BAASMTC 3. BAASMTC 4 also gives $u$, zn $u, D(r), A(r)$ to $15 \mathrm{D}$ for the 7 and 17 sections in the lemniscate case $\left(\theta=45^{\circ}\right)$, the values of $u / K$ or $r / 90$ being $0(1 / 7) 1$ and $0(1 / 17) 1$ respectively. A few numerical values relating to lemniscate sections are contained in WILTON 1.

Various lemniscate constants are given in Gauss $1_{1}$ (p. 31), $1_{2}$ (p. 150), 2 (p. 364, 413421), and various rational powers of $e^{-x}$ to many figures in GAUSS 2 (p. 418-432) and BAASMTC 4.

The final result of the GREenhill-HipPISLEY work for integral degrees of modular angle was published in the Smithsonian tables of HippisLey 1. These give, in columns headed

$$
F(\phi), \phi, E(r), D(r), A(r),
$$

the quantities $u=r K / 90, \phi$, zn $u, D(r), A(r)$ for $\theta=5^{\circ}\left(5^{\circ}\right) 80^{\circ}\left(1^{\circ}\right) 89^{\circ}, r=0(1) 90$; all values are to $10 \mathrm{D}$, except those of $\phi$, which are to the nearest minute. The heading for each modular angle provides values of $K, K^{\prime}, E, E^{\prime}, q, \Theta(0)=\vartheta_{4}, \mathbf{H}(K)=\vartheta_{2}$; these have been listed in Sections II, III, IV. 
The important GREENHILL-HipPISLEY work has been greatly extended in the recent monumental tables of the SPENCELEYs, the most important elliptic tables ever published. These give (i) tables for each degree of $\theta$, compared with $\theta=5^{\circ}\left(5^{\circ}\right) 80^{\circ}\left(1^{\circ}\right) 89^{\circ}$ in HIPPISLEY 1, (ii) Jacobian functions sn, cn, dn (see Section XI), omitted in HippISLEY 1, as well as theta functions, etc. as described in the next paragraph, (iii) more decimals than in HipPISLEY 1.

Apart from three columns giving sn $u, \operatorname{cn} u, \operatorname{dn} u$, the SPENCEley 1 tables give, in columns headed

$$
u=(r / 90) K=F(\phi, k), \phi, E(\phi, k), A(r), D(r),
$$

values of these quantities to $12 \mathrm{D}$ for $\theta=1^{\circ}\left(1^{\circ}\right) 89^{\circ}, r=0(1) 90$. The tabulated functions are as in the Hippisley 1 tables, except that $\phi$ is expressed in radians and that $E(\phi, k)$ is the second integral, or el $u$, while HippisLEy's $E(r)$ is the zeta function, or zn $u$. The table of $\phi$ is by far the most extensive in existence, and will make it comparatively easy to check LEGENDRE's great double-entry tables, by inverse interpolation in SPENCELEY 1. The arrangement of all tables is quadrantal. The headings for each modular angle give values of $K, K^{\prime}, E$, $E^{\prime}, q, q^{\prime}, D(90)=\vartheta_{3} / \vartheta_{4}, 1 / D(90)=\vartheta_{4} / \vartheta_{3}$; these have been listed in Sections II, III, IV.

On a few theta functions tabulated in NBSCL 2, see $M T A C$, v. 1, p. 126, 1943.

LEGENDRE 3 (p. 96), 5 (p. 88) gives $\phi$ to $6 \mathrm{D}$ of $1^{\prime \prime}$ with $\Delta^{3}$ and el $u=E(\phi)$ to $11 \mathrm{D}$ with $\Delta^{4}$ for $\theta=45^{\circ}, 200 u / K=0$ (1)20. LegendRE 3 (T.VII), 5 (T.VII) gives $\phi$ to 7D of $1^{\prime \prime}$ with $\Delta^{3}$ for $\theta=0\left(0^{\circ} .1\right) 45^{\circ}, u=K / 10$.

MILNE-Thomson 4 gives $\mathrm{Z}(u)=\mathrm{zn} u$ to $7 \mathrm{D}$, with second differences in $u$, for $k^{2}=.1(.1) 1$ and for $u$ at interval .01 from 0 to a limit $2,2.5$ or 3 , depending on $k^{2}$, but always greater than $K$ (except of course at $k^{2}=1$, where $K$ is infinite).

Fox \& McNAmeE 1 have recently tabulated the Jacobian zeta function of complex argument. They write

$$
f_{1}\left(\psi_{1}, \phi, \alpha\right)+i f_{2}\left(\psi_{1}, \phi, \alpha\right)=\mathrm{zn}\left(K \psi_{1}+i K^{\prime} \phi, k\right)+i \pi \phi /(2 K),
$$

the notation $\psi_{1}$ and $\phi$ for the fractions of the quarter-periods arising from their potential problem, and $\alpha$ denoting the modular angle $\sin ^{-1} k$. It is unnecessary to tabulate $f_{1}$ and $f_{2}$ separately, as the authors show that $f_{2}\left(\psi_{1}, \phi, \alpha\right)=f_{1}\left(1-\phi, 1-\psi_{1}, \frac{1}{2} \pi-\alpha\right)$. They tabulate $f_{1}$ to $3 S$ for $\alpha=1^{\circ}\left(1^{\circ}\right) 5^{\circ}\left(5^{\circ}\right) 85^{\circ}\left(1^{\circ}\right) 89^{\circ}, \psi_{1}=0(.1) 1, \phi=0(.1) 1$.

On coefficients in an expansion for am $u$, see Section VII-7 (GLAISHER 1).

\section{Section XI. Jacobian Elliptic Function:}

If $x=M u=\pi u / 2 K$, we have

$$
\operatorname{sn} u=\frac{1}{\sqrt{ } k} \frac{\vartheta_{1}(x)}{\vartheta_{4}(x)}, \quad \text { cn } u=\sqrt{\frac{k^{\prime}}{k}} \frac{\vartheta_{2}(x)}{\vartheta_{4}(x)}, \quad \operatorname{dn} u=\sqrt{k^{\prime}} \frac{\vartheta_{3}(x)}{\vartheta_{4}(x)} .
$$

The connection with the theta functions of Glaisher 3 is

$$
\text { sn } u=\Theta_{1}(x) / \Theta_{4}(x), \quad \text { cn } u=\Theta_{2}(x) / \Theta_{4}(x), \quad \operatorname{dn} u=\Theta_{3}(x) / \Theta_{4}(x) .
$$

Elliptic functions may be computed from HipPISLEY's tables by the formulae

$$
\text { sn } u=\frac{1}{\sqrt{ } k^{\prime}} \frac{A(r)}{D(r)}, \quad \text { cn } u=\frac{B(r)}{D(r)}, \quad \operatorname{dn} u=\sqrt{ } k^{\prime} \frac{C(r)}{D(r)},
$$

where $r=90 u / K$.

The great SPENCEleEy 1 tables give sn $u, \operatorname{cn} u, \operatorname{dn} u$ to $12 \mathrm{D}$ for $\theta=1^{\circ}\left(1^{\circ}\right) 89^{\circ}, r=90 u / K$ $=0(1) 90$, that is, $x=0\left(1^{\circ}\right) 90^{\circ}$.

The NBSCL 2 manuscript gives sn $u, \operatorname{cn} u, \operatorname{dn} u$ to $15 \mathrm{D}$ for $k^{2}=0(.01) 1, u / K=.01$, $.1(.1) 1$, that is, $x=10,10^{\circ}\left(10^{\circ}\right) 100^{\circ}$. The ReNo 1 manuscript tabulates sn $u$ for $k^{2}=0(.01) 1$, $u / K=0(.01) 1$. BYERLY 1 gives sn $u$, cn $u, \operatorname{dn} u$ to $3 \mathrm{D}$ for $k^{2}=\frac{1}{2}, u=.05(.1) 1.85$. 
Milne-Thomson 3 tabulates sn $u$, cn $u, \operatorname{dn} u$ to $5 \mathrm{D}$, with first differences in $u$, for $k^{2}=0(.1) 1$ and for $u$ at interval .01 from 0 to a limit 2 or more, depending on $k^{2}$, but greater than $K$ except at $k^{2}=1$.

F. W. Newman 1 (p. 126), 2 (p. 131) gives $-\log \operatorname{dn} \frac{2}{3} K$ to $16 \mathrm{D}$ for $\rho=\pi K^{\prime} / 2 K$ $=-\frac{1}{2} \ln q=1(.1) 6.4$.

Bergmann 1 tabulates sn $(u+i v)$ to $2-3 \mathrm{D}$ for $\theta=15^{\circ}, 20^{\circ}, 75^{\circ}, u=0(K / 10) K$, v $=0\left(K^{\prime} / 10\right) K^{\prime}$.

On coefficients in the Fourier expansion of sn $u$ cn $u$, see Section VII-7 (GLAISHER 1).

S. A. E. War Engineiring BoARD 1 gives (p. 346) $\gamma$ to $5 \mathrm{D}$ of $1^{\circ}$ and $\sin \gamma$ to $7 \mathrm{D}$, where $\sin \frac{1}{2} \gamma=\sin \frac{1}{2} \gamma_{0} \operatorname{sn} u$, where $\gamma_{0}=2 \theta=10^{\circ}\left(10^{\circ}\right) 160^{\circ}$ and $\tau=\pi u / 2 K=0\left(10^{\circ}\right) 90^{\circ}$. More specialized tables of a similar kind follow. See $M T A C$, v. 2, p. 121-122, 1946.

\section{Section XII. Weierstrassian Functions}

Accounts of the Weierstrassian functions are to be found in various texts, for instance in Whittaker \& Watson, Modern Analysis. Tables relating to such functions are not numerous. Weierstrass \& SCHWARZ 1 provides a good collection of formulae and theorems, and on p. 7 tabulates coefficients in the expansion of the sigma function $\sigma(u)$. If

$$
\sigma(u)=\sum_{m, n} a_{m n}\left(\frac{1}{2} g_{2}\right)^{m}\left(2 g_{3}\right)^{n} u^{4 m+6 n+1} /(4 m+6 n+1) !(m, n=0,1,2, \cdots)
$$

the table gives the (integral) values of $a_{m n}$ for the 33 combinations of $m$ and $n$ for which $4 m+6 n+1 \leqslant 35$. A number of functions are expanded to a considerable length in the lists in TANNERY \& MOLK 1, v. 4, p. 88 f.

Several Weierstrassian formulae for evaluating half-periods and incomplete integrals (WeIERSTRASS \& SchWARz 1, p. 67-71) involve quantities $\mathfrak{R}_{0,1}, \mathfrak{R}_{0,2}, \mathfrak{R}_{0,3}$ defined by omitting from the series

$$
\mathfrak{R}_{0}=1+\left(\frac{1}{2}\right)^{2} l^{4}+\left(\frac{1.3}{2.4}\right)^{2} l^{8}+\left(\frac{1.3 .5}{2.4 .6}\right)^{2} l^{12}+\cdots
$$

its first, first two, and first three terms respectively. The three quantities are tabulated, when appreciable to the number of decimals given (10 or more), with first differences in the case of $\mathfrak{l}_{0,1}$, in NAGAOKA \& SAKuraI 1 , p. 56, for $k^{2}=0(.001) .5$, where $l=\left(1-\sqrt{ } k^{\prime}\right) /$ $\left(1+\sqrt{ } k^{\prime}\right)$.

Greenhill published two tables, both calculated by A. G. HADCock, relating to the Weierstrassian function $\wp(u)$ for which

$$
\wp^{\prime 2}=4 \wp^{3}-g_{2} \varnothing-g_{3}
$$

in the "equianharmonic" case $g_{2}=0$, the discriminant $g_{2}{ }^{3}-27 g_{3}{ }^{2}$ being negative and consequently two roots of the cubic complex.

Greenhill 1 tabulates $\varphi(u)$ to 5-7S when $g_{3}=4$, for arguments $u=r \omega_{2} / 180$ and $u=r \omega_{2}^{\prime} / 180$, where $r=0(1) 180$ in both cases. Here $\omega_{2}$ is the real half-period, and $\omega_{2}^{\prime}=$ $\omega_{3}-\omega_{1}=i \omega_{2} \sqrt{ } 3$. The corresponding Jacobian modulus is $\sin 15^{\circ}$, and $\omega_{2}=K / 3^{\ddagger}$. The last figures are very inaccurate (see Part III).

Greenhill 2 tabulates $\wp^{\prime}(u), \wp(u), \zeta(u)$ and $\sigma(u)$ to about 5D when $g_{3}=1$, for $u=r \omega_{2} / 180, r=0(1) 240$. The Jacobian modulus is still sin $15^{\circ}$, and the real half-period $\omega_{2}$ is now

$$
\left.\omega_{2}=2^{1} K / 3^{1}=\frac{1}{2}\left\{\Gamma\left(\frac{1}{3}\right)\right\}^{2} /\left[3 \frac{2}{3}\right)\right]=1.52995 .
$$

The values of $\wp(u)$ are $2^{-t}$ times those in GREenhiLl 1. The table is reproduced in Gossot 1 , and to not more than $4 \mathrm{D}$ in JAHNKE \& EMDE 1.

In the case when $g_{2}, g_{3}$ are real and the discriminant $g_{2}{ }^{3}-27 g_{3}{ }^{2}$ is positive, so that the cubic has real roots, I have encountered no tables of $\varnothing(u)$. But owing to the occurrence of this case of real roots in Gauss's elliptic ring method of calculating secular perturbations of planets, there have been several tables from astronomical sources for calculating the quantities $\omega$ and $\eta$, in terms of which various real complete integrals involving $\sqrt{ } S=\sqrt{ }\left(4 s^{3}-g_{2} s-g_{3}\right)$ may be expressed. 

have

Supposing the roots of the cubic in the order $e_{1}>e_{2}>e_{3}$, and all surds positive, we

$$
\begin{aligned}
& \omega=\omega_{1}=\int_{e_{3}}^{e_{2}} \frac{d s}{\sqrt{ } S}=\int_{e_{1}}^{\infty} \frac{d s}{\sqrt{ } S}, \\
& \eta=\eta_{1}=-\int_{e_{3}}^{e_{2}} \frac{s d s}{\sqrt{ } S} .
\end{aligned}
$$

The expressions in terms of complete elliptic integrals of modulus given by $k^{2}=\left(e_{2}-e_{2}\right) /$ $\left(e_{1}-e_{3}\right)$ are

$$
\omega=K / \sqrt{ }\left(e_{1}-e_{3}\right), \quad \eta=\sqrt{ }\left(e_{1}-e_{3}\right)\left\{E-\frac{1}{3}\left(2-k^{2}\right) K\right\},
$$

but it was pointed out by H. BRUNS ${ }^{1}$ that $\omega$ and $\eta$ may be evaluated in terms of hypergeometric functions, without first finding the roots $e_{1}, e_{2}, e_{3}$. If an absolute invariant $g$ is defined by

$$
g=\frac{g_{2}{ }^{3}}{27 g_{3}{ }^{2}}=\frac{4\left(1-k^{2} k^{\prime 2}\right)^{3}}{\left\{\left(2-k^{2}\right)\left(1+k^{2}\right)\left(1-2 k^{2}\right)\right\}^{2}},
$$

and $x=1-g^{-1}$, then, if $g_{3} \geqslant 0$,

$$
\begin{gathered}
\omega\left(12 g_{2}\right)^{\frac{1}{2}} / \pi=F_{\omega}=F\left(\frac{1}{12}, \frac{5}{12}, 1, x\right), \\
12 \eta\left(12 g_{2}\right)^{-\frac{1}{2} / \pi}=F_{\eta}=F\left(-\frac{1}{12}, \frac{7}{12}, 1, x\right) .
\end{gathered}
$$

ARNDT 1 tabulates $F_{\omega}$ and $F_{\eta}$ to $7 \mathrm{D}$ with $\Delta$ for $x=0(.001) 1$. Interpolation is difficult when $x>$.98; ARNDT recommends instead the use of formulae involving four hypergeometric series, for which he tabulates coefficients of powers of $1-x$.

If a different absolute invariant $\gamma$ is defined by

$$
\cos 3 \gamma=g_{3} \sqrt{ }\left(27 / g_{2}{ }^{3}\right), \quad 0 \leqslant 3 \gamma \leqslant 180^{\circ},
$$

$\cos 3 \gamma$ having the same sign as $g_{3}$, then whichever this sign is, we have ${ }^{2}$

$$
\begin{aligned}
& F_{\omega}=F\left(\frac{1}{6}, \frac{5}{6}, 1, \sin ^{2} \frac{3}{2} \gamma\right)=P_{-\downarrow}(\cos 3 \gamma), \\
& F_{\eta}=F\left(-\frac{1}{6}, \frac{7}{6}, 1, \sin ^{2} \frac{3}{2} \gamma\right)=P_{t}(\cos 3 \gamma),
\end{aligned}
$$

$P$ as usual denoting a Legendre function. WIrT 3 supplements ARNDT 1 by tabulating $F_{w}$ and $F_{\eta}$ to $8 D$ with $\Delta$ for $\xi=.4(.001) .5$, where

$$
\xi=\frac{1}{2}\{1-\sqrt{ }(1-x)\}=\frac{1}{2}\left(1-g^{-\frac{1}{3}}\right)=\sin ^{2} \frac{2}{2} \gamma .
$$

The range in $\xi$ corresponds to $.96 \leqslant x \leqslant 1$, the region of difficulty in "ARNDT 1. Wirt 3 tabulates also, logarithmically, coefficients in continued fractions for $F_{\omega}$ and $F_{\eta}$.

The tables of ARNDT 1 give $\omega_{1}$ and $\eta_{1}$ only when $g_{3} \geqslant 0$, corresponding to $0 \leqslant 3 \gamma \leqslant{ }^{\circ} 90^{\circ}$, and Wirt 3 does not extend the range. When $g_{3}<0$, they may be used to determine $\omega_{3}$ and $\eta_{3}$. For, connected with a given cubic expression, $S=4 s^{2}-g_{2} s-g_{3}$, having real $g_{2}$ and $g_{3}$ such that $g_{2}{ }^{3}>27 g_{3}{ }^{2}$, there are four positive quantities, " $\omega, \eta_{-}$and what I propose here to call $\omega^{*}, \eta^{*}$, such that

$$
\omega_{1}=\omega, \quad \omega_{3}=i \omega^{*}, \quad \eta_{1}=\eta, \quad \eta_{8}=-i \eta^{*}, \quad \eta \omega^{*}+\eta^{*} \omega=\frac{1}{2} \pi .
$$

$\omega$ and $\eta$ are as defined above, while

$$
\omega^{*}=\int_{e_{2}}^{e_{1}} \frac{d s}{\sqrt{ }(-S)}=\int_{-\infty}^{e_{2}} \frac{d s}{\sqrt{ }(-S)}, \quad \eta^{*}=\int_{e_{2}}^{e_{1}} \frac{s d s}{\sqrt{ }(-S)},
$$

all square roots being taken positively. For given $g_{2}$, we have

$$
\omega^{*}\left(g_{3}\right)=\omega\left(-g_{3}\right), \quad \eta^{*}\left(g_{3}\right)=\eta\left(-g_{3}\right) .
$$

Thus it is immaterial whether we consider two functions, say $\omega$ and $\eta$, in the whole range $0 \leqslant 3 \gamma \leqslant 180^{\circ}$, or four functions in half the range, say $0 \leqslant 3 \gamma \leqslant 90^{\circ}$. This is similar to the well-known choice between quadrantal and semi-quadrantal tabulation of the trigonometric functions or of the complete integrals $K, E, K^{\prime}, E^{\prime}$. However the matter is regarded, the tables of ARNDT 1 give only half the desirable information, the sign of $g_{8}$ being lost in the argument $x=1-27 g_{z^{2}} / g_{2}{ }^{3}$. 
INNES used an absolute invariant $~$ (iota), sometimes with numerical suffix, identical with $3 \gamma$ above. As $\iota$ is an inconvenient symbol, and the angle $\gamma$ (rather than thrice it) is the simplest quantity to use in writing down the trigonometric solution of the cubic, I shall describe the INNES-RoBbins-MERFIELD tables in the $\gamma$ notation. These tables between them cover the whole range $0 \leqslant 3 \gamma \leqslant 180^{\circ}$, and so form a complete set of tables for calculating $\omega, \eta, \omega^{*}, \eta^{*}$ for any $\gamma$. The formulae for this purpose are set out in INNEs 4 . They involve the hypergeometric series

$$
F\left(-\frac{1}{6}, \frac{7}{8}, 2, \sin ^{2} \frac{3}{2} \gamma\right) \quad \text { and } \quad F\left(\frac{1}{6}, \frac{5}{6}, 2, \sin ^{2} \frac{3}{2} \gamma\right) \text {, }
$$

which, unlike the series for $P_{ \pm \xi}(\cos 3 \gamma)$, remain finite (and in fact vary little) over the whole range $0 \leqslant 3 \gamma \leqslant 180^{\circ}$. Logarithms of these two hypergeometric functions are tabulated to $7 \mathrm{D}$ with $\Delta^{2}$ for $3 \gamma=0\left(1^{\circ}\right) 90^{\circ}$ in both RoBBINS 1 and INNES 4 , and for $3 \gamma=90^{\circ}\left(1^{\circ}\right) 180^{\circ}$ in MERFIELD 2. Logarithms of the first 20 coefficients in each series are given to 8D in MERFIELD 1.

If the four quantities $\omega, \eta, \omega^{*}, \eta^{*}$ are to be calculated for given $g_{2}, g_{3}$, whichever the sign of $g_{3}$, two hypergeometric functions are taken from the INNES-RoBbins table, and two from the table of MERField 2; the latter is an important complement to the former. A small illustrative table of $2 \omega / \pi, 2 \eta / \pi$, etc. is given for 16 values of $\gamma$ in INNES 4 (p. 363). This interesting table covers the whole range, but the use of either $\gamma($ or $3 \gamma)$ or $g_{3} \sqrt{ }\left(27 / g_{2}{ }^{3}\right)$ as equidistant argument would have been better; the table would have been symmetrical, and moreover it is curious to see the roots of the cubic figuring as primary arguments when the work aims at avoiding their determination.

The above tables are astronomically related to those of Hill 1, Callandreau 1 and InNes 1. Those of Hill 1 , having $\theta=\sin ^{-1} k$ as argument, have been mentioned in Section VII-5. Callandreau 1 and InNes 1 are too specialized to be of much general mathematical interest, and all three may probably be regarded as superseded by the later work described above. Discussions of the various methods from an astronomical point of view are given in INNES 3 and by E. DoolitTle. ${ }^{3}$

$1 \mathrm{H}$. Bruns, Ueber die Perioden der elliptischen Integrale erster und zweiter Gattung, Dorpat, 1875. (I have seen only the reprint in Math. Ann., v. 27, 1886, p. 234-252. It is here stated that this reprint is "einer im Jahre 1875 zum Doctorjubiläum von V. J. Buniakowsky von der physiko-mathematischen Facultät der Universität Dorpat dargebrachten Festschrift.") p. 214.

2 H. C. Plummer, An Introductory Treatise on Dynamical Astronomy, Cambridge, 1918,

E. Doolitrle, The Secular Variations of the Elements of the Orbits of the Four Inner Planets, Amer. Phil. Soc., Trans., n.s., v. 22, part 2, Philadelphia, 1912.

\section{Section XIII. Dixon Functions}

A theory of elliptic functions based upon the cubic curve $x^{3}+y^{3}-3 \alpha x y=1$ was developed by A. C. Dixon. ${ }^{1}$ The case $\alpha=0$, which corresponds to the "equianharmonic" case of Weierstrassian functions, has been used in O. S. ADAMS 1 in calculations concerning map projections. When $\alpha=0$, functions $\operatorname{sm} u$ and $\mathrm{cm} u$ are defined by

$$
\begin{gathered}
x=\operatorname{sm} u, \quad y=\mathrm{cm} u, \quad \operatorname{sm}^{3} u+\mathrm{cm}^{3} u=1, \\
u=\int_{0}^{x}\left(1-x^{3}\right)^{-3} d x=\int_{y}^{1}\left(1-y^{3}\right)^{-1} d y,
\end{gathered}
$$

and a real period $3 \lambda$ is given by

$$
\lambda=\int_{0}^{1}\left(1-x^{3}\right)^{-3} d x=\frac{1}{3}\left\{\Gamma\left(\frac{1}{3}\right)\right\}^{2} / \Gamma\left(\frac{2}{3}\right)=1.76663875 .
$$

Adams 1 writes $K$ instead of $\lambda$, but Dixon's notation is more convenient here.

The connection with the equianharmonic Weierstrassian functions tabulated in GREENHLL 2 and JAHNKE \& EMDE 1 (see Section XII) is

$$
\operatorname{sm} u=\frac{2 \sqrt{ } 3 \varphi(u / \sqrt{ } 3)}{\sqrt{ } 3-\varphi^{\prime}(u / \sqrt{ } 3)^{\prime}}, \quad \operatorname{cm} u=\frac{\varphi^{\prime}(u / \sqrt{ } 3)+\sqrt{ } 3}{\wp^{\prime}(u / \sqrt{ } 3)-\sqrt{ } 3} .
$$


$u=\lambda$ corresponds to $r=120$ in these Weierstrassian tables, and ADAMs 1 constructs his table with arguments $u=0(\lambda / 120) \lambda$. He gives $\operatorname{sm} u, \mathrm{~cm} u$ and $\operatorname{sm} u / \mathrm{cm} u$ to $4 \mathrm{D}$. In addition, he gives $1-\mathrm{cm} u$ to $8-5 \mathrm{D}$ for $u=0(\lambda / 120) \lambda / 3$. Values in the remaining two-thirds of the period are given by

$$
\begin{aligned}
& \operatorname{sm}(\lambda+u)=1 / \mathrm{cm} u, \quad \operatorname{cm}(\lambda+u)=-\operatorname{sm} u / \mathrm{cm} u, \\
& \operatorname{sm}(2 \lambda+u)=-\operatorname{cm} u / \operatorname{sm} u, \quad \operatorname{cm}(2 \lambda+u)=1 / \operatorname{sm} u .
\end{aligned}
$$

1 A. C. Dixon, Quart. Jn. of Math., v. 24, 1890, p. 167-233.

\section{PART II}

\section{Bibliography of Authors of Tables}

Roman numerals in square brackets refer to sections of Part I. Numerals following such a square bracket denote inclusive pages for the totality of tables thus indicated. Asterisks (*) attached to Roman numerals refer to errata notes in Part III.

O. S. Adams, 1. Elliptic Functions applied to Conformal World Maps. U. S. Coast and Geodetic Survey, Special Publication, no. 112, Washington, 1925, iv, 118 p. [XIII], 112.

J. R. Arrey, 1. "Toroidal functions and the complete elliptic integrals," Phil. Mag., s. 7, v. 19,1935 , p. 177-188. [II*, VII] 180-187.

E. S. Allen, 1. Six-Place Tables. New York and London, (a) sixth ed., 1941, xxiii, 181 p. (b) seventh ed., 1947, xxiii, 232 p. [II], (a) 177-178, (b) 228-229, not in earlier editions.

H. Andoyer, 1. Cours de Mécanique Céleste. V. 1, Paris, 1923, vi, 439 p. [V], 419-422.

L. ARNDT, 1. Beitrag zur Berechnung der störenden Kräfte in der Theorie der säcularen Störungen. Diss. Berlin. Berlin?, 1895, 44 p. [XII], 25, 32-44.

1. "Recherches sur le calcul des forces perturbatrices dans la théorie des perturbations séculaires," Soc. des Sci. nat. de Neuchâtel, Bull., v. 24 (1895-1896), 1896, p. 3-44. [XII], 26, 32-44.

W. BARTKy, 1. "Numerical calculation of a generalized complete elliptic integral," Rev. Mod. Physics, v. 10, 1938, p. 264-269. [I, IX], 267.

S. BergmanN, 1. "Über die Berechnung des magnetischen Feldes in einem EinphasenTransformator," Z. angew. Math. Mech., v. 5, 1925, p. 319-331. [XI], 326-327.

J. L. F. Bertrand, 1. Traité de Calcul Différentiel et de Calcul Intégral, deuxième partie, Calcul Intégral. Paris, 1870, xii, 725 p. [II, III*, IV*, VIII], 711-717.

G. Blanch, see Lowan

K. Bohlin, 1. Om Tillämpningen af Lambert's Lag inom den Celesta Fotometrien. Svenska Vetensk.-Akad., Bihang till Handlingar, v. 25, Afd. I, no. 7, Stockholm, 1900, 39 p. [II, III, VIII], 26-39.

1. Tables des Fonctions Elliptiques. Stockholm, 1900 ; exact reprint of tables with French introduction, p. 3-9, and a folding plate of proportional parts. [II, III, VIII], 10-23. M. Boll, 1. Tables Numériques Universelles. Paris, 1947, iv, 882 p. [II, VI, VIII], 346-357. M. Born, 1. "On the quantum theory of the electromagnetic field," R. Soc. London, Proc., v. 143A, 1934, p. 410-437. [VIII], 432.

BAASMTC, 1. BAAS, Report of 1911 meeting, London, 1912, p. 67-73. [X], 68-71.

2. Report of 1912, London, 1913, p. 39-55. [X], 48-55.

3. Report of 1913 , London, 1914, p. $87-113$, and 3 folding sheets containing graphs. [X], 92-111 and sheets.

4. Report of 1919, London, 1920, p. 43-81. [X], 72-81. 
D. Brouwer, see Brown

E. W. Brown, 1. "The Fourier expansions of $\left(1+\alpha^{2}-2 \alpha k \cos \psi\right)^{-\varepsilon, " ~ R A S, ~ M o . ~ N o t ., ~}$ v. 88, p. $459-465,622,1928$. [V], 460-461.

2. "The development of the disturbing function with large values of the ratio of the distances," RAS, Mo. Not., v. 92, p. 224-227, 1932. [V], 227.

E. W. Brown \& D. Brouwer, 1. Tables for the Development of the Disturbing Function. Yale Univ., Astr. Obs., Trans., v. 6, part 5, p. 67-157, 1932. [V], 73-153.

12. Same in book form, Tables for the Development of the Disturbing Function. Cambridge, 1933, p. 66-157. [V], 73-153.

E. W. Brown \& C. A. Sноoк, 1. Planetary Theory. Cambridge, 1933, xii, 302 p. [V], 105.

R. S. Burington, 1 . Handbook of Mathematical Tables and Formulas. Sandusky, Ohio, (a) first ed., 1933, viii, 251 p., (b) second, 1940, viii, 275 p.; separate publication of 12. [II], (a) 240, (b) 263.

12. Mathematical Tables and Formulas, appendix in Handbook of Chemistry, edited by N. A. Lange and others. Sandusky, Ohio, (a) first ed., 1934, (b) second, 1937, (c) third, 1939, (d) fourth, 1941, (e) fifth, 1944. In (c) the appendix has i, 249 p., in (d, e) i, 271 p. [II], (c) 241, (d, e) 263.

S. Butterworth, 1. "On the self-inductance of single-layer flat coils," Phys. Soc. London, Proc., v. 32, 1919, p. 31-37. [VI], 34.

W. E. ByerLy, 1. Elements of the Integral Calculus, second ed. Boston, 1889, xvi, 339, 63-76, 32 p., the last 32 p. being Peirce 1. Reprint, New York, 1926. [VIII, XI], 233-234, 251. (No tables in first ed., 1881.)

O. Callandreau, 1. "Calcul des variations séculaires des éléments des orbites," Paris, Observatoire, Annales, Mém., v. 18, 1885, p. A.1-A.46. [XII], A.26-A.31.

E. CAmbi, 1. "Complete elliptic integrals of complex Legendrian modulus," Jn. Math. Phys., v. 26, p. 234-245, 1948. [II, III], 238-244.

D. F. Campbell, 1. The Elements of the Differential and Integral Calculus. New York, 1904, xii, 364 p. [VIII], 270-271.

A. Cecconi, 1. "Intersezioni di superficie cilindriche con formule e tabelle per le applicazioni técniche," Ist. Veneto Sci. Lett. Arti, Atti, Parte II, Cl. Sci. Mat. Nat., v. 101, 1942, p. 419-439. [II, VII], 436-437.

L. Cohen, see Rosa

F. Conforto \& T. Viola, 1. "Sul calcolo di un integrale doppio che interviene nella determinazione della profondità degl' ipocentri sismici," La Ricerca Scientifica, 1936, anno VII, vol. II, p. 161-198 and 2 folding plates. [IX], 198.

H. L. Curtis \& C. M. Sparks, 1. "Formulas, tables, and curves for computing the mutual inductance of two coaxial circles," NBS, Sci. Pap., v. 19, no. 492, 1924, p. 541-576 and 3 folding charts. [VI], 563.

J. B. DALE, 1. Five-Figure Tables of Mathematical Functions. London, 1903, xv, 92 p. [II*, VIII], 68-76.

B. B. Devison, 1. Part 3, [Movement of Subterranean Waters], p. 217-356 of S. A. Khrisrianovich, S. G. Mikhlin \& B. B. Devison, Nekotorye novye voprosy mekhaniki sploshnot sredy [Some new questions in mechanics of a continuous medium]. Moscow and Leningrad, Akad. N., Matem. Inst. imeni V. A. Steklova, 1938, 407 p. [VII], 334-336. In this book and elsewhere DEvison is transliterated as DAvison.

N. E. Dorsey, see Rosa

H. B. Dwighr, 1. Tables of Integrals and Other Mathematical Data. New York, (a) first ed., 1934, ix, 222 p., (b) revised ed., 1947, ix, 250 p. [II], (a) 208-210, (b) 234-236. 
2. "Elliptic integrals of large moduli," Elect. Engineering, v. 54, 1935, p. 709-711. [II*], 710-711.

3. Mathematical Tables. New York and London, (a) first edition, 1941, viii, 231 p., (b) "first ed., third impression (with additions)," [1944], viii, $231+8$ p. [II], (a,b) 199205.

F. Emde (see also Jahnke and Legendre), 1. "Die Berechnung eisenfreier Drosselspulen für Starkstrom," Elektrotechnik u. Maschinenbau, v. 30, 1912, p. 221-226, 246-251, 267-271. [VI], 224.

2. "Zur Zahlenrechnung bei vollständigen elliptischen Integralen," Archiv. f. Elektrotechnik, v. 30, 1936, p. 243-250. [VII], 249-250.

A. Fletcher, 1. "Tables of the two chief Laplace coefficients," RAS, Mo. Not., v. 99, p. 259-265, 1939. [V], 261-265.

2. "A table of complete elliptic integrals," Phil. Mag., s. 7, v. 30, 1940, p. 516-519. [II], 517-519.

3. Manuscript tables in possession of the author. [II].

A. G. Forsdyke, see Levy

W. FouQuet, 1. "Dipolare Koordinaten und Kugelfunktionen," Z. angew. Math. Mech., v. 17, 1937, p. 48-55. [VII], 54-55.

F. E. Fowle, 1 1. Smithsonian Physical Tables, Washington. (a) First ed., by T. Gray, 1896, (b) rev. ed., Gray, 1897, (c) second rev., Gray, 1903, (d) third rev., Gray, 1904, (e) fourth rev., GRAY, 1908, (f) fif th rev., by FowLE, 1910. [II, VI], (a-e) 42-43, (f) 56-57.

12. (a) Sixth rev. ed., 1914, (b) seventh rev., 1920, (c) eighth rev., 1933, (d) reprint with additions, 1934, all by FowLe. [II], (a) 66, (b) 69, (c, d) 71.

The first edition and fifth to eighth revised editions are also contained in Smithsonian Miscellaneous Collections, v. 35, 58, 63, 71, 88.

E. N. Fox and J. MCNAMEe, 1. "The two-dimensional potential problem of seepage into a cofferdam," Phil. Mag., s. 7, v. 39, 1948, p. 165-203. [X], 187-199.

J. G. Freeman, 1. "Mathematical theory of deflection of beam," Phil. Mag., s. 7, v. 37, 1946, p. 855-862. [VIII], 858.

R. FRICKE, 1. Analytisch-funktionentheoretische Vorlesungen. Leipzig, 1900, ix, 520 p. [II, III, VIII], 273-283.

(This book is usually referred to by the above short title, which appears on the binding. The title-page has Kurzgefasste Vorlesungen über verschiedene Gebiete der höheren Mathematik mit Berücksichtigung der Anwendungen. Analytisch-functionentheoretischer Teil.)

C. F. GAUSs, 1. "Disquisitiones generales circa seriem infinitam $1+\frac{\alpha \beta}{1 . \gamma} x+\cdots, "$ Gesell.

d. Wissen., Göttingen, Comment. recentiores, v. 2, 46 p., 1813. [X], 31.

12. Werke, v. 3, Göttingen, 1866, 1876, 123-162. [X], 150.

2. Nachlass, Werke, v. 3 (ed. E. J. Schering), Göttingen, 1866, or second impression, 1876. [II*, X*], 363-364, 403, 413-432.

J. W. L. Glaisher, 1. "On an elliptic function solution of Kepler's problem," RAS, Mo. Not., v. 37, p. 366-386, 1877. [III*, VII, X, XI], 372-374, 383-386.

2. "On the coefficients in the $q$-series for $\pi / 2 K$ and $2 G / \pi$, , Quart. Jn. Math., v. 21, p. 60-76, 1885. [IV], 66.

3. Unpublished tables. $[\mathrm{X}, \mathrm{XI}]$.

S. P. Glazenap, 1. Matematicheskie i Astronomicheskie Tablitsy [Mathematical and Astronomical Tables]. Leningrad, 1932, v, 240 p. [II, III, VIII], 79-89.

H. C. F. F. Gossot, 1. "Trajectoire d'un projectile dans le cas où la résistance de l'air est proportionnelle au cube de la vitesse," Revue Maritime et Coloniale, v. 105, 1890, p. 225-262, 417-443. (Includes a slightly modified translation of GREENHILL 2.) [XII*], 442-443. 


\section{J. Graindorge, see Schlömilch}

A. Gray, 1. Absolute Measurements in Electricity and Magnetism, first ed., v. 2. London and New York, 1893, xxiv, 4, 346, xx, 347-868 p. [VI], 852-854.

12. Same, second ed. [in one vol.], London, 1921, xix, 837 p. [II, VI], 800-803.

T. Gray, see Fowle

Great Britain, Admiralty Computing Service, 1. "Solution of integral equations occurring in an aerodynamical problem," Report no. 89, 1945, 17 p. See MTAC, v. 2, p. 294. [VII], 15, 17.

A. G. Greenhill, 1. "Solution of the cubic and quartic equations by means of Weierstrass's elliptic functions," London Math. Soc., Proc., s. 1, v. 17, p. 262-287, 1886. [XII*], 268-269.

2. "The trajectory of a projectile for the cubic law of resistance," R. Artillery Inst., Proc., v. 17, p. 181-216, 1889. The table is reproduced in the French translation of Gossot and, with slight abbreviation, in JAHNKE \& EMDE 1. [XII*, XIII], 212-213.

3. The Applications of Elliptic Functions. London \& New York, 1892, xii, 357 p. [II, VIII], 10-11, 177.

3. French translation by J. Griess, Les Fonctions Elliptiques et leurs Applications. Paris, 1895, xviii, 574 p. [II, VIII], 567-570.

The tables of BAASMTC $1-4$ and HipPISLEy 1 owe their arrangement to Greenhill.

J. Griess, see Greenhill

F. L. Grifrin, 1 1. Mathematical Analysis, Higher Course. Boston, 1927, x, 512 p. [VIII], 499.

1. Calculus Tables, reprinted from $1_{1}$, Boston, 1927, iii, 492-508 p. [VIII], 499.

F. W. Grover (see also Rosa), 1. "Calculation of the maximum force between two coaxial circular currents," NBS, Bull., v. 12, p. 317-373, 1916; Sci. Pap., no. 255. [VI], 368-373.

2. "Additions to the formulas for the calculation of mutual and self inductance," NBS, Bull., v. 14, p. 537-570, 1919; Sci. Pap., no. 320. [VI], 570.

3. "Tables for the calculation of the inductance of circular coils of rectangular cross section," NBS, Sci. Pap., v. 18, no. 455, p. 451-487, 1922. [VI], 480.

4. "Formulas and tables for the calculation and design of single-layer coils," Inst. Radio Eng., Proc., v. 12, 1924, p. 193-208. [VI], 203-206.

5. "Tables for the calculation of the mutual inductance of circuits with circular symmetry about a common axis," NBS, Sci. Pap., v. 20, no. 498, p. 1-18, 1924. [VI], 8-18.

6. Inductance Calculations. New York, 1946, xiv, 286 p. [III, VI], 79, 113, 144, 152, 250-252.

H. GyLDEN, 1. Hülfstafeln zur Berechnung der Hauptungleichheiten in den absoluten Bewegungstheorien der kleinen Planeten. Astr. Gesell., Publ. 21, Leipzig, 1896, liv, 242 p. [V], 2-242.

J. HAK, 1. Eisenlose Drosselspulen. Leipzig, 1938, viii, 316 p.; reprinted Ann Arbor (Edwards), 1944. [VI], 16-18.

H. Hancock, 1. Elliptic Integrals. New York \& London, 1917, 104 p. [II*, VIII], 93-101.

K. Hayashi, 1. Tafeln der Besselschen, Theta-, Kugel- und anderer Funktionen. Berlin, 1930, v, 125 p.; later copies have a folding sheet of Berichtigungen, Fukuoka, 1932. [I, II*, III*, $\left.\mathrm{IV}^{*}\right]$, 61-104.

2. Fünfstellige Funktionentafeln. Berlin, 1930, viii, 176 p.; later copies have a folding sheet of Berichtigungen, Fukuoka, 1932. [I, II, III, IV, VIII], 126-154.

3. Tafeln für die Differenzenrechnung sowie für die Hyperbel-, Besselschen, elliptischen und anderen Funktionen. Berlin, 1933, vi, 66 p. [II*], 62-65.

C. Hermite, 1. "Sur quelques développements en série dans la théorie des fonctions elliptiques," Kazan, Phys.-Math. Soc., Bull., s. 2, v. 6, 1897, p. 1-21. [III], 10.

1. Oeuvres, v. 4, Paris, 1917, p. 470-487. [III], 477. 
C. Heuman, 1. "Tables of complete elliptic integrals," Jn. Math. Phys., v. 20, 1941, p. 127206, 336. Also supplement, Stockholm, 1941, 4 p. [II*, IX*], 146-197.

G. W. HILl, $1_{1}$. "On Gauss's method of computing secular perturbations," Astr. Papers of Am. Ephemeris and Naut. Almanac, v. 1 (1882), pt. 5, p. 315-361, Washington, 1881. [VII, XII], 343-354.

1. Coll. Math. Works, v. 2, Washington, 1906, p. 1-46. [VII, XII], 27-39.

R. L. Hippisley, 1. "Tables of Elliptic Functions," Smithsonian Mathematical Formulae and Tables of Elliptic Functions (Smithson. Misc. Coll., v. 74, no. 1). Washington, 1922, p. 259-309; first reprint, 1939. [II, III, IV, X*, XI], 260-309.

C. D. Hodgman, $1_{1}$. Handbook of Chemistry and Physics. 30th ed., Cleveland, Ohio, 1946, xviii, 2686 p. [II], 209-211.

12. Mathematical Tables from Handbook of Chemistry and Physics. 8th ed., Cleveland, Ohio, 1946, vi, 358 p. [II], 209-211.

13. Mathematical Tables. 8th. ed., Cleveland, Ohio, 1946, vi, 354 p. This edition has slightly larger pages and type, and very slightly different contents (though the elliptic tables are identical with those in $1_{1}, 1_{2}$ ); the words from Handbook of Chemistry and Physics occur on the binding, not on the title-page. [II], 211-213.

\section{W. HoRENSTEIN, see Lowan}

J. HoüEL, $1_{1}$. Recueil de Formules et de Tables Numériques. Paris, 1866, lxxi, 64 p. This is found both separately and bound up as Cahier 2 of Soc. Sci. Phys. Nat., Bordeaux, Mémoires, s. 1 , v. 4, 1866. [II, III, IV, VIII, X], 57-59.

1. Second edition, Paris, 1868, lxxi, 64 p. [II, III, IV, VIII, X], 57-59.

1. Third edition, Paris, 1885, nouveau tirage 1901, reprinted 1927, lxxi, 64 p. [II, III, IV, VIII, X], 57-59.

HüTTE, 1. "Hütte," des Ingenieurs Taschenbuch, herausgegeben vom Akademischen Verein Hütte. 26th ed., v. 1, Berlin, 1931, xx, 1199 p. The small elliptic tables are not in 24th ed., 1923; I have not seen the intervening ed. [II, VIII], 50.

N. IDELson, 1. "Remarks on the calculation of the elliptic integral," Astr. Nach., v. 230, no. 5508, 1927, col. 225-228. [II], 226.

R. T. A. INNEs (see also RobBins), 1. "Tables to facilitate the application of Gauss's method of computing secular variations," RAS, Mo. Not., v. 54, p. 289-296, 1894. [XII], 292-296.

2. "Jacobi's nome $(q)$ in astronomical formulae with numerical tables," RAS, Mo. Not., v. 62, p. 494-503, 1902. [III*], 496-503.

3. "Computation of secular perturbations," RAS, Mo. Not., v. 67, p. 427-443, 576, 1907. [XII].

4. "On the periods of the elliptic functions of Weierstrass," R. Soc. Edinburgh, Proc., v. 27,1907 , p. $357-368$. [XII], 361-368.

5. "Note on certain coefficients appearing in the algebraical development of the perturbative function," RAS, Mo. Not., v. 69, p. 633-647, 1909. [V].

C. G. J. Jacobi, 1. "Zur Theorie der elliptischen Functionen," Jn. . . Math. (Crelle), v. 26, 1843, p. 93-114. [III], 109-114. 24-29.

12. Mathematische Werke (Opuscula Mathematica), v. 1. Berlin, 1846, p. 8-29. [III],

1. Gesammelte Werke, v. 1. Berlin, 1881, p. 343-368. [III], 363-368.

E. JAHNKe \& F. EMDE, 1 . Funktionentafeln mit Formeln und Kurven. Leipzig and Berlin, 1909, xii, 176 p. [Corrected] reprints, Leipzig and Berlin, 1923, 1928. [II*, III*, IV, VI, VIII*, X, XII*, XIII], 46-79.

1. Second edition, Leipzig and Berlin, 1933, xviii, 330 p. [II*, III*, IV, VI, VIII*, X, XII*, XIII], 114-172. 
13. Third edition, Leipzig and Berlin, 1938, xii, 305 p. Reprint, New York (Stechert), 1941. Reprint (with p. 1-76 of $1_{2}$ ), New York (Dover), 1943. [II*, III*, IV, VI, VII, VIII*, $\mathrm{X}, \mathrm{XII} *$ XIII], 41-106.

14. Fourth edition (corrected reprint of $1_{3}$ and p. 1-76 of $1_{2}$, with supplementary bibliography by R. C. ARChibald), New York (Dover), 1945. [II*, III*, IV, VI, VII, VIII*, X, XII*, XIII], 41-106.

L. JeLíner, 1. Fünfstellige Tafeln für den Mathematik-Unterricht. 26th ed., by A. Hossner, Vienna, 1946, 176 p. (Earlier edited by K. Herold.) [II], 161.

\section{J. JOUBERT, See MASCART}

E. L. Kaplan, 1. "Auxiliary table of complete elliptic integrals," Jn. Math. Phys., v. 25, 1946 , p. 26-36. [II*], 29-36.

2. "Auxiliary table for the incomplete elliptic integrals," $J n$. Math. Phys., v. 27, p. 11-36, 1948. [II, VIII], 20-36. This paper also gives important lists of LEGENDRE errata; see Part III.

L. KIEPERT, 1. Grundriss der Differential- und Integral-Rechnung. II. Teil: Integral-Rechnung. Hanover. 8th ed., 1903, p. 621-624; 9th, 1908, and unchanged 10th, 1912, p. 681-684. The Grundriss was originally, 1862-63, by M. STEGEMANN, but the table of elliptic integrals first appeared in the 8th ed., by KIEPERT, of the second (integral calculus) part. The table is also contained in the little Tabelle der wichtigsten Formeln aus der Integral-Rechnung, extracted from the larger work; this is certainly true of the 9th, 1908, ed., in which the table occupies p. 3-6 of the Tabelle as issued separately. [II, VIII].

12. Grundriss der Integral-Rechnung, v. 1, 14th ed. Hanover, 1926, xx, 636 p. [II, VIII], 595-598. In this v. the Tabelle der wichtigsten Formeln . . . is on p. 599-636, thus does not include the tables, but I have not seen the Tabelle separately. I have not seen editions not mentioned above.

G. W. King, 1. "Punched-Card Methods in Analyzing Infra-Red Spectra," Progress Report, April 1-May 31, 1947. Cambridge, Mass., June 1947, A. D. Little Inc. [IX].

2. "Punched-Card Methods in Analyzing Infra-Red Spectra," Progress Report, June 1July 31, 1947. Cambridge, Mass., August 1947, A. D. Little Inc. [IX]. The tables in these two reports have been described in detail in RMT 467.

3. "The asymmetric rotor. VI. Calculation of higher energy levels by means of the correspondence principle," Jn. Chem. Phys., v. 15, 1947, p. 820-830. [IX], 825-829. See RMT 544.

W. LÁsKa, 1. Sammlung von Formeln der reinen und angewandten Mathematik. Brunswick, 1888-1894. Zweite Lieferung, 1889, v, 297-576 p. [II, III, VIII], 402-404.

A. M. Legendre, 1. Exercices de Calcul Intégral, v. 1. Paris, 1811-13, i, 386, 3, 50 p. [II], 118.

2. Same, v. 2. Paris, 1814-17, xx, 544 p. [V], 289-293.

3. Same, v. 3. Paris, 1816,463 p. [I*, II*, VIII*, X], 84-87, 96, 126-155, 323-416.

4. Traité des Fonctions Elliptiques et des Intégrales Eulériennes, v. 1. Paris, 1825, xii, 590 p. [I], 226.

5. Same, v. 2. Paris, 1826, viii, 596 p. [I*, II*, V, VIII*, X], 77-80, 88, 222-251, 269$363,551-554$.

6. Potin, p. 754-827; facsimile reproduction of the great table from 3. [II*, VIII*], 754-827.

7. F. EMDE, A. M. Legendres Tafeln der Elliptischen Normalintegrale erster und zweiter Gattung. Stuttgart, 1931, vii, 81 p.; facsimile reproduction of the great table, etc. from 3. $\left[\mathrm{II}^{*}, \mathrm{VIII}^{*}\right], 2-81$.

8. K. Pearson, Tables of the Complete and Incomplete Elliptic Integrals, reissued from Tome II of Legendre's Traité des Fonctions Elliptiques. London, 1934, xliii, 94 p.; facsimile reproduction of the great table, etc. from 5 . [II*, VIII*], 1-94. 
Of the numerous tables of elliptic integrals copied, directly or indirectly, and usually with abbreviation, from Legendre, only the three facsimile reprints are included above.

U. J. J. Leverrier, 1. "Formules pour le calcul des coefficients du développement de la fonction $\left(1+\alpha^{2}-2 \alpha \cos \theta\right)^{-8}, "$ Paris, Observatoire, Annales, Mémoires, v. 2, 1856, p. $[1]-[15]$. [V], [1]-[15].

H. LEVy \& A. G. ForSDYKe, 1. "The vibrations of an infinite system of vortex rings," R. Soc. London, Proc., v. 116A, 1927, p. 352-379. [VII], 378.

L. LEvy, 1. Précis Élémentaire de la Théorie des Fonctions Elliptiques avec Tables Numériques et Applications. Paris, 1898, xii, 237 p. [II*, III*, VIII], 227-237.

W. Ligowski, 1. Taschenbuch der Mathematik. Berlin, (a) first edition, 1867, (b) second, 1873, xviii, 211 p., (c) third, 1893, xxiv, 220 p. [II, VIII], (b) 54-56, (c) 64-66.

A. N. Lowan, G. BLANCh \& W. Horenstein, 1. "On the inversion of the $q$-series associated with Jacobian elliptic functions," Am. Math. Soc., Bull., v. 48, 1942, p. 737-738. [III], 738.

W. MACGreGOR, 1. "Basic curve methods in road-curve design," Institution of Engineers and Shipbuilders in Scotland, Trans., v. 85, Glasgow, 1942, p. 302-356. [VIII], 331-333.

A. T. MCKAY, 1. "Diffusion into an infinite plane sheet subject to a surface condition, with a method of application to experimental data," Phys. Soc., Proc., v. 42, p. 547-555, 1930. [VII], 552.

H. MASAL, 1. "Table de l'intégrale $\int_{0}^{\pi / 2}\left(1-\alpha^{2} \sin ^{2} \phi\right)^{-s / 2} \sin ^{2 n} \phi d \phi$ servantà la détermination des perturbations des petites planètes par Jupiter et Saturne," Stockholm, Astron. Observatoriet, Astronomiska Iakttagelser $\cdots$, v. 4, no. 3, 1891, 5, 71, 2 p. [V], 2-71. Serial name changed, v. $12+$, to Annalen.

E. Mascart \& J. Joubert, $1_{1}$. Lȩ̧ons sur l'Électricité et le Magnétisme, v. 2, 1st ed., Paris, 1886 , iv, 875 p. [VI], 144-145.

1 2. English translation by E. Atkinson, v. 2. London, 1888, v, 792 p. [VI], 128-129.

1. Leçons sur l'Électricité et le Magnétisme, v. 2, 2nd ed., Paris, 1897, iv, 917 p. [VI], 143-144, 157.

J. C. MAXwELl, $1_{1}$. A Treatise on Electricity and Magnetism, second edition (ed. W. D. Niven). V. 2, Oxford, 1881, xxiii, 456 p., plates. Table not in 1st ed. [VI], 317-319.

12. Lehrbuch der Electricität und des Magnetismus, German trans. of $1_{1}$ by B. Weinstein. V. 2, Berlin, 1883, xiv, 624 p., plates. [VI], 609-611.

1. Traité d'Électricité et de Magnétisme, French trans. of $1_{1}$ by G. SÉligmann-Lur. V. 2, Paris, 1887 , iii, 651 p. [VI], 397-399.

14. Third edition (ed. J. J. Thomson). V. 2, Oxford, 1892, xxiv, 500 p., plates. [VI], 347-349.

E. D. F. MersseL, 1. Sammlung mathematischer Tafeln, erste Lieferung. Iserlohn (im Selbstverlag), 1860, 20 p. [III*], 2-19.

C. J. Merfield, 1. "Secular perturbations of Ceres, arising from the action of Jupiter," Astr. Nach., v. 176, no. 4215, 1907, col. 237-246. [XII], 246.

2. "Tables of the two hypergeometrical functions . . .," RAS, Mo. Notices, v. 68, p. $605-608,1908$. [XII], 606-608.

J. M. Miller, see Rosa

L. M. Milne-Thomson, 1. "Ten decimal table of the nome $q$," London Math. Soc., Jn., v. 5,1930 , p. $148-149$. [III*], 149.

2. "Ten-figure table of the complete elliptic integrals $K, K^{\prime}, E, E^{\prime}$, and a table of $1 / \vartheta_{3}{ }^{2}(0 \mid \tau), 1 / \vartheta_{3}{ }^{2}\left(0 \mid \tau^{\prime}\right)$, London Math. Soc., Proc., s. 2, v. 33, p. 160-164, 1931. [II*], 162-164.

3. Die elliptischen Funktionen von Jacobi. Berlin, 1931, xiv, 69 p. [II*, III*, X, XI], $2-69$. 
4. "The zeta function of Jacobi," R. Soc. Edinburgh, Proc., v. 52, p. 236-250, 1932. $[\mathrm{II}, \mathrm{X}], 238-250$.

\section{J. MOLK, see TANNERY}

R. DE Montessus DE BAllore, 1. Leçons sur les Fonctions Elliptiques en vue de leurs applications. Paris, 1917, x, 267 p. [II, III, VIII], 41-44, 243.

J. MoORE, 1. An Excellent Table for the finding the Periferies or Circumferences of all Elleipses or Ovals, single sheet, no place or date. I have seen the British Museum copy. J. W. L. Glaisher (BAAS, Report of 1873) gives "? London, 1660," but the British Museum catalogue gives "[London ?] 1674." In any case, the table is very inaccurate (see Part III), and of only historic interest. [ $\left.\mathrm{II}^{*}\right]$.

H. Moseley, 1. o A Treatise on Definite Integrals. London, 1837, 56 p. [II]. Compare Q 28.

12. "Definite Integrals," Enc. Metrop., First Division, Pure Sciences, v. 2. London, 1843, p. 491-544. [II], 520.

13. "Definite Integrals," Enc. Metrop., v. II (Pure Sciences, v. 2), London, 1845, p. 491-544. [II], 520.

H. NAGAOKA, 1. "On the potential and lines of force of a circular current," Phil. Mag., s. 6 , v. 6, 1903, p. 19-29. [III, VI], 28.

2. "The inductance coefficients of solenoids," Tokyo, Imp. Univ., Faculty of Sci., Jn., v. 27, art. 6, 33 p., 1909. [III, VI], 5-8, 28-33.

3. "A table for facilitating the calculation of mutual inductance of two parallel coaxial circles," Nippon sugaku-triturigakkwai, Tokyo, Proc., s. 2, v. 6, p. 47-51, 1911. [VI], 49.

4. "Attraction between two coaxial parallel circular currents," Nippon sugaku-triturigakkwai, Tokyo, Proc., s. 2, v. 6, p. 152-158, 1911. [VI], 154

5. "Note on the mutual inductance of two coaxial circular currents," Phys. Soc. London, Proc., v. 25, p. 31-34 and 1 p. table, 1912. [VI], 1 p. table.

H. Nagaoka \& S. SakuraI, 1. "Tables of theta-functions, elliptic integrals $K$ and $E$, and associated coefficients in the numerical calculation of elliptic functions," Tokyo, Inst. Phys. Chem. Res., Sci. Papers, Table no. 1, 1922, p. 1-67. [I, II*, III, IV, XII], 7-63.

2. "Tables for facilitating the calculation of self-inductance of circular coil and of mutual inductance of coaxial circular currents," Same, Table no. 2, 1927, p. 69-180. [VI], 77-180.

NBS, 1. "Radio instruments and measurements," NBS, Circulars, no. 74, 1918, 345 p., and later reprints. [VI], 283-286.

NBSCL, 1. Tables of Associated Legendre Functions. New York, 1945, xlvi, 306 p. [VII], 229-291, 299-300.

2. Manuscript tables, see $M T A C$, v. 1, p. 125-126, 1943. Forty pages of duplicated typescript, of date 1942, containing most of the tables there described, have been inspected; see $M T A C$, v. 1, p. 425,1945 . [I, II, III, X, XI].

S. Newcomв, 1. "Development of the perturbative function . .,"Astr. Papers of Am. Ephemeris and Naut. Almanac, v. 3, pt. 1, p. 1-200, Washington, 1884. [II, V], 63-69, 126-200.

A. B. Newman, 1. "The drying of porous solids: diffusion calculations," Amer. Inst. Chem. Eng., Trans., v. 27, p. 310-333, 1932. Interim publication 1931. [VII], 328.

2. "The drying of porous solids: diffusion and surface emission equations," Amer. Inst. Chem. Eng., Trans., v. 27, p. 203-220, 1932. [VII], 212-215.

3. "The temperature-time relations resulting from the electrical heating of the face of a slab," Amer. Inst. Chem. Eng., Trans., v. 30, p. 598-613, 1934. [VII], 607.

F. W. Newman, 1. Mathematical Tracts, Part II. Cambridge, 1889, 81-139 p. [I, VII, XI], 125-139.

2. Elliptic Integrals. Cambridge, 1889, xv, 200 p. [I, II, XI], 29-30, 131-133. 
G. NorÉn \& S. RAAB, 1. "Hülfstafeln zur Berechnung der säkularen Störungen der kleinen Planeten," Lund, 1900, 50 p. Lund, Universitet, Acta (Arsskrift), v. 36, Afd. 2, no. $8=$ R. Soc. Physiogr. Lund. (K. Fysiogr. Sällsk. Lund), Acta (Handlingar), n.s., v. 11, no. 8 = Lund, Observatoriet, Meddelanden, s. 2, no. 2. [V], 9-19.

E. J. Nyströм, 1. "Praktische Auswertung von elliptischen Integralen dritter Gattung," Finska Vetensk.-Societeten, Helsingfors, Comment. Phys.-Math., v. 8, no. 12, 1935, 17 p. $[\mathrm{IX}], 6-9,15$.

F. C. W. Olson \& O. T. Schultz, 1. "Temperatures in solids during heating or cooling," Indust. and Eng. Chem., v. 34, 1942, p. 874-877. [VII], 875.

J. A. Osborn, 1. "Demagnetizing factors of the general ellipsoid," Phys. Rev., s. 2, v. 67, 1945, p. 351-357. See RMT 389, MTAC, v. 2, p. 270. [VIII], 353-354.

K. Pearson, see Legendre

B. O. Peirce, $1_{1}$. A Short Table of Integrals, first ed. Boston, 1889, 32 p., separately and also bound in at end of BYERLY 1. [II], 31.

12. Revised ed., Boston, 1899, 135 p. [II, VIII], 117-119.

1s. Second revised ed., Boston, 1910, 144 p. [II, VIII], 113-115.

14. Second revised ed. [enlarged], Boston, 1918 impression seen, 152 p. [II, VIII], 121-123.

16. Third revised ed. [by W. F. OsGood], Boston, 1929, ii, 156 p. [II, VIII], 121-123.

2. A Short Table of Integrals, "abridged edition." Boston, 1914, 32 p. [II], 31. (The table of complete elliptic integrals is larger than that which appears in the unabridged editions $1_{1}-1_{6}$.)

F. B. Pidduck, 1 . A Treatise on Electricity, first edition. Cambridge, 1916, xv, 646 p. [VI], 197-203.

12. Second edition, Cambridge, 1925, xiv, 664 p. [VI], 186-192.

J. Plana, 1. "Nouvelles formules pour réduire l'intégrale $V=\int T d x / \sqrt{ } X$ à la forme trigonométrique des transcendantes elliptiques . ..,"Jn. . Math. (Crelle), v. 36, 1848, p. 1-74. [III*], 71-74.

L. Potin (see also Legendre), 1. Formules et Tables Numériques. Paris, 1925, xvi, 4 errata, 862 p. [II, III*, IV*, VIII*], 754-833.

\section{S. RAAB, see NOREN}

Lord Rayleigh (J. W. Strutt) \& Mrs. H. Sidgwick, 1. "On the electrochemical equivalent of silver, and on the absolute electromotive force of Clark cells," R. Soc. London, Trans., v. 175, p. 411-460, 1884. [VI] 455.

12. Sci. Papers, v. 2, Cambridge, 1900, p. 278-332. [VI], 327.

F. V. Reno, 1. Manuscript tables of elliptic functions, see $M T A C, \mathrm{v} .1$, p. 330, 1944. [VIII, $\mathrm{XI}$.

F. RobBins, 1. "Tables for the application of Mr. Innes's method," RAS, Mo. Not., v. 67, p. 444-447, 1907 (follows InNes 3). [XII], 444-447.

1. Table in above, reproduced in INNES 4. [XII], 365-368.

2. "Notes added to Mr. Innes' paper on certain coefficients, etc.," RAS, Mo. Not., v. 69, p. 648-650, 1909 (follows INNES 5). [II, V], 649-650.

E. B. Rosa \& L. Cohen, 1. "Formulae and tables for the calculation of mutual and selfinductance," NBS, Bull., v. 5, p. 1-132, 1908; Sci. Pap., no. 93. [II, VI], 110-130.

E. B. Rosa, N. E. Dorsey \& J. M. Miller, 1. "A determination of the international ampere in absolute measure," NBS, Bull., v. 8, p. 269-393, 1912; Sci. Pap., no. 171. [VI], 392-393. 
E. B. Rosa \& F. W. Grover, 1. "Formulas and tables for the calculation of mutual and selfinductance," NBS, Bull., v. 8, 1912, p. 1-237; Sci. Pap., no. 169. A revised and enlarged edition of RosA \& CoHEN. [II, III, VI], 190-225.

J. B. Rosenbach, E. A. Whitman \& D. Moskovitz, 1. Mathematical Tables. Boston, 1937, xl, 208 p. Second ed., 1943, xl, 212 p. [II, VIII*], 189-197.

L. Rosenhead, 1. "The Kármán street of vortices in a channel of finite breadth," R. Soc. London, Trans., v. 228A, p. 275-329, 1929. [X], 295.

J. D. RunkLE, 1. New Tables for determining the Values of the Coefficients, in the Perturbative Function of Planetary Motion, which depend upon the Ratio of the Mean Distances. Smithsonian Contributions, v. 9, 1856, Appendix, viii, 56, 71 p. [V*], 1-44.

A. Russell, 1. A Treatise on the Theory of Alternating Currents, second edition, v. 1. Cambridge, 1914, xiv, 534 p. [II, VI], 114, 117-120; not in first edition.

S. Sakurai, see Nagaoka

N. S. Samol̆lova-ГAknontova, 1. Tablițy Ellipticheskikh Integralov [Tables of Elliptic Integrals]. Moscow and Leningrad, 1935, 108 p. + errata slip. [II*, III*, VIII], p. 13-106.

O. X. Sснцӧміссн, 1. Fünfstellige logarithmische und trigonometrische Tafeln, third edition. Brunswick, 1871, xxviii, 171 p. (First edition 1866. Many other editions, but it is in the third that the table of elliptic quadrants has been checked.) [II*], 150-151.

2. Compendium der höheren Analysis, second ed., v. 2, first ed., Brunswick, 1866, viii, 540 p. [III], 440.

2. Augmented French translation, by J. GraIndorge, of elliptic part of $2_{1}$, Théorie des Integrales et des Fonctions Elliptiques. Liége and Paris, 1873, xxviii, 219 p. [III], 180.

2. Compendium der höheren Analysis, v. 2, second ed., Brunswick, 1874, viii, 540 p. [III], 442.

24. Third ed., Brunswick, 1879, viii, 546 p. [III], 448.

25. Fourth ed., Brunswick, 1895, x, 546 p. [III], 448.

J. G. Schmidr, 1. System elliptischer Bogen. Berlin, 1842, iv, 212 p. [II*, VIII], 3-212.

O. T. Schultz, see Olson

H. A. Schwarz, see Weierstrass

T. K. Sherwood, 1. "Application of theoretical diffusion equations to the drying of solids," Am. Inst. Chem. Eng., Trans., v. 27, p. 190-202, 1932. [VII], 199.

C. A. Shook (see also Brown \& Shook), 1. "The mixed mean function," Annals of Math., s. 2, v. 28, 1927, p. 171-179. [VII], 179.

Mrs. H. Sidgwick, see Rayleigh

L. Silberstein, 1. Bell's Mathematical Tables. London (Bell), 1922, xi, 250 p. [II, III, VIII], 160-170.

12. Synopsis of Applicable Mathematics, with Tables. London (Bell), also New York (Van Nostrand), 1923, xi, 250 p.; same work as $1_{1}$ with different title. [II, III, VIII], 160-170.

A. Smekal, 1. "Über die gegenseitigen Störungen der Elektronenringe im Atom und über die Erklärung der Röntgenspektren," Akad. d. Wiss., Vienna, math.-naturw. Kl., Sitzungsb., Abt. IIa, v. 127, 1918, p. 1229-1252. [VII], 1236-1242.

Soc. Automotive Engins., War Engineering BoARd, 1. The Development of Improved Means for Evaluating Effects of Torsional Vibration on Internal Combustion Engine Installations. New York, 1945, 579 p. [II, XI], 345-348.

C. M. Sparks, see Curtis 
G. W. Spenceley \& R. M. Spenceley, 1. Smithsonian Elliptic Functions Tables. (Smithson. Misc. Coll., v. 109.) Washington, 1947, iv, 366 p. [II*, III*, IV, X, XI], 2-357. (Brown University Library has a photographic copy of the original $15 \mathrm{D}$ manuscript.)

J. SpIElrein, 11. "Die Induktivität eisenfreier Kreisringspulen," Archiv f. Electrotechnik, v. 3, p. 187-202, 1915; corrections, ibid., v. 26, p. 744, 1932. [VI], 189, 200. 507.

12. Reprinted in Jahrb. d. drahtl. Telegr. u. Teleph., v. 13, p. 490-511, 1919. [VI], 494,

H. TALlQvist, 1. "Tafeln zur scheinbaren Grösse des Kreises," Finska Vetens.-Societeten, Helsingfors, Comment. Phys.-Math., v. 5, no. 24, 1931, 36 p. [IX], 19-36.

2. "Potentialtafeln für die Kreislinie, Kreisfläche und Kreisscheibe," same, v. 6, no. 11, 1932,46 p. [IX], 16-45.

J. Tannery \& J. Molk, 1. Éléments de la Théorie des Fonctions Elliptiques. 4 v., Paris, 1893-1902. [II, III, XII], v. 3, p. 215, v. 4, p. 88-166, 121.

F. E. Terman, 1. Radio Engineers' Handbook. New York and London, 1943, xi, 1019 p. [VI], 69.

P. F. Verhulst, 1. Traité Elémentaire des Fonctions Elliptiques. Brussels, 1841, xii, 316 p. + folding plate. [III*], 305-309.

T. Viola, see Conforto

A. Wayne, 1. "A table for computing perimeters of ellipses," Amer. Math. Mo., v. 51, 1944, p. 219-220. [II*], 219.

K. Weierstrass \& H. A. Schwarz, 1. Formeln und Lehrsätze zum Gebrauche der elliptischen Functionen. Nach Vorlesungen und Aufzeichnungen des Herrn $K$. Weierstrass bearbeitet und herausgegeben von $H$. A. Schwarz. First edition, Göttingen, 1883-1885, 96, 2 p. [XII], 7, 67-71.

1. Second edition, "erste Abtheilung" [all published]. Berlin, 1893, xii, 96 p. [XII], 7, 67-71.

13. o French trans. of $1_{2}, \mathrm{H}$. PADE, Formules et propositions pour l'emploi des fonctions elliptiques. . . Paris, 1894. [XII].

V. Wellmann, 1. "Tafeln zur Berechnung der Störungsfunction der kleinen Planeten," Astr. Nach., v. 127, no. 3040, 1891, col. 257-266. [V], 261-262.

K. P. Williams, 1. "The constants of the disturbing function," Am. Jn. Math., v. 52, 1930, p. 571-584. [V], 583-584.

J. R. Wilton, 1. "The eleven-twentytwo section of the zeta function," Mess. Math., v. 44 , p. $178-188,1915$. [X], 183-187.

A. W. Wiтkowski, 1. Tablice matematyczno-fizyczne. Warsaw, 1904, iv, 158 p. [II], 80-83.

G. Wirt, 1. "Tafeln zur bequemen Berechnung der vollständigen elliptischen Integrale erster und zweiter Gattung," Astr. Nach., v. 165, no. 3939-40, 1904, col. 33-50. [II], 46-50.

2. "Zur Berechnung der Koeffizienten der Störungsfunktion," Astr. Nach., v. 246, no. 5892, 1932, col. 221-230. [II, V], 229-230.

3. "Zur Berechnung der Perioden der elliptischen Integrale," Astr. Nach., v. 261, no. 6262, col. 429-434, 1937. [XII], 431-433.

\section{PART III}

\section{ERrors in Elliptic TABles}

Note. Absence of a table from this part does not mean that it contains no errors. I have included all information pointed out by others and known to me, but Part III describes mainly my own investigations. My program related only to single-entry tables, mainly of a 
basic and many-figure character. Inclusion of an author in Part III does not mean that all his elliptic tables have been examined; only those mentioned have been examined. I have checked no double-entry tables whatever; but for the convenience of the user I have placed together under LEGENDRE the known errors in his great double-entry tables of $F(\theta, \phi)$ and $E(\theta, \phi)$. Anyone using one of the many abbreviations of these double-entry tables should see whether they are affected by the errors mentioned under LEGENDRE.

Airey 1.

(a) $K_{1}, K_{8}, k^{\prime 2}=[0(.00001) .00010 ; 13 \mathrm{D}]$.

Differencing shows freedom from gross error, in both function values and second differences. I have also confirmed the values at .00010 by direct calculation. In most of these tables, Airey gives smoothly-varying second differences (presumably rounded from values computed with extra decimals).

( $\beta$ ) $K_{1}, K_{2}, k^{\prime 2}=[0(.0001) .0010 ; 12 \mathrm{D}]$.

Differencing shows complete freedom from gross error. I have also confirmed the values at .0010 by direct computation.

( $\gamma) K_{1}, K_{2}, k^{\prime 2}=[0(.001) .170 ; 10 \mathrm{D}]$.

There is a gross error in $K_{2}$ at $k^{\prime 2}=.014$; for 352 , read 353 . When this is corrected, both $K_{1}$ and $K_{2}$ difference well. Airey's smoothed second differences agree well with the second differences of his function values; the two quantities rarely differ by two final units.

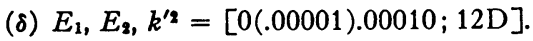

At $k^{\prime 2}=.00010, E_{1}$ should end in 75 , not 57 . Apart from this, differencing shows complete freedom from gross error. At $.00010 \mathrm{I}$ have also confirmed $E_{1}$ (as corrected) and $E_{2}$ by direct computation.

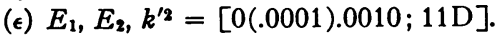

Differencing shows complete freedom from gross error. I have also confirmed nearly half the values by direct computation.

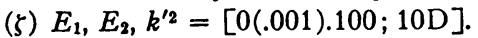

Differencing shows complete freedom from gross error, Airey's second differences again agreeing well with the second differences of his printed values. But recalculation with extra decimals for $k^{\prime 2}=.001(.001) .010$, while it confirms the values of $E_{2}$, shows that the values of $E_{1}$ for $k^{\prime 2}=.003(.001) .009$ average about a unit too low, the deduced values of $E$ being (since $E_{1}$ has to be multiplied by about 4 ) too low by from 2 to 5 units of the tenth decimal. The errors cannot be due to Airey's having used incorrect coefficients in his power series, for his $E_{1}$ is correct for much higher values of $k^{\prime 2}$, for instance, for $k^{\prime 2}=.1$ at the end of the table.

\section{Bertrand 1.}

(a) $\log q, \theta=\left[0\left(5^{\prime}\right) 90^{\circ} ; 5 \mathrm{D}\right]$.

I have compared this table with Meissel's $8 \mathrm{D}$ table. There are only three errors in MEISSEL 1 which could affect Bertrand's abridgment; all three (marked M below) occur in Bertrand, and are proof that Bertrand's table was extracted without acknowledgment from Meissel's. In addition, Bertrand (or his collaborator THoman) has rounded MEISSEL's value incorrectly in two cases. At $8^{\circ} 45^{\prime}$ and $51^{\circ} 15^{\prime}$ MeISSEL's values end in 500, but I have not thought it necessary to investigate more closely.

\begin{tabular}{ccccc}
\multicolumn{1}{c}{$\theta$} & $D$ & For & Read \\
M $17^{\circ} 20^{\prime}$ & 4 & 0 & 1 \\
M 4625 & 5 & 1 & 2 \\
5120 & 5 & 3 & 4 \\
550 & 5 & 1 & 2 \\
M 655 & 5 & 4 & 5
\end{tabular}

(B) $\log \vartheta_{3}$ [called $\left.\log \Theta(\omega)\right], \theta=\left[0\left(30^{\prime}\right) 90^{\circ} ; 9 \mathrm{D}\right]$.

The function tabulated is $\frac{1}{2} \log (2 K / \pi)$. I have recalculated the table, using $12 \mathrm{D}$ values of $\log K$ from LEGENDRE (slightly corrected where necessary). There are the following errors : 


\begin{tabular}{|c|c|c|c|c|c|c|c|}
\hline$\theta$ & $D$ & For & Read & $\theta$ & $D$ & For & Read \\
\hline $6^{\circ} 30^{\prime}$ & 7 & 1 & 6 & $52^{\circ} 30^{\prime}$ & 4 & 6 & 5 \\
\hline 730 & 9 & 1 & 7 & 6730 & 0 & 9 & 0 \\
\hline 80 & $8-9$ & 81 & 08 & 6930 & 9 & 1 & 2 \\
\hline 410 & 9 & 4 & 3 & 780 & 9 & 0 & 1 \\
\hline 5130 & 9 & 0 & 1 & 8230 & 9 & 6 & 7 \\
\hline
\end{tabular}

DALE 1.

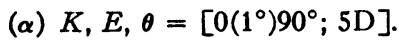

There is one rounding error; in $K$ at $88^{\circ}$, for final 1 , read 2.

\section{Dwight 2.}

(a) $K / \ln (4 \sec \theta), \theta=\left[86^{\circ}\left(1^{\prime}\right) 90^{\circ} ; 7\right.$ or more $\left.\mathrm{D}\right]$.

Differencing shows that the table is free from gross error up to at least $89^{\circ} 50^{\prime}$, and the values at $89^{\circ} 50^{\prime}\left(1^{\prime}\right) 90^{\circ}$ I have confirmed by recalculation. Dwight's differences agree with his function values.

(B) $K, \theta=\left[86^{\circ}\left(1^{\prime}\right) 90^{\circ} ; 5 \mathrm{D}\right]$.

Differencing shows that the table is free from gross error up to at least $89^{\circ} 50^{\prime}$, and the values at $89^{\circ} 50^{\prime}\left(1^{\prime}\right) 90^{\circ}$ I have confirmed by recalculation. Dwight's differences agree with his function values. Comparison of Dwight's values at $\theta=86^{\circ}\left(6^{\prime}\right) 90^{\circ}$ with antilogarithms of LEGENDRE's $\log K$ shows all such values correct, except for one very fine rounding error; at $\theta=87^{\circ} 24^{\prime}$, for 4.48114 , read 4.48115 . There may be other unimportant rounding errors, but both tables are evidently of high accuracy.

Gauss 2

The argument in Gauss's table on p. 403 will be called $\gamma$. If $\theta$ is the usual modular angle, $\gamma=180^{\circ}-2 \theta$. Thus Gauss's $\gamma=1^{\circ}\left(1^{\circ}\right) 180^{\circ}$ is equivalent to $\theta=89^{\circ} .5\left(-0^{\circ} .5\right) 0$.

(a) $M=\pi / 2 K, \gamma=\left[1^{\circ}\left(1^{\circ}\right) 180^{\circ} ; 7 \mathrm{D}\right]$.

There are six errors which are not merely rounding errors:

\begin{tabular}{rrrrr}
$r$ & \multicolumn{1}{c}{$\boldsymbol{D}$} & \multicolumn{1}{c}{$\boldsymbol{D}$} & For & Read \\
$2^{\circ}$ & $89^{\circ} .0$ & $5-7$ & 201 & 198 \\
13 & 83.5 & 7 & 4 & 5 \\
41 & 69.5 & 7 & 4 & 6 \\
82 & 49.0 & 7 & 1 & 2 \\
156 & 12.0 & 7 & 8 & 6 \\
179 & 0.5 & 6 & 0 & 1
\end{tabular}

There are also some 25 rounding errors.

(B) $\log M, \gamma=\left[1^{\circ}\left(1^{\circ}\right) 180^{\circ} ; 7 \mathrm{D}\right]$.

There are five errors which are not merely rounding errors:

\begin{tabular}{rcrrr}
$\gamma$ & 0 & \multicolumn{1}{c}{$D$} & For & Read \\
$2^{\circ}$ & $89^{\circ} .0$ & $6-7$ & 80 & 75 \\
7 & 86.5 & 7 & 1 & 0 \\
13 & 83.5 & $5-7$ & 699 & 701 \\
41 & 69.5 & 7 & 2 & 3 \\
45 & 67.5 & 7 & 4 & 5
\end{tabular}

There are also 15 rounding errors.

$(\gamma)$ On a number of errors in the lemniscate constants on p. 413-432, see J. W."WrENCH, JR., $M T A C$, v. 3, p. 201, 1948.

GLAisher 1.

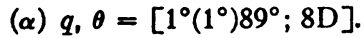

Before receiving the SPENCELEY tables I had differenced Glaisher's table and found it free from gross error up to at least $80^{\circ}$. I have since compared the two tables, and found Glaisher in complete agreement with the SPENCELEY values rounded to 8D. Glaisher thus appears free from error of any kind. 
(B) $\log q, \theta=\left[1^{\circ}\left(1^{\circ}\right) 89^{\circ} ; 8 \mathrm{D}\right]$.

Two very slight rounding errors, exactly as in Merssel: at $33^{\circ}$, for 819 , read 820 , and at $42^{\circ}$, for 332 , read 333 .

I have not examined the other tables.

Gossot, see Greenhill 2.

\section{Greenhill 1.}

( $\alpha) s=\varnothing\left(r \omega_{2} / 180\right), S=\varnothing\left(r \omega_{2}^{\prime} / 180\right), r=0(1) 180,5$ or more figures, case $\wp^{\prime 2}=4 \varphi^{3}-4$.

I have not examined the table in detail, but it may be useful to warn that the final digits are demonstrably unreliable. The values near the end of the table should be derivable from those near the beginning by the relations

$$
s(180-r)-1=3 /[s(r)-1], \quad S(180-r)-1=3 /[S(r)-1],
$$

but some of Greenhill's values do not satisfy this test fully. The table could easily be recalculated, using HIPPISLEY or SPENCELEY at $\theta=15^{\circ}$ and $75^{\circ}$, since for $0 \leqslant r \leqslant 90$

$$
\begin{aligned}
& s(r)=1+\sqrt{ } 3[D(r)+B(r)] /[D(r)-B(r)]=1+\sqrt{ } 3 \cot ^{2} \frac{1}{2} \phi \quad\left(\theta=15^{\circ}\right) \\
& S(r)=1-\sqrt{ } 3[D(r)+B(r)] /[D(r)-B(r)]=1-\sqrt{ } 3 \cot ^{2} \frac{1}{2} \phi \quad\left(\theta=75^{\circ}\right)
\end{aligned}
$$

with obvious modifications when $90 \leqslant r \leqslant 180$.

GREENHILL 2.

( $\alpha) \varnothing\left(r \omega_{2} / 180\right), \wp^{\prime}\left(r \omega_{2} / 180\right), \zeta\left(r \omega_{2} / 180\right), \sigma\left(r \omega_{2} / 180\right), r=0(1) 240$, about 5D, case $\ell^{\prime 2}=4 \wp^{2}-1$.

I have not examined the tables for errors. Two errors were pointed out in O. S. ADAMS, and one by MILLER:

\begin{tabular}{lrrr} 
Function & \multicolumn{1}{c}{$r$} & \multicolumn{1}{c}{ For } & \multicolumn{1}{c}{ Read } \\
$\wp(u)$ & 3 & 1468.820 & 1537.9625 \\
$\wp^{\prime}(u)$ & 35 & -73.4302 & -75.9603 \\
$\sigma(u)$ & 123 & 1.0441 & 1.0438
\end{tabular}

See $M T A C$, v. 1 , p. 109,1943 , and v. 1 , p. 395,1945 . The errors occur also in the reprints in Gossot and in JahnKe \& EMDE $1_{1}-1_{3}$, but are corrected in JahNKE \& EMDE $1_{4}$.

\section{HANCOCK 1.}

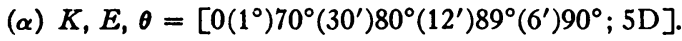

With one exception, the table is accurately copied from LEvy 1 , none of the errors (which I list under LEvy) being corrected. The additional error introduced by Hancock is in $E$ at $89^{\circ} 54^{\prime}$; in the fourth decimal, for 1 , read 0 .

\section{HAYASHI 1.}

This contains a great variety of elliptic tables with $k^{2}$ as argument. I have examined only those tables mentioned below, which appeared to me to be the most important. The volume was published in 1930, and the Berichtigungen sheet of 1932 will be lacking in copies bought before its appearance. Thus I have thought it useful to include in the lists of corrections those given by Hayashi himself in relation to the tables which I have examined, especially since Hayashi's corrections require occasional emendation. I have not reprinted his corrections relating to unexamined tables.

(a) $K, k^{2}=[0(.001) 1 ; 10-12 \mathrm{D}]$.

There are the following errors:

$\begin{array}{lcrrc}\text { p. } & k^{2} & D & \text { For } & \text { Read } \\ 72 & .999 & 8-9 & 06 & 60 \\ 72 & .013 & 8-9 & 68 & 86 \\ 72 & .987 & 11-12 & 53 & 47 \\ 73 & .939 & 12 & 4 & 1 \\ 73 & .095 & 0 & 0 & 1 \\ 74 & .877 & 11-12 & 61 & 57 \\ 77 & .737 & 9-10 & 56 & 65 \\ 81 & .493 & 9 & 4 & 9\end{array}$


Those at $.999, .737$ and .493 were corrected in the 1932 Berichtigungen sheet, which also gives a false and unnecessary correction at .956 . The obvious error at .095 was pointed out

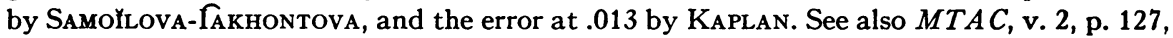
1946, and Comrie, Math. Rev., v. 7, 1946, p. 485. As far as I am aware, the errors of 6, 4 and 3 final units at $.987, .877$ and .939 respectively have not previously been published.

When the above corrections are made, differencing (up to twentieth differences at the end) shows freedom from gross error up to at least $k^{2}=.984$. The last 15 values, for $k^{2}$ $=.985(.001) .999$, I have recomputed to about 14 decimals; except for the errors at .987 and .999 , mentioned above, Hayashi is completely correct.

(B) $\log q, k^{2}=[0(.001) 1 ; 10 \mathrm{D}]$.

The first four of the following corrections were given in Hayashi's 1932 Berichtigungen sheet (the argument .232 being misprinted .223), and the fif th in Samollova-

\begin{tabular}{lcrrr} 
p. & $k^{2}$ & \multicolumn{1}{c}{$D$} & For & Read \\
73 & .050 & 3 & 3 & 5 \\
74 & .874 & 10 & 8 & 7 \\
76 & .232 & $4-5$ & 62 & 26 \\
78 & .688 & 10 & 8 & 9 \\
81 & .503 & $1-2$ & 36 & 63
\end{tabular}

When these corrections are made, differencing shows freedom from gross error, except that some ten or twelve values at each end of the table cannot be completely checked by differencing. I have, however, recomputed 28 values, for $k^{2}=.001(.001) .014$ and $k^{2}=.986$ (.001).999, to about 13D, and find no important error (my values suggest rounding errors at $k^{2}=.010, .012, .013$, where for final $8,1,7$, I find 7, 0, 6 respectively).

$(\gamma) q, k^{2}=[0(.001) .5 ; 8 \mathrm{D}]$.

Hayashi's 1932 Berichtigungen sheet gives the following corrections:

$\begin{array}{rcccc}\text { D. } & k^{2} & D & \text { For } & \text { Read } \\ 94 & .279 & 8 & 7 & 8 \\ 98 & .395 & 5 & 4 & 6 \\ 102 & .482 & 3 & 0 & 1\end{array}$

When these corrections are made, differencing shows freedom from gross error. The last decimal appears to be good, which is not surprising, as Hayashi also tabulates 10D logarithms; see $(\beta)$ above. Every tenth value has been compared with the $10 \mathrm{D}$ value given in Milne-THomson 1 ; this failed to disclose any rounding errors in Hayashi at $k^{2}=0(.01) .5$, and computation shows that Hayashi is correctly rounded at $k^{2}=.47$, where MILNETHомson ends in 50 .

(ס) $q^{4}, k^{2}=[0(.001) .5 ; 8 \mathrm{D}]$.

Hayashi's 1932 Berichtigungen sheet gives the following corrections (that at .118 is illegible, but should be as below):

\begin{tabular}{lcrrr} 
p. & \multicolumn{1}{c}{$k^{2}$} & \multicolumn{1}{c}{$D$} & \multicolumn{1}{c}{ For } & \multicolumn{1}{c}{ Read } \\
84 & .008 & 8 & 7 & 8 \\
84 & .024 & $3-5$ & 648 & 739 \\
86 & .068 & $3-8$ & 816360 & 756984 \\
86 & .077 & 4 & 1 & 0 \\
86 & .081 & 8 & 6 & 3 \\
88 & .118 & $4-8$ & 58203 & 63000 \\
88 & .125 & $7-8$ & 70 & 66 \\
88 & .142 & $5-7$ & 928 & 784 \\
90 & .161 & $6-8$ & 493 & 049 \\
92 & .236 & $0-5$ & 011 & 0.36011 \\
94 & .256 & $6-8$ & 728 & 073 \\
96 & .315 & $4-5$ & 60 & 06
\end{tabular}


The above leaves the following errors uncorrected:

\begin{tabular}{lrrrr} 
p. & $k^{2}$ & \multicolumn{1}{c}{$D$} & For & \multicolumn{1}{c}{ Read } \\
84 & .028 & 5 & 6 & 5 \\
88 & .120 & 7 & 2 & 0 \\
90 & .193 & $0-5$ & 022 & 0.34022
\end{tabular}

When all the above corrections have been made, differencing shows freedom from gross error, except that about 8 values at the beginning of the table cannot be checked to the full 8 decimals by differencing. I have, however, recomputed the first 14 values, for $k^{2}=.001$ (.001).014, to 10 decimals, and confirmed Hayashi's results completely.

(द) $\pi \vartheta_{1}^{\prime}, k^{2}=[0(.001) .5 ; 8 \mathrm{D}]$.

The function is called $\vartheta_{1}^{\prime}(0)$ in Hayashi. His 1932 Berichtigungen sheet gives the following corrections:

\begin{tabular}{rcccc}
\multicolumn{1}{c}{ p. } & $k^{2}$ & $D$ & For & Read \\
84 & .049 & 3 & 1 & 7 \\
92 & .207 & 8 & 6 & 5 \\
94 & .292 & 5 & 1 & 2 \\
96 & .312 & 5 & 4 & 6 \\
96 & .342 & 4 & 2 & 1 \\
102 & .498 & 5 & 3 & 8
\end{tabular}

This leaves one gross error uncorrected: p. $102, k^{2}=.465,5 \mathrm{D}$, for 8 , read 9 .

When all these corrections have been applied, differencing shows freedom from gross error, except that the first 9 values cannot be fully checked by differencing. I have, however, recomputed the first 10 values, for $k^{2}=.001(.001) .010$, to 9 or more decimals, and confirmed Hayashi's values (apart from one or two possible slight rounding errors).

(५) $\vartheta_{2}, k^{2}=[0(.001) .5 ; 8 \mathrm{D}]$.

Hayashi's 1932 Berichtigungen sheet gives the following corrections:

$\begin{array}{rrrrr}\text { p. } & k^{2} & D & \text { For } & \text { Read } \\ 97 & .328 & 5 & 9 & 4 \\ 101 & .442 & 4-5 & 37 & 73\end{array}$

When these are applied, differencing shows that no gross error remains, except that the first 8 values cannot be fully checked by differencing. I have, however, recomputed the first 10 values, for $k^{2}=.001(.001) .010$, to about 10 decimals, and confirmed Hayashi's results.

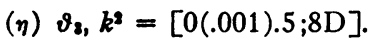

Hayashi's 1932 Berichtigungen sheet gives the following correction:

p. $85, k^{2}=.026,7 \mathrm{D}$, for 8 , read 9 .

When this is applied, differencing shows freedom from gross error throughout the table.

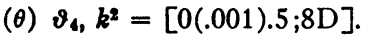

This is called $\vartheta_{0}(0)$ in Hayashi. Differencing reveals one gross error:

$$
\text { p. } 88, k^{2}=.112,6 \mathrm{D}, \text { for } 2 \text {, read } 3 \text {. }
$$

Otherwise there are no gross errors.

HaYashi 3.

( $\alpha) E, k^{2}=[0(.001) 1 ; 10 \mathrm{D}]$.

There are known errors as follows (KAPLAN ; also ComRIE, Math. Rev., v. 7, 1946, p. 485):

$\begin{array}{lrrrr}\text { p. } & k^{2} & D & \text { For } & \text { Read } \\ 62 & .052 & 9 & 4 & 5 \\ 62 & .939 & 9 & 4 & 3 \\ 62 & .936 & 9 & 9 & 8 \\ 63 & .201 & 3-4 & 65 & 86 \\ 63 & .732 & 10 & 6 & 8 \\ 64 & .668 & 0 & 0 & 1\end{array}$


At .669, the first two digits of the argument are missing. Samollova-rakmontova gave a faulty correction at .201, misprinting the argument as .151 and failing to correct the fourth decimal.

When the above corrections are made, differencing shows freedom from gross error up to at least $k^{2}=.991$. I have recomputed the values for $k^{2}=.990(.001) .999$, and found only two rounding errors; at $k^{2}=.991$, for final 1 , read 0 , and at $k^{2}=.996$, for final 8 , read 9 .

Comparison with my 12D calculations at $k=.1(.1) .9$, with Schmidr 1 at $k^{\prime}=.1(.1) .9$ and with SPENCELey 1 at $\theta=30^{\circ}, 45^{\circ}, 60^{\circ}$ reveals only one very fine rounding error; at $k^{2}=.360$, for final 5 , read 4 . Slight roughness in differences near $k^{2}=.938$ points to at least one other last-figure error, but in general the final digit appears to be good.

\section{Heuman 1.}

It is not surprising that the $6 \mathrm{D}$ tables of $F_{0}(\alpha)$ and $E_{0}(\alpha)$, our $2 K / \pi$ and $2 E / \pi$, are very exact, for Heuman says that he calculated to 10D, from LEGENDRE's logarithms. As these tables are, as far as I know, the only natural tables of, substantially, $K$ and $E$ at interval $0^{\circ} .1$ throughout the quadrant, I have examined them with care.

(a) $F_{0}(\alpha)=2 K / x, \alpha=\left[0\left(0^{\circ} .1\right) 90^{\circ} ; 6 \mathrm{D}\right]$.

Assuming the values at $67^{\circ} .5$ and $76^{\circ} .8$ corrected to 1.527948 and 1.838639 , as shown in Heuman's errata, the table is then certainly free from anything like gross error. I have differenced up to $70^{\circ}$ and also recomputed to at least $8 \mathrm{D}$ the values at $0\left(0^{\circ} .5\right) 70^{\circ}\left(0^{\circ} .1\right) 90^{\circ}$. In the values recomputed, I have found only one certain rounding error; at $5^{\circ} .5$, for final 8 , read 9. I have not investigated further cases where my seventh and eighth decimals were 50. All Heuman's differences accurately correspond to his function values (corrected at $67^{\circ} .5$ and $76^{\circ} .8$ ).

( $\beta$ ) Auxiliary function $G_{0}(\alpha), \alpha=\left[65^{\circ}\left(0^{\circ} .1\right) 90^{\circ} ; 6 \mathrm{D}\right]$.

Differencing shows that the table is free from gross error, and that Heuman's differences accurately correspond to his function values.

(r) $E_{0}(\alpha)=2 E / \pi, \alpha=\left[0\left(0^{\circ} .1\right) 90^{\circ} ; 6 \mathrm{D}\right]$.

Differencing shows that the table is free from gross error, and that Heuman's differences accurately correspond to his function values. Here also the rounding to $6 \mathrm{D}$ appears to be highly accurate. I have recomputed the values at $0\left(1^{\circ}\right) 90^{\circ}$ to nine decimals, and find only one very slight rounding error; at $16^{\circ}$, for final 7 , read 6 .

( $\delta) \Lambda_{0}(\alpha, \beta), \alpha=0\left(1^{\circ}\right) 90^{\circ}, \beta=0\left(1^{\circ}\right) 90^{\circ}$, etc., 6D.

I have not examined this important table, as it is of double entry and so falls outside my program. Heuman himself gives two corrections:

$\begin{array}{ccccc}\text { p. } & \alpha & \beta & \text { For } & \text { Read } \\ 185 & 71^{\circ} & 15^{\circ} & 94145 & 84145 \\ 196 & 0^{\circ} .3 & 87^{\circ} & 8523 & 8623\end{array}$

HipPISLey 1.

I have not examined the tables for errors. Seven corrections are given in $M T A C, v .1$, p. $325,1944$.

INNES 2.

(a) $\log q, \theta=\left[0\left(1^{\circ}\right) 45^{\circ} ; 10 \mathrm{D}\right]$.

I have derived $10 \mathrm{D}$ logarithms (uncertain by about a unit in the tenth place) of the values of $q$ given in SPENCELEy 1. These never differ from the values of Innes by more than four units in the tenth place. The table is thus free from gross error. Innes did not expect his tenth decimal to be exact.

( $\beta) \log \log (1 / q), \theta=\left[0\left(1^{\circ}\right) 45^{\circ} ; 10 \mathrm{D}\right]$.

The table is correctly abbreviated from VERHULST 1 . The only error in Innes is therefore at $21^{\circ}$; in the ninth and tenth decimals, for 23 , read 17. 
(r) $\log q, \theta=\left[0\left(1^{\prime}\right) 10^{\prime}, 44^{\circ} 50^{\prime}\left(1^{\prime}\right) 45^{\circ} ; 8 \mathrm{D}\right]$.

At $44^{\circ} 55^{\prime}$, for 380981 , read 380891 . Also on p. 496 are little tables of $q$ and $\log \log (1 / q)$ for the same arguments; these are free from gross error.

\section{JAHNKE \& EMDE 1.}

I have read only the tables of $\log q, K, E$ as functions of $\theta$; and only in the latest edition, which seems the simplest way to contribute to the perfection of future editions. I add a few corrections pointed out by others in various editions. I am concerned here only with tables; on errors in formulae, see $M T A C$, v. 1, p. 108, 198, 391-399.

(a) $\log q, \theta=\left[0\left(5^{\prime}\right) 90^{\circ} ; 4 \mathrm{D}\right]$.

The table is abbreviated from Bertrand's $5 \mathrm{D}$ table with the same arguments. It thus descends ultimately from MEISSEL's $8 \mathrm{D}$ table.

Bowman, $M T A C$, v. 3, p. 41, 1948, has pointed out the following errors in the characteristics of the logarithms in all editions of Jahnke \& Emde: at $2^{\circ} 55^{\prime}, 3^{\circ} 55^{\prime}, 4^{\circ} 55^{\prime}, 5^{\circ} 55^{\prime}$, for $\overline{5}$, read $\overline{4}$; at $37^{\circ} 50^{\prime}$, for $\overline{5}$, read $\overline{2}$.

All other errors in 14 are errors of 1 unit in the fourth place, and were found by reading against MEISSEL.

There are first the following three errors:

\begin{tabular}{|c|c|c|}
\hline$\theta$ & For & Read \\
\hline $\begin{array}{r}17^{\circ} 20^{\prime} \\
3855\end{array}$ & $\begin{array}{l}\overline{3} .7640 \\
\overline{2} .4960\end{array}$ & $\begin{array}{l}\overline{3} .7641 \\
\overline{2} .4959\end{array}$ \\
\hline M 655 & $\overline{1} .0270$ & 1.0271 \\
\hline
\end{tabular}

The first and last, marked $M$, are due uitimately to errors in Meissel. The second corresponds to no error in BERTRAND (if all copies agree with mine), but could have been caused by an error in LEvy.

There are also 56 further errors, all of the same type. BERTRAND's last figure is 5, and Jahnke \& Emde wrongly round upwards. In all 56 cases their value should be reduced by one unit of the fourth decimal. The arguments concerned are:

\begin{tabular}{|c|c|c|c|c|c|c|c|}
\hline $\begin{array}{rr}2^{\circ} & 5^{\prime} \\
5 & 25 \\
6 & 45 \\
7 & 40 \\
8 & 15 \\
9 & 45 \\
10 & 0\end{array}$ & $\begin{array}{lr}11^{\circ} & 10^{\prime} \\
11 & 15 \\
11 & 40 \\
12 & 5 \\
13 & 45 \\
13 & 50 \\
15 & 20\end{array}$ & $\begin{array}{ll}17^{\circ} & 25^{\prime} \\
18 & 20 \\
18 & 30 \\
18 & 55 \\
19 & 25 \\
20 & 20 \\
27 & 25\end{array}$ & $\begin{array}{lr}28^{\circ} & 30^{\prime} \\
29 & 15 \\
34 & 55 \\
35 & 35 \\
37 & 0 \\
41 & 50 \\
43 & 5\end{array}$ & $\begin{array}{ll}45^{\circ} & 10^{\prime} \\
45 & 45 \\
49 & 20 \\
49 & 25 \\
49 & 35 \\
49 & 40 \\
50 & 25\end{array}$ & $\begin{array}{lr}53^{\circ} & 25^{\prime} \\
63 & 0 \\
64 & 45 \\
66 & 0 \\
68 & 0 \\
68 & 15\end{array}$ & $\begin{array}{lr}71^{\circ} & 5^{\prime} \\
73 & 5 \\
76 & 50 \\
78 & 40 \\
79 & 20 \\
80 & 30 \\
83 & 20\end{array}$ & $\begin{array}{ll}83^{\circ} 50^{\prime} \\
85 & 10 \\
85 & 40 \\
86 & 50 \\
86 & 55 \\
87 & 30 \\
89 & 30\end{array}$ \\
\hline
\end{tabular}

The above are all the errors in 14. Comrie, in his list in $M T A C$, v. 1, p. 392, 1945, gives two errors in $1_{1}$ only; at $64^{\circ} 5^{\prime}$, for 4087 , read 0087 , and at $69^{\circ} 55^{\prime}$, for 1195 , read 1159 . I observe that both are corrected in the 1923 reprint.

( $\beta$ ) $K, E, \theta=\left[0\left(1^{\circ}\right) 70^{\circ}\left(30^{\prime}\right) 80^{\circ}\left(12^{\prime}\right) 89^{\circ}\left(6^{\prime}\right) 90^{\circ} ; 4 \mathrm{D}\right]$.

The errors surviving in 14 are:

\begin{tabular}{|c|c|c|c|}
\hline Function & $\theta$ & For & Read \\
\hline \multirow[t]{6}{*}{$K$} & $35^{\circ} 0^{\prime}$ & 1.7313 & 1.7312 \\
\hline & 460 & 1.8692 & 1.8691 \\
\hline & 8412 & 3.6853 & 3.6852 \\
\hline & 8648 & 4.2746 & 4.2744 \\
\hline & 8724 & 4.4812 & 4.4811 \\
\hline & 8812 & 4.8479 & 4.8478 \\
\hline \multirow[t]{4}{*}{$E$} & 70 & 1.5650 & 1.5649 \\
\hline & 220 & 1.5142 & 1.5141 \\
\hline & 540 & 1.2682 & 1.2681 \\
\hline & 620 & 1.1921 & 1.1920 \\
\hline
\end{tabular}




\begin{tabular}{ccccc} 
Function & \multicolumn{1}{c}{$\theta$} & For & Read \\
$E$ & 66 & 0 & 1.1546 & 1.1545 \\
& 67 & 0 & 1.1454 & 1.1453 \\
& 690 & 1.1273 & 1.1272 \\
& 8124 & 1.0313 & 1.0314 \\
& 86 & 0 & 1.0087 & 1.0086 \\
& 8812 & 1.0022 & 1.0021 \\
& 8918 & 1.0005 & 1.0004
\end{tabular}

The following errors, in earlier editions only, are given in $M T A C$, v. 1, p. 198, 1944, from GlaZenaP 1:

$\begin{array}{ccccc}\text { Function } & \theta & \text { For } & \text { Read } & \\ K & 86^{\circ} 48^{\prime} & 4.2744 & 4.2746 & 1_{1}, 1_{2}, 1_{3} \\ & 8736 & 4.5619 & 4.5609 & 1_{1}, 1_{2}, 1_{8} \\ & 8936 & 6.3504 & 6.3509 & 1_{1}, 1_{2}, 1_{\mathbf{3}} \\ E & 80 & 1.5630 & 1.5632 & 1_{1}, 1_{2}\end{array}$

( $\gamma) F(\theta, \phi), E(\theta, \phi)$

See the note at the beginning of Part III. Also $M T A C$, v. 1, p. 198, 1944, and v. 1, p. $395,1945$.

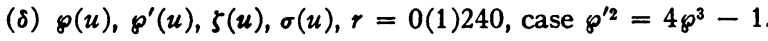

See under Greenhill 2.

$M T A C$, v: 1 , p. 392,1945 , gives, from AIREy, a correction to $\omega_{2}$ on p. 72 of $1_{1}$ only (correct in the 1923 reprint); for 1.53995 , read 1.52995 .

KAPLAN 1.

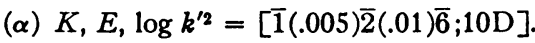

Differencing shows the function values in these useful tables to be free from gross error. I have not examined Kaplan's differences.

LEGENDRE (general remarks).

I have had the modern photographic reprints, Legendre 6 (PoTIN), 7 (EMDE) and 8 (PEARSON) continuously available. The original publications, Legendre 1-5, I have inspected only in libraries. Legendre 6 and 7 reproduce Legendre 3, while Legendre 8 reproduces Legendre 5 . The lists of errors will relate primarily to the reprints on which $I$ have worked. The contents of the reprints are not identical, and in fact natural values of $K$ and $E$ are reproduced only from 3 (in 7), and logarithmic values of $K$ and $E$ only from 5 (in 8). I state whether the errors listed for $K$ and $E$ also occur in 5, but have not otherwise examined $K$ and $E$ in 5 ; similarly for $\log K$ and $\log E$ and 3 .

Legendre's great double-entry tables of $F(\theta, \phi)$ and $E(\theta, \phi)$ are reproduced in all three reprints, so that it is easy for a modern worker to compare Legendre 3 (through 6 or 7 ) with Legendre 5 (through 8 ). Double-entry tables have fallen outside my own program of differencing and recomputation, but in view of the importance of Legendre's double-entry tables, a rearrangement of an errata list due to E. L. KAPLAN is included. Complete checking of the double-entry tables would be such a large task that, as far as I know, it has never been performed, but KAPLAN's list contains many more items than any previous list of errors.

The original tables of Legendre are now so rare that I believe that the reprints alone have now much general working value. Moreover, photographic reproductions of this kind give a guarantee against variations from one copy to another, so that a complete list of errors in one copy would enable all other copies to be completely corrected with certainty. I trust that my investigations concerning the single-entry tables in the reprints will form a useful contribution. It will be evident that much work remains to be done even in this limited sphere, in connection with the tables of $\log K$ and $\log E$. 
LEGENDRE 3, 5 .

Table VI (p. 323-332 of Legendre 3, p. 269-278 of Legendre 5), containing logarithms of the moduli in Landen's scale (see Part I, Section I), has not been reprinted. The following errors were pointed out by C. J. MerfieLd, Astron. Jn., v. 30, p. 190, 1917, in relation to Legendre 5; I observe that the last two are absent in Legendre 3. I have corrected the last two arguments, which MERFIELD misprinted.

\begin{tabular}{|c|c|c|c|}
\hline$\theta$ & Function & For & Read \\
\hline $5^{\circ} .1$ & $\log c$ & $\underline{5} .94887$ & $\underline{8} .94887$ \\
\hline 9.5 & $\log b^{0}$ & $9.9999 \underline{9} 96$ & $9.9999 \underline{8} 96$ \\
\hline 34.0 & $\log c$ & $9.9475 \overline{6}$ & $9.7475 \overline{6}$ \\
\hline
\end{tabular}

\section{LEGENDRB 7.}

The tables were reproduced by EMDE from Legendre 3. I have not examined the unimportant first part (p. 338-341) of T.VIII.

(a) $K, E, \theta=\left[0\left(1^{\circ}\right) 90^{\circ} ; 12 \mathrm{D}\right]$.

The complete integrals in the second part (p. 342-344) of T.VIII are highly important. Before receiving the SPENCELEY tables I had differenced Legendre's values of $K$ and $E$, and also recomputed these functions for $\theta=5^{\circ}\left(5^{\circ}\right) 70^{\circ}\left(1^{\circ}\right) 89^{\circ}$, and for various other arguments where errors were suspected. The following lists should be complete; they are based on SPENCELEY, and I agree with the correction in every case which I have recalculated. Besides the erroneous and corrected digits in the eleventh and twelfth decimals, the corrections (SPENCELEY minus Legendre) are also shown; $r$ indicates that the error is merely one of rounding, Legendre's value being within $1 \mathrm{final}$ unit of the true (unrounded) value; +1 and -1 consequently indicate departures of between 1 and $1 \frac{1}{2}$ final units from the truth. It will be observed that the maximum correction is 18 units of the twelf th decimal in $K\left(85^{\circ}\right)$, and that the corrections in the table of $E$ are all small.

There are two gross errors in Legendre's differences:

$$
\Delta^{2} E\left(10^{\circ}\right) \text {, for } \underline{2} 5070 \text {, read } 15070 ; \Delta^{2} K\left(33^{\circ}\right) \text {, for } 820 \underline{0} 0 \text {, read } 820 \underline{8} 0 \text {. }
$$

Otherwise his differences are consistent with his function values, except for errors in the last two figures of $\Delta^{6} E\left(36^{\circ}\right), \Delta^{5} E\left(37^{\circ}\right), \Delta^{6} E\left(37^{\circ}\right), \Delta K\left(62^{\circ}\right), \Delta K\left(63^{\circ}\right), \Delta K\left(65^{\circ}\right)$.

$\begin{array}{cccrcccr}\theta & \text { For } & \text { Read } & \text { corr. } & \theta & F_{\text {or }} & E_{\text {Read }} & \text { corr. } \\ \mathbf{1 1}^{\circ} & 75 & 76 & \mathrm{r} & 5^{\circ} & 77 & 78 & \mathbf{r} \\ \mathbf{1 2} & 27 & 28 & \mathrm{r} & 23 & 15 & 17 & +2 \\ \mathbf{2 4} & 13 & 12 & \mathrm{r} & 24 & 53 & 54 & \mathrm{r} \\ 39 & 04 & 06 & +2 & 27 & 43 & 44 & +1 \\ \mathbf{4 6} & 31 & 26 & -5 & 28 & 26 & 27 & +1 \\ \mathbf{4 7} & 84 & 80 & -4 & 39 & 85 & 86 & \mathrm{r} \\ \mathbf{4 8} & 65 & 64 & -1 & 40 & 23 & 24 & \mathrm{r} \\ \mathbf{4 9} & 38 & 36 & -2 & 46 & 31 & 30 & -1 \\ \mathbf{5 0} & 06 & 05 & -1 & 47 & 18 & 17 & \mathrm{r} \\ \mathbf{5 3} & 35 & 34 & \mathrm{r} & 48 & 82 & 81 & \mathrm{r} \\ 54 & 01 & 05 & +4 & 50 & 97 & 98 & \mathrm{r} \\ \mathbf{6 2} & 81 & 79 & -2 & 54 & 64 & 65 & +1 \\ \mathbf{8 1} & 43 & 44 & \mathrm{r} & 55 & 78 & 80 & +2 \\ 83 & 73 & 72 & -1 & 66 & 25 & 24 & \mathrm{r} \\ \mathbf{8 5} & 66 & 84 & +18 & 69 & 57 & 58 & \mathrm{r} \\ \mathbf{8 9} & 25 & 26 & \mathrm{r} & 73 & 36 & 38 & +2 \\ & & & & 74 & 74 & 73 & -1 \\ & & & & 79 & 45 & 44 & \mathrm{r}\end{array}$

All the above errors, except one in the differences, also appear in the second part (p. 288-290) of T.VIII in Legendre 5. The error in $\Delta^{2} K\left(33^{\circ}\right)$ is present neither in Legendre 5 nor in 6 
copies of Legendre 3 inspected, although Legendre 7 (EMDE) reproduces another copy of Legendre 3 ! This illustrates the advisability of concentrating research on the reprints.

\section{LEGENDRE 8.}

The tables were reproduced by PEARson from Legendre 5. The extremely important tables of $\log K$ and $\log E$ will be considered in six parts. From 0 to $15^{\circ}$ and from $75^{\circ}$ to $90^{\circ}$ the function values have $14 \mathrm{D}$, but the differences throughout relate to $12 \mathrm{D}$ values. In the 14D portions, I have aimed primarily at finding errors seriously affecting the first 12D, but in the case of $\log K$ I have gone further, and the corrections given will turn Legendre's $14 \mathrm{D}$ tables into reasonably good $13 \mathrm{D}$ tables.

In general, I have not read Legendre's differences systematically against my difference sheets, and the only statement I make concerning them will be found under $(\beta)$. See also KAPLAN 2, and my comment in RMT 568.

( $\alpha) \log K, \theta=\left[0\left(0^{\circ} .1\right) 15^{\circ} ; 14 \mathrm{D}\right]$.

I have differenced the values to the full 14D. The largest error is undoubtedly one of 14 units of the last place at $\theta=5^{\circ} .0$. I have recalculated a few values at arguments suggested by the differencing. When the following corrections to the end figures are made, it is probable that no further correction will exceed some four units of the fourteenth decimal.

$\begin{array}{ccc}\theta & \text { For } & \text { Read } \\ 1^{\circ} .1 & 35 & 30 \\ 5.0 & 26 & 40 \\ 5.3 & 06 & 11 \\ 5.5 & 01 & 05\end{array}$

All the above errors also occur in Legendre 3.

(B) $\log K, \theta=\left[15^{\circ}\left(0^{\circ} .1\right) 75^{\circ} ; 12 \mathrm{D}\right]$.

I have differenced the values. The only gross errors in the function values are: $\theta=24^{\circ} .9$, 7D, for 2 , read $3 ; \theta=30^{\circ} .9,0 \mathrm{D}$, for 8 , read 0 .

These corrections have previously been pointed out by HEUMAN; the differences correspond to the corrected values, and, as has been pointed out by ARChibald (MTAC, v. 2, p. 181, 1946), the errors are absent in Legendre 3. When the corrections are made, the table differences very well; the sixth difference never exceeds 17 , so that even the twelf th decimal must be quite good.

I have examined the first differences between $15^{\circ}$ and $75^{\circ}$, and found one gross error; at $74^{\circ} .5$, for 955 , read 953 . There are no other gross errors, but the last digit is one unit out of correspondence with Legendre's function values at $37^{\circ} .0$ and $75^{\circ} .0$. The first of these three errors is absent in Legendre 3.

(r) $\log K, \theta=\left[75^{\circ}\left(0^{\circ} .1\right) 90^{\circ} ; 14 \mathrm{D}\right]$.

As in $(\alpha)$, function values are to $14 \mathrm{D}$, differences to $12 \mathrm{D}$. Differencing to the full $14 \mathrm{D}$ proved the later decimals to be unreliable, although the first 9D are everywhere correct and only in one instance (at $89^{\circ} .3$ ) is the 10th affected. Attempts to detect errors affecting the twelfth decimal quickly showed that more than differencing would be required, and in order to make a satisfactory first contribution to the correction of the table I have lavished more time on it than on any other table investigated for this Guide; yet much more could still be done. I recalculated to $14 \mathrm{D}$ (with slight uncertainty in the last place) values of $\log K$ for 81 of the 150 arguments, including $\theta=75^{\circ}\left(0^{\circ} .5\right) 84^{\circ}\left(0^{\circ} .1\right) 85^{\circ} .5\left(0^{\circ} .5\right) 88^{\circ}\left(0^{\circ} .1\right) 89^{\circ} .9$, and found disagreements of more than three final units in the 27 cases listed below. These 27 cases I have recalculated to 15 or $16 \mathrm{D}$, in order to try to give definitive corrections for them. When the corrections are made, differencing now suffices to show freedom from other than last-figure error up to at least $88^{\circ}$. The list is not very likely to be complete in respect of errors exceeding three final units, but from the difference tables $I$ judge it to include all errors of ten or more final units, and it may even be found ultimately to include all errors of six or more final units. A noteworthy feature of the results is that the errors are largely 
in the twelf th decimal, the next two being frequently correct or nearly so. To exhibit this more clearly, the list gives, besides the erroneous and corrected values in the tenth to fourteenth places, the correction (true value minus Legendre). There is clearly an unexpected number of errors approximately multiples of 100 ; in particular, nine of ten successive values (between $84^{\circ} .3$ and $85^{\circ} .2$ ) are too small by about two units in the twelf th place. The attempt to correct the table has convinced me (as other computations convinced KarL PeArson) of the vast labor which Legendre, without calculating machines, must have put into his tables.

\begin{tabular}{|c|c|c|c|}
\hline$\theta$ & For & Read & corr. \\
\hline $78^{\circ} .6$ & 19291 & 19301 & +10 \\
\hline 79.1 & 38162 & 38189 & +27 \\
\hline 79.4 & 45626 & 45631 & +5 \\
\hline 79.5 & 34061 & 34067 & +6 \\
\hline 80.1 & 26294 & 26289 & -5 \\
\hline 80.3 & 60617 & 60515 & -102 \\
\hline 83.0 & 63180 & 63170 & -10 \\
\hline 83.2 & 57234 & $5 ? 269$ & +35 \\
\hline 83.7 & 47733 & 47632 & -101 \\
\hline 84.3 & 92765 & 92965 & +200 \\
\hline 84.4 & 52700 & 52900 & +200 \\
\hline 84.5 & 32799 & 33002 & +203 \\
\hline 84.6 & 87556 & 87623 & +67 \\
\hline 84.7 & 08925 & 09130 & +205 \\
\hline 84.8 & 81351 & 81552 & +201 \\
\hline 84.9 & 67275 & 67475 & +200 \\
\hline 85.0 & $31833\}$ & 32033 & +200 \\
\hline 85.1 & $\begin{array}{l}31823 \\
08187\end{array}$ & 08385 & $\begin{array}{r}+210 \\
+198\end{array}$ \\
\hline 85.2 & 09462 & 09661 & $\begin{array}{r}+199 \\
\end{array}$ \\
\hline 85.3 & 93083 & 93116 & +33 \\
\hline $85 . .7$ & 48980 & 48989 & +9 \\
\hline 86.8 & 54662 & 51623 & -3039 \\
\hline 86.9 & 34046 & 34188 & +142 \\
\hline 87.1 & 30193 & 30198 & +5 \\
\hline 88.7 & 05699 & 06099 & +400 \\
\hline 88.9 & 76200 & 76194 & -6 \\
\hline 89.3 & 21710 & 31710 & +10000 \\
\hline
\end{tabular}

All the above errors also occur in Legendre 3.

(8) $\log E, \theta=\left[0\left(0^{\circ} .1\right) 15^{\circ} ; 14 \mathrm{D}\right]$.

I have differenced the $14 \mathrm{D}$ values. The maximum fifth difference is 162 , so that, as in $(\alpha)$, no error will seriously affect the twelf th decimal.

(c) $\log E, \theta=\left[15^{\circ}\left(0^{\circ} .1\right) 75^{\circ} ; 12 \mathrm{D}\right]$.

I have differenced the values. The only gross errors in the function values are:

$\begin{array}{crcc}\theta & D & \text { For } & \text { Read } \\ 22^{\circ} .4 & 12 & 0 & 9 \\ 34.4 & 9 & 8 & 0 \\ 36.2 & 10 & 7 & 5 \\ 47.7 & 11 & 1 & 0\end{array}$

The correction at $34^{\circ} .4$ has already been pointed out by HeUMAN; the others have recently been published in KAPLAN 2, and I found them independently. All four also occur in Legendre 3. In all four cases Legendre's differences agree with function values corrected as above, so 
that the mistakes are simply misprints. When the corrections have been made, the table differences extremely well; the fifth difference never exceeds 11 , and the twelf th decimal must be quite good. In $\Delta \log E\left(37^{\circ} .0\right)$, for 181 , read 151 (MERFIELD, loc. cit.).

(५) $\log E, \theta=\left[75^{\circ}\left(0^{\circ} .1\right) 90^{\circ} ; 14 \mathrm{D}\right]$.

Legendre differences to only 12D. Differencing of the full $14 \mathrm{D}$ values shows that the table is not reliable to more than 12D. A gross error, pointed out by Heuman, is: $\theta=86^{\circ} .0$, 9D, for 6, read 3. Legendre's differences again agree with the corrected value, and, as pointed out by ARChibald ( $M T A C$, v. 2, p. 181, 1946), the error is absent in Legendre 3. At $\theta=84^{\circ} .4$, a decimal point should replace the letter $x$. Between $75^{\circ}$ and $89^{\circ}$, the differencing shows that values rounded to $12 \mathrm{D}$ will be free from gross error, once that at $86^{\circ} .0$ has been corrected. The table deserves detailed investigation of the kind described in $(\gamma)$ for the corresponding table of $\log K$.

\section{LEGENDRE 6, 7, 8.}

I have not examined Legendre's great double-entry tables for errors by differencing or recomputation, but for the convenience of the reader $I$ had, before receiving KAPLAN 2, drawn up lists of the errors stated by Bohlin, Merfield, Glazenap, SAmollova-ГAKhontova, Heuman, Witt and ARchibald ; for references, see RMT 568 (in the present number). As I found Kaplan 2 to contain all such known errors, and also many more found by KaPlan, I have, by kind permission, incorporated all Kaplan's material on p. 18-19 of his paper, as well as his information on p. 15 about $F\left(76^{\circ}, \phi\right)$, into fresh lists, separating errors in $F(\theta, \phi)$ from errors in $E(\theta, \phi)$, and arranging each list in order of increasing $\theta$. The lists below also contain three known errors in $E(\theta, \phi)$ of 1816 , absent from PEARson's reprint of the 1826 values, and hence outside the scope of KaPLAN's list.

There are two versions of the tables; Legendre 3 (1816) is reproduced in Legendre 6 and 7, while Legendre 5 (1826) is reproduced in Legendre 8. Legendre 6 and 7 no doubt reproduce different copies of Legendre 3, but these two reprints give identical values at all arguments mentioned below. An index, 1 or 2 , attached to an erroneous value indicates that the error occurs only in the 1816 or 1826 version respectively. The values labeled "obscure" in KAPLAN 2 are so only in Legendre 8, not in the beautifully printed table in Legendre 5, hence I have called them "Obscure ${ }^{2}$ reprint."

Owing to repetition of first and last columns and lines, tabular values are given twice if $\theta$ is one of $5^{\circ}\left(5^{\circ}\right) 85^{\circ}$, twice if $\phi=45^{\circ}$, and four times if both hold. Errors are included in the lists if they occur at all, even if the multiple presentation includes the correct value in another place.

The errors of one or two units given on p. 15 of KAPLAN 2 have not been incorporated; KAPLAN remarks that they are presumably only typical of considerable portions of the double-entry tables.

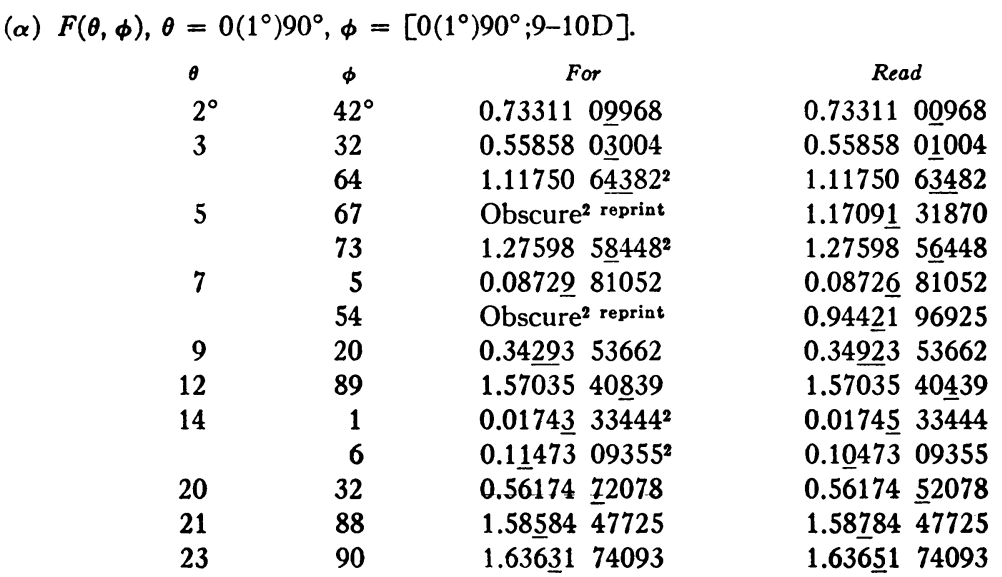




\begin{tabular}{|c|c|c|c|}
\hline$\theta$ & $\phi$ & For & Read \\
\hline 26 & 89 & $1.636278 \underline{6} 937$ & $1.636278 \underline{5} 937$ \\
\hline \multirow[t]{3}{*}{27} & 42 & $0.74 \underline{75} 401816$ & $0.74 \underline{574} 01816$ \\
\hline & 59 & $1.06251 \underline{39233}$ & $1.06251 \underline{29233}$ \\
\hline & 85 & $1.56 \underline{840} 67133$ & $1.56 \underline{80} \quad 67133$ \\
\hline 30 & 35 & $0.62 \underline{2} 0301811^{2}$ & $0.62 \underline{003} 01811$ \\
\hline 31 & 12 & $0.2098442225^{2}$ & $0.209844224 \underline{5}$ \\
\hline 34 & 84 & $1.5951805 \underline{3} 43$ & $1.59518 \quad 05 \underline{5} 43$ \\
\hline 44 & 80 & $1.5 \underline{8906} 49280$ & 1.5980649280 \\
\hline \multirow[t]{2}{*}{46} & 51 & $0.9515 \underline{8} \quad 7953$ & $0.9515 \underline{7} 7953$ \\
\hline & 90 & $1.86914754 \underline{5}$ & $1.86914 \quad 754 \underline{6}$ \\
\hline 57 & 90 & 2.080358167 & $2.080358 \underline{067}$ \\
\hline 59 & 65 & $1.3419 \underline{5} 7808$ & $1.3419 \underline{6} 7808$ \\
\hline 60 & 60 & $1.2125 \underline{3} 6614$ & $1.2125 \underline{9} 6614$ \\
\hline 64 & 79 & $1.84 \underline{693} 8718$ & $1.84 \underline{793} 8718$ \\
\hline 66 & 89 & $2.30100 \quad 51 \underline{7} 7$ & $2.3010051 \underline{5} 7$ \\
\hline 71 & 61 & $1.29 \underline{179} 6493$ & $1.29 \underline{719} 6493$ \\
\hline 74 & 85 & $2.39615 \underline{7101}$ & $2.39615 \underline{6101}$ \\
\hline \multirow[t]{2}{*}{75} & 37 & $0.691 \underline{30} 9761^{2}$ & $0.691 \underline{90} 9761$ \\
\hline & $84-88$ & Increase by $1 \times 10^{-9}$ & \\
\hline \multirow[t]{34}{*}{76} & 55 & $1.13561 \quad 6 \underline{079}$ & $1.13561 \quad 6 \underline{100}$ \\
\hline & 56 & $1.164683 \underline{355}$ & $1.164683 \underline{376}$ \\
\hline & 57 & $1.19438 \quad 49 \underline{25}$ & $1.1943849 \underline{46}$ \\
\hline & 58 & $1.2247539 \underline{02}$ & $1.2247539 \underline{23}$ \\
\hline & 59 & $1.25582 \quad 54 \underline{54}$ & $1.2558254 \underline{75}$ \\
\hline & 60 & $1.2876369 \underline{43}$ & $1.2876369 \underline{64}$ \\
\hline & 61 & $1.3202280 \underline{66}$ & $1.3202280 \underline{88}$ \\
\hline & 62 & $1.35364 \quad 10 \underline{02}$ & 1.353641024 \\
\hline & 63 & $1.3879205 \underline{52}$ & $1.3879205 \underline{75}$ \\
\hline & 64 & $1.42311 \quad 4 \underline{279}$ & $1.423114 \underline{302}$ \\
\hline & 65 & 1.459272632 & $1.4592726 \underline{56}$ \\
\hline & 66 & $1.4964490 \underline{58}$ & $1.4964490 \underline{83}$ \\
\hline & 67 & $1.534700 \underline{0075}$ & $1.534700 \underline{101}$ \\
\hline & 68 & $1.57408 \quad 53 \underline{05}$ & $1.5740853 \underline{31}$ \\
\hline & 69 & $1.6146674 \underline{46}$ & $1.6146674 \underline{73}$ \\
\hline & 70 & 1.656512149 & $1.6565121 \underline{76}$ \\
\hline & 71 & $1.699687 \underline{781}$ & $1.699687 \underline{809}$ \\
\hline & 72 & $1.7442650 \underline{22}$ & $1.7442650 \underline{51}$ \\
\hline & 73 & $1.7903162 \underline{5} 4$ & $1.79031 \quad 62 \underline{8} 4$ \\
\hline & 74 & $1.837914 \underline{673}$ & $1.837914 \underline{703}$ \\
\hline & 75 & 1.887133051 & $1.8871330 \underline{82}$ \\
\hline & 76 & 1.938042064 & 1.938042095 \\
\hline & 77 & $1.990708 \underline{091}$ & 1.990708120 \\
\hline & 78 & $2.0451903 \underline{71}$ & $2.0451903 \underline{98}$ \\
\hline & 79 & $2.10153 \quad 74 \underline{63}$ & $2.1015374 \underline{88}$ \\
\hline & 80 & $2.1597829 \underline{27}$ & $2.1597829 \underline{50}$ \\
\hline & 81 & 2.219940244 & $2.2199402 \underline{65}$ \\
\hline & 82 & $2.28199 \quad 7 \underline{092}$ & $2.281997 \underline{111}$ \\
\hline & 83 & $2.3459092 \underline{31}$ & $2.3459092 \underline{47}$ \\
\hline & 84 & 2.411594470 & $2.4115944 \underline{85}$ \\
\hline & 85 & $2.47892 \quad 7378$ & $2.4789273 \underline{91}$ \\
\hline & 86 & $2.5477356 \underline{14}$ & 2.547735625 \\
\hline & 87 & $2.6177988 \underline{34}$ & $2.6177988 \underline{\underline{3}}$ \\
\hline & 88 & 2.688851060 & $2.68885 \quad 1066$ \\
\hline
\end{tabular}




\begin{tabular}{crrr}
$\theta$ & \multicolumn{1}{c}{$D$} & For & Read \\
7430 & 5 & 2 & 3 \\
8248 & 5 & 2 & 3 \\
8312 & 5 & 4 & 5 \\
8536 & 5 & 7 & 6 \\
8612 & 5 & 6 & 7 \\
8736 & $3-5$ & 190 & 091 \\
8936 & $4-5$ & 38 & 89
\end{tabular}

(B) $E, \theta=\left[0\left(1^{\circ}\right) 70^{\circ}\left(30^{\prime}\right) 80^{\circ}\left(12^{\prime}\right) 89^{\circ}\left(6^{\prime}\right) 90^{\circ} ; 5 \mathrm{D}\right]$.

Comparison with an accurate table deduced from LEGENDRE shows the following errors:

\begin{tabular}{crrc}
$\theta$ & \multicolumn{1}{c}{$D$} & For & Read \\
$8^{\circ} 0^{\prime}$ & $3-4$ & 29 & 31 \\
8124 & 4 & 2 & 3 \\
8918 & 4 & 4 & 3 \\
8954 & 4 & 1 & 0
\end{tabular}

(r) $\log q, \theta=\left[0\left(5^{\prime}\right) 90^{\circ} ; 5 \mathrm{D}\right]$.

This table was copied with acknowledgment from BERTRAND, who abbreviated from MEIsSEL without acknowledgment. In addition to the errors listed under BERTRAND $(\alpha)$, Lévy has seven more through faulty copying:

\begin{tabular}{crrr}
\multicolumn{1}{c}{$\theta$} & \multicolumn{1}{c}{$D$} & For & Read \\
$1^{\circ} 30^{\prime}$ & 2 & 8 & 3 \\
255 & 0 & $\overline{5}$ & 4 \\
3345 & 1 & 4 & 3 \\
3855 & 5 & 5 & 3 \\
5935 & 1 & 7 & 9 \\
645 & 1 & 4 & 0 \\
6955 & $3-4$ & 95 & 59
\end{tabular}

Meissel 1.

(a) $\log q, \theta=\left[0\left(1^{\prime}\right) 90^{\circ} ; 8 \mathrm{D}\right]$.

This is the largest single-entry table relating to elliptic functions in existence. It is not so well known as many slighter works, and copies are somewhat rare. Lack of acknowledgment, especially in BERTRAND 1, has hindered recognition of the fact that it is the source of several better known abbreviations. Three errors obviously derived from Meissel show that the 5D table at interval $5^{\prime}$ in Bertrand 1 was extracted from Meissel 1. Bertrand said (p. xii) that his tables were due to F. Thoman. Bertrand's book was published in 1870; if in the later part of the year (on which point I lack information), it is possible that the FrancoPrussian war made inopportune a candid acknowledgment of the German origin of the table of $\log q$. Subsequent copyists and abbreviators (LEvy, Potin, even JAHNKE \& EMDE) have followed BERTRAND, not Meissel.

I have not differenced Meissel's table completely, but in order to check several other tables I have differenced (i) the values at $0\left(6^{\prime}\right) 90^{\circ}$, (ii) the values at $0\left(5^{\prime}\right) 90^{\circ}$. In this way one-third of the values (ten in every half-degree) have been tested for gross errors.

In addition, I have differenced the values at $0\left(1^{\prime}\right) 1^{\circ} 10^{\prime}$ and $89^{\circ}\left(1^{\prime}\right) 90^{\circ}$; moreover, I have checked the values at $0\left(1^{\prime}\right) 10^{\prime}$ and $89^{\circ} 50^{\prime}\left(1^{\prime}\right) 90^{\circ}$, the former by comparison with the little table on p. 496 of INNEs 2 , and the latter by simple calculation therefrom. This supplementary work revealed no gross error in the regions at the beginning and end where differencing at interval $6^{\prime}$ or $5^{\prime}$ fails as a check.

The values at $0\left(6^{\prime}\right) 90^{\circ}$ are entirely free from gross error. I have compared the values at $0\left(1^{\circ}\right) 90^{\circ}$ with logarithms, to 10 or more $\mathrm{D}$, of the values of $q$ given in SPENCELEY 1. This revealed only two rounding errors, both very fine; at $33^{\circ}$, for 819 , read 820 (rounding 819507 ), and at $42^{\circ}$, for 332 , read 333 (rounding 332520 ). 
Differencing at interval $5^{\prime}$ does reveal three gross errors and one rather large last-figure error:

\begin{tabular}{|c|c|c|c|}
\hline$\theta$ & $D$ & For & Read \\
\hline $4^{\circ} 50^{\prime}$ & 8 & 4 & 9 \\
\hline 1720 & 4 & 0 & 1 \\
\hline 4625 & 5 & 0 & 1 \\
\hline 655 & 5 & 4 & 5 \\
\hline
\end{tabular}

In confirming the corrections at $46^{\circ} 25^{\prime}$ and $65^{\circ} 5^{\prime}$ by differencing at interval $1^{\prime}$, it was found that in each case a neighboring value is affected by gross error: $\theta=46^{\circ} 26^{\prime}, 5 \mathrm{D}$, for 6 , read $7 ; \theta=65^{\circ} 4^{\prime}, 5 \mathrm{D}$, for 3 , read 4 .

On p. 14 the right-hand argument 11 is erroneously printed as 12 .

In general the table is evidently accurate, but its 5400 values may perhaps contain 15 or 20 gross errors. Differencing of the whole table at interval $1^{\prime}$ is highly desirable.

MiLNe-Thomson 1.

( $\alpha), k^{2}=[0(.01) 1 ; 10 \mathrm{D}]$.

Differencing suffices to show freedom from gross error up to at least $k^{2}=.88$. For $k^{2}=.88(.01) .99 \mathrm{I}$ have deduced 10D natural values from the 10D table of $\log q$ in HAYASH 1 ; in all cases I found agreement within one unit of the tenth decimal. Thus all the function values are free from gross error. Moreover, Milne-Thomson's differences accurately correspond to his function values.

\section{Milne-Thomson 2.}

( $\alpha) K, E, k^{2}=[0(.01) 1 ; 9 \mathrm{D}]$

"About 70 errors (in 200 values) of a unit each, one of two units, and none greater" (Comrie, Math. Rev., v. 7, p. 485). The error of two units is in $K^{\prime}$, at $m=k^{2}=.01$, where for final 5, read 3. Comparison with the 10D values in Hayashi 1, 3 confirms that in all other cases Milne-Thomson's values are within $1 \frac{1}{2}$ units of the truth, the greatest remaining discrepancy between the two values being one of 15 units of the tenth decimal, in $K^{\prime}$ at $m=.37$, where Milne-Thomson ends in 81, HAYASHI ends in 795, and I find 79528. I have not checked the differences, nor the table of $1 / \vartheta_{3}{ }^{2}=\pi / 2 K$.

\section{Milne-Thomson 3.}

( $\alpha) \mathrm{K}, \mathrm{E}, k^{2}=[0(.01) 1 ; 7 \mathrm{D}]$.

Free from error. I have read against both HAYASHI 1, 3 and Milne-Thomson 2.

(B) $q, k^{2}=[0(.01) 1 ; 8 \mathrm{D}]$.

Free from error, assuming the table correct in a few cases in which the 10D table in Milne-Thomson 1 ends in 50.

\section{MOORE 1.}

(a) $2 E, k^{\prime}=[0(.01) 1 ; 4 \mathrm{D}]$.

Since FMR Index was published, I have seen MOORE's table in the British Museum. It gives $2 E$ (not $4 E$, as erroneously stated on p. 317 of FMR Index). The last two decimals are of ten false, and the table is of no interest apart from its early date.

\section{Nagaoka \& Sakurai 1.}

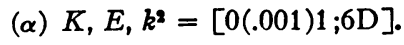

"In comparing the first 250 values of $K$ [with the 7D values of SAmollova-rakrontova] only slight last figure differences were found in about a score of cases" (ARCHibald, Scripta Math., v. 3, 1935, p. 365). 
Plana 1.

$(\alpha) \log (1 / q), \theta=\left[0\left(0^{\circ} .1\right) 45^{\circ}\left(1^{\circ}\right) 90^{\circ} ; 10 \mathrm{D}\right]$.

The present writer was responsible for printing Plana 1848 in bold type on p. 321 of FMR Index. Further experience has unfortunately shown the implied recommendation to be quite unwarranted. Differencing immediately proved the table to be scandalously inaccurate. While it would not be difficult to recompute the whole 10D table (for instance, mainly by taking twelve-figure antilogarithms of VERHULST's values, corrected where necessary), I have lacked time, and shall confine myself to stating the numerous corrections necessary to

\begin{tabular}{|c|c|c|c|c|c|}
\hline$\theta$ & Plana (8D) & Meissel & $\theta$ & Plana (8D) & MEISSEL \\
\hline $1^{\circ} .2$ & 4.56207605 & $4.56197 \quad 100$ & $35^{\circ} .4$ & 1.59296681 & 1.59296451 \\
\hline 4.2 & 3.47347021 & $3.47347 \quad 740$ & 35.6 & 1.58771573 & $\begin{array}{lll}1.58771 & 568\end{array}$ \\
\hline 5.5 & $3.23897 \quad 197$ & $3.23897 \quad 195$ & 40.1 & 1.47743564 & 1.47563204 \\
\hline 9.4 & 2.77213727 & 2.77215327 & 40.9 & 1.45678520 & $1.45678 \quad 185$ \\
\hline 10.1 & 2.70946393 & 2.70946258 & 41.1 & 1.45211467 & 1.45211450 \\
\hline 13.4 & 2.46216418 & 2.46216318 & 41.6 & 1.44052385 & $1.44052 \quad 284$ \\
\hline 13.6 & 2.44917384 & 2.44917385 & 42.0 & 1.43132888 & 1.43132667 \\
\hline 14.1 & $2.41750 \quad 352$ & $2.41750 \quad 252$ & 42.1 & 1.42900828 & 1.42903813 \\
\hline 15.2 & 2.35152745 & 2.35152845 & 42.2 & 1.42675335 & 1.42675374 \\
\hline 15.7 & 2.32306816 & 2.32306793 & 42.3 & 1.42417316 & 1.42447347 \\
\hline 15.8 & $2.31748 \quad 196$ & $2.31748 \quad 197$ & 42.4 & 1.42219736 & 1.42219730 \\
\hline 16.0 & 2.30641298 & 2.30641257 & 42.5 & 1.41992512 & 1.41992520 \\
\hline 16.1 & 2.30092808 & 2.30092827 & 42.6 & 1.41765690 & 1.41765715 \\
\hline 16.3 & 2.29006836 & 2.29005836 & 42.7 & 1.41539320 & 1.41539312 \\
\hline 16.9 & 2.25789743 & 2.25820939 & 42.8 & 1.41313315 & 1.41313309 \\
\hline 18.0 & 2.20256652 & 2.20256662 & 42.9 & 1.41087671 & $1.41087 \quad 704$ \\
\hline 18.3 & $2.18794 \quad 474$ & $2.18796 \quad 174$ & 43.7 & 1.39296873 & 1.39296884 \\
\hline 18.4 & $2.18314 \quad 464$ & $2.18314 \quad 474$ & 44.0 & 1.38631594 & 1.38631596 \\
\hline 18.5 & 2.17835396 & 2.17835290 & 44.2 & 1.38195353 & 1.38189922 \\
\hline 18.8 & 2.16412567 & 2.16412568 & 44.8 & 1.36873522 & 1.36873581 \\
\hline 20.0 & 2.10931747 & 2.10931745 & 45.0 & 1.36438892 & 1.36437635 \\
\hline 20.3 & 2.09610811 & 2.09610832 & 46 & 1.34278395 & 1.34278396 \\
\hline 20.6 & 2.08308433 & 2.08308444 & 48 & 1.30055663 & 1.30055763 \\
\hline 22.0 & 2.02460039 & 2.02460036 & 49 & 1.27988537 & 1.27988450 \\
\hline 22.7 & 1.99667024 & 1.99667036 & 50 & 1.25949994 & 1.25947994 \\
\hline 26.2 & 1.86812129 & 1.86812124 & 53 & 1.19970369 & 1.19970347 \\
\hline 26.4 & 1.86126771 & 1.86126797 & 54 & 1.18020131 & 1.18020158 \\
\hline 26.5 & 1.85785945 & 1.85785926 & 55 & 1.16088275 & 1.16088475 \\
\hline 26.9 & 1.84434183 & $1.84434 \quad 182$ & 60 & 1.06653416 & $1.06653 \quad 431$ \\
\hline 27.0 & 1.84099060 & 1.84099133 & 63 & 1.01117242 & 1.01115242 \\
\hline 27.4 & 1.82769382 & $1.82770 \quad 224$ & 86 & 0.52945956 & 0.52945958 \\
\hline 27.5 & 1.82440592 & 1.82440774 & 88 & 0.45221546 & $0.45202 \quad 155$ \\
\hline 27.6 & 1.82112718 & 1.82112418 & & & \\
\hline 27.7 & $1.81784 \quad 242$ & $1.81785 \quad 147$ & \multicolumn{3}{|c|}{ Obvious errors in integral part only: } \\
\hline 28.1 & 1.80486789 & 1.80486753 & & For & Read \\
\hline 28.2 & 1.80091548 & 1.80164786 & $29^{\circ} .9$ & 7 & 1 \\
\hline 28.7 & $1.78520 \quad 349$ & 1.78570349 & 64 & 1 & 0 \\
\hline 29.4 & 1.76379582 & 1.76379882 & 65 & 1 & 0 \\
\hline 29.7 & 1.75455482 & 1.75455478 & 66 & 1 & 0 \\
\hline 30.2 & 1.73933275 & 1.73933272 & 67 & 1 & 0 \\
\hline 30.9 & 1.71839436 & 1.71839602 & & & \\
\hline 34.9 & 1.60617525 & 1.60619744 & \multicolumn{3}{|c|}{ For argument 86.6 read 36.6.} \\
\hline
\end{tabular}


turn the table into a reasonably good $8 \mathrm{D}$ table. I have compared Plana's $10 \mathrm{D}$ values with MEIsSEL's 8D values, or rather with their complements, since Plana tabulates $\log (1 / q)$ and Meissel $\log q$. Meissel's values at arguments which are multiples of $6^{\prime}$ are entirely free from gross error and the eighth decimal is generally very accurate. On p. 277 are listed the 79 cases (out of 495 values!) in which Plana's value differs by more than 100 units (in fact, 122 or more) of the tenth decimal from MEISSEL's $8 \mathrm{D}$ value. Plana's values are given rounded to $8 \mathrm{D}$. These are all gross errors in Plana. There are also more than a score of cases, not listed, in which Plana's value differs from MeIssel's by between 51 and 100 units of the tenth decimal. Some of these will be due to errors of rounding in MeIssel, but many will be gross errors in Plana, and there will probably be other gross errors in Plana not affecting the eighth decimal. The list on p. 277 aims partly at salvaging something from the chaos of Plana's table, which is fairly accessible, and partly at making more widely available to scientists at least the gist of MEISSEL's rare work.

\section{Potin 1.}

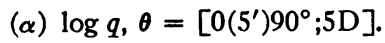

Contains all the errors given under BERTRAND $1(\alpha)$ and none of those given under LEvy $1(\gamma)$. I have not read the table against BERTRAND to see whether Potin has introduced any copying errors.

(及) $\log \vartheta_{3}$ [called $\left.\log \theta_{2}(0)\right], \theta=\left[0\left(30^{\prime}\right) 90^{\circ} ; 9 \mathrm{D}\right]$.

The function tabulated is $\frac{1}{2} \log (2 K / \pi)$. Except that the integral part at $67^{\circ} 30^{\prime}$ is corrected, the table is faithfully copied from BERTRAND, and has the same errors as those already given in BERTRAND $1(\beta)$.

( $\gamma$ ) $F(\theta, \phi), E(\theta, \phi), \theta=0\left(1^{\circ}\right) 90^{\circ}, \phi=\left[0\left(1^{\circ}\right) 90^{\circ} ; 9-10 \mathrm{D}\right]$.

See under LEGENDRE.

Rosenbach, Whitman \& Moskovitz 1.

I have not examined the tables for errors. On two errors, see ArChIBALD, MTAC, v. 2 , p. 217, 1947.

\section{RUNKLE 1.}

Not too bad up to $\alpha=.5$, rather unreliable from .5 to .7 , and so unreliable as to be almost useless between .7 and .75 .

\section{Samollova- Гakhontova 1.}

I have not checked the extensive double-entry tables.

( $\alpha) K, E, k^{2}=[0(.001) 1 ; 7 \mathrm{D}]$.

The values are based on HAYASHI 1, 3, which give at least three further decimals over the whole range. I have examined the tables only for those arguments at which HAYASH has errors, and for two arguments at which Samoilova-fakhontova herself points out errors in the errata slip. The first and fourth of the following errors are due to errors in the source; the second and third are from the errata slip.

\begin{tabular}{rccrrr} 
p. & $k^{2}$ & Function & \multicolumn{1}{c}{$D$} & For & \multicolumn{1}{c}{ Read } \\
90 & .201 & $E$ & 4 & 5 & 6 \\
92 & .310 & $K$ & 2 & 2 & 1 \\
94 & .439 & $E$ & $1-7$ & 387428 & 3807428 \\
105 & .999 & $K$ & 7 & 5 & 6
\end{tabular}

Archibald (Scripta Math., v. 3, 1935, p. 365) has checked that the values of $K$ for $k^{2}=0(.01) 1$ are in agreement with the 9D values of MiLNE-Thomson 2.

(B) $q, k^{2}=[0(.001) 1 ; 8 \mathrm{D}]$.

This table falls for purposes of checking into two parts.

For $k^{2}=0(.001) .5$, the function values were reprinted from HAYASHI 1, first differences being added. I have confirmed that the function values were correctly copied, the major 
errors at $k^{2}=.395$ and .482 being corrected; at $k^{2}=.279$, the last-figure correction (for final 7, read 8) also given by HAYASHI in 1932 has, however, not been made. See HAYASHI 1 $(\gamma)$. The function values are thus free from gross error. At $k^{2}=.403$, the last digit is almost illegible in my copy, but the differences show that 5 is intended.

For $k^{2}=.501(.001) 1$, the table is original. Differencing shows freedom from gross error up to at least $k^{2}=.988$, and I have recomputed the values at $k^{2}=.986(.001) .999$ to $10 \mathrm{D}$, finding only two rounding errors. Comparison of every tenth value with the ten-decimal table at interval .01 in MiLne-Thomson 1 also revealed two rounding errors, as well as two cases (at .58 and .79) in which Milne-Thomson 1 ends in 50, and in both of which recomputation showed HAYASH to be wrongly rounded. Recomputation of a small stretch with rough differences round $k^{2}=.977$ discovered three more rounding errors. The various rounding errors referred to are:

$\begin{array}{lccccccccc}k^{2} & .580 & .670 & .790 & .975 & .977 & .979 & .980 & .992 & .997 \\ \text { for } & 8 & 0 & 8 & 7 & 8 & 4 & 8 & 6 & 2 \\ \text { read } & 9 & 1 & 7 & 8 & 9 & 5 & 7 & 5 & 3\end{array}$

Further rounding errors doubtless exist, but in general the final digit is evidently accurate. The differences are printed in small and occasionally defective type, a few digits being barely legible, but, as far as I can see, the differences in the whole table of $q$ accurately correspond to the printed function values.

\section{SCHLÖMILCH 1.}

(a) $E, k^{\prime}=[0(.01) 1 ; 5 \mathrm{D}]$.

Comparison with the accurate 11D table of Schmidt 1 shows that Schlömilch's values are all correct, if his last-digit underlinings are disregarded. The last digits should be underlined (to denote tabular values in excess of the true values) at .07 and .60 .

\section{SchMidT 1.}

I have not examined the extensive double-entry tables.

(a) $E, k^{\prime}=[0(.01) 1 ; 11 \mathrm{D}]$.

These are quadrants of ellipses with semi-axes 1 and $k^{\prime}$. The table is by far the most important of its kind, and it is unfortunate that it has not been more widely known, as it is thoroughly reliable. Differencing, supplemented by recomputation at $k^{\prime}=0(.01) .10$, shows that there are no gross errors. It should be noted that, in all cases where my information goes beyond the eleventh decimal, Schmidt's value has been obtained by rounding downwards, that is, he has not raised the digit in the eleventh place, even when the following digit exceeds 4 . Presumably this holds throughout the table.

\section{SPENCEley 1.}

I have not examined the double-entry tables. In the page headings are given three transcendental functions, namely $K, E, q$. The quantities $D(90)$ and $1 / D(90)$ also given in the headings are not transcendental, being equal to $1 / \sqrt{ } k^{\prime}$ and $\sqrt{ } k^{\prime}$ respectively, and thus merely algebraic functions of the modulus. I have examined the values of $K, E, q$ as given (each twice, without any disagreements) on p. $2-181$; the values are given another twice in the second half of the table, which I have not examined.

( $\alpha) K, \theta=\left[0\left(1^{\circ}\right) 90^{\circ} ; 15 \mathrm{D}\right]$.

I have differenced the values for $0\left(1^{\circ}\right) 81^{\circ}$; at the end this requires twenty-second differences. The process proves the Spenceley values to be free from gross error for $\theta=0\left(1^{\circ}\right) 69^{\circ}$; beyond $69^{\circ}$, the table cannot be checked to the full 15 decimals by differencing. For $\theta=70^{\circ}$ $\left(1^{\circ}\right) 89^{\circ}, 13 \mathrm{D}$ values of my own agree with the Spenceley values to that number of decimals, so that the whole table is certainly accurate enough for all practical purposes.

( $\beta) E, \theta=\left[0\left(1^{\circ}\right) 90^{\circ} ; 15 \mathrm{D}\right]$.

I have differenced the values for $\theta=0\left(1^{\circ}\right) 83^{\circ}$, and so proved freedom from gross error up to at least $73^{\circ}$. For $70^{\circ}\left(1^{\circ}\right) 89^{\circ}$, my own calculations check the Spenceley values to at least $13 \mathrm{D}$. Thus the whole table is again of great accuracy. 
( $\gamma) q, \theta=\left[0\left(1^{\circ}\right) 90^{\circ} ; 16 \mathrm{~S}\right]$.

I first differenced the values for $\theta=0\left(1^{\circ}\right) 71^{\circ}$ to $16 \mathrm{D}$, rounding to this number for $\theta=0\left(1^{\circ}\right) 63^{\circ}$, where further decimals are given. This proved freedom from gross error to $16 \mathrm{D}$ up to at least $63^{\circ}$. The process could be pushed a few degrees higher. I have, so far, checked the values above $63^{\circ}$ only to the extent that I have derived 10D logarithms of all the Spenceley values of $q$, and these agree with 9D logarithms which I had earlier deduced from the $K$ and $K^{\prime}$ of Legendre 7, using $\log q=-C K^{\prime} / K$, where $C=\pi \log e$. This check will suffice for most purposes.

Later, out of curiosity, I differenced the Spenceley values of $q$ for $\theta=0\left(1^{\circ}\right) 22^{\circ}$ to $18 \mathrm{D}$, and to my surprise found incontestable evidence of errors in the eighteenth decimal. I have, so far, recomputed $q$ to $20 \mathrm{D}$ for $\theta=1^{\circ}\left(1^{\circ}\right) 12^{\circ}$. These values difference well, and give the following corrections, the first digit mentioned being in the sixteenth decimal in each case:

$\begin{array}{lccccc}0 & \text { For } & \text { Read } & \theta & \text { For } & \text { Read } \\ 3^{\circ} & 4727 & 4708 & 9^{\circ} & 192 & 198 \\ 5 & 8574 & 8571 & 10 & 284 & 286 \\ 6 & 8341 & 8369 & 11 & 765 & 770\end{array}$

At the other six arguments I agree completely with the Spenceleys. The largest error so revealed is 6 units in the eighteenth decimal at $9^{\circ}$; the largest error expressed in units of the last place kept by the Spenceleys is 28 final units at $6^{\circ}$.

I have not yet differenced the values up to $63^{\circ}$ to $17 \mathrm{D}$. Anyone not content with $16 \mathrm{D}$ in this range should difference or recalculate. The errors which I have found are unlikely to affect the main Spenceley tables.

VERHULST 1.

Verhulst says (p. 252) that the table of $\log \log (1 / q)$ was calculated for him by LOXнAY, a young Belgian mathematician, from LEGENDRE's tables. The formula is

$$
\log \log (1 / q)=\log K^{\prime}-\log K+0.1349341839946706 .
$$

I shall deal with the table in two parts.

$(\alpha) \log \log (1 / q), \theta=\left[0\left(0^{\circ} .1\right) 15^{\circ} ; 14 \mathrm{D}\right]$.

After differencing, I first recalculated all values, correcting $\log K$ as in LEGENDRE $8(\alpha)$ and $\log K^{\prime}$ as in LEGENDRE $8(\gamma)$; in the latter case LEGENDRE's table is, of course, now regarded as a table of $\log K^{\prime}$ for $\theta=0\left(0^{\circ} .1\right) 15^{\circ}$ rather than as a table of $\log K$ for $\theta=75^{\circ}$ $\left(0^{\circ} .1\right) 90^{\circ}$. As $\log K$ and $\log K^{\prime}$ so obtained are still liable in most cases to considerable lastfigure errors, my results are in general very uncertain in the 14th decimal, but are sufficient to correct Verhulst into a table to 13 working decimals.

There are two gross errors due presumably to slips by Loxhay : $\theta=1^{\circ} .2,5 \mathrm{D}$, for $_{\mathrm{i}}^{\mathrm{m}} \mathrm{6}$, read $5 ; \theta=4^{\circ} .2,6-7 \mathrm{D}$, for 35 , read 44 . These are the only errors due to Loxhay.

\begin{tabular}{crrrrr}
$\theta$ & \multicolumn{1}{c}{ For } & Read & \multicolumn{1}{c}{$\boldsymbol{\theta}$} & \multicolumn{1}{c}{ For } & Read \\
$0^{\circ} .7$ & 795573 & 805573 & $5^{\circ} .4$ & 86983 & 87050 \\
1.1 & 35632 & 35631 & 5.5 & 12965 & 13165 \\
1.3 & 95056 & 95456 & 5.6 & 83793 & 83994 \\
2.9 & 56794 & 56799 & 5.7 & 30859 & 31059 \\
3.1 & 79255 & 79397 & 6.3 & 81232 & 81131 \\
3.2 & 60913 & 57874 & 6.8 & 71013 & 71048 \\
4.3 & 74463 & 74472 & 7.0 & 91125 & 91115 \\
4.7 & 25150 & 25183 & 9.7 & 27826 & 27723 \\
4.8 & 57083 & 57282 & 9.9 & 92341 & 92336 \\
4.9 & 33199 & 33397 & 10.5 & 99630 & 99632 \\
5.0 & 83774 & 83960 & 10.6 & 51339 & 51341 \\
5.1 & 83060 & 83260 & 10.9 & 13635 & 13660 \\
5.2 & 85112 & 85311 & 11.4 & 33851 & 33861 \\
5.3 & 11686 & 11886 & & &
\end{tabular}


The errors at the 27 arguments corresponding to those listed under Legendre $8(\alpha, \gamma)$ are given at the bottom of p. 280, the last digit being always in the fourteenth place. The list probably omits no error of more than ten final units in Verhulst. The corrections are slightly provisional, but are liable to errors of only a unit or so in the last place, as I later applied a few small corrections to log $K$ not listed under LEGENDRE $8(\alpha)$, and kept extra decimals in the calculations when I knew them. At $1^{\circ} .1$ LEGENDRE's errors in $\log K$ and $\log$ $K^{\prime}$ nearly cancel, so that Verhulst is nearly correct.

( $\beta) \log \log (1 / q), \theta=\left[15^{\circ}\left(0^{\circ} .1\right) 45^{\circ} ; 12 \mathrm{D}\right]$.

There are exactly four gross errors:

\begin{tabular}{crrr}
$\theta$ & \multicolumn{1}{c}{$D$} & For & Read \\
$15^{\circ} .5$ & 11 & 4 & 3 \\
21.0 & $9-10$ & 22 & 16 \\
30.9 & 8 & 6 & 5 \\
37.7 & 12 & 9 & 0
\end{tabular}

The correction to the last figure at $37^{\circ} .7$ is approximate, being that which brings Verhulst's value into agreement with LEGENDRE's $\log K$ and $\log K^{\prime}$, and also rectifies the differences. When the above corrections are made, the table differences very well, especially when it is remembered that it was formed by subtracting Legendre's log $K$ from his $\log K^{\prime}$ (and adding a constant, which, however, will not affect the differences); even if LEGENDRE had no rounding errors, Verhulst's values could frequently be wrong by one final unit. A similar remark applies to the $14 \mathrm{D}$ portion considered in $(\alpha)$ above. Verhulst's values are unaffected by the two gross errors (one obvious) at $24^{\circ} .9$ and $30^{\circ} .9$ in LEGENDRE 5 , listed under LEGENDRE $8(\beta)$, his error at $30^{\circ} .9$ being quite different; thus he probably used LEGENDRE 3 .

WAYNE 1.

(a) $E, k^{\prime}=[0(.01) 1 ; 3 \mathrm{D}]$.

Comparison with Schlömilch 1 and Schmidt 1 shows two slight rounding errors; at $k^{\prime}=.20$, for 1.050 , read 1.051 , and at $k^{\prime}=.81$, for 1.426 , read 1.425 .

\section{The Memory Tube and Its Application to Electronic Computation}

In a paper presented on 10 June 1947 at the IRE Electron Tube Conference, the author described a novel electronic device which is called the Memory Tube. ${ }^{1}$ The Memory Tube has the ability to record electrical signals in the form of a charge pattern deposited by an electron beam on a dielectric target, to store this information for any desired period of time, and to reproduce the stored information in the form of electrical signals as many times as desired, without erasing the recorded information. The recorded charge pattern or any part of it can be erased whenever desired. These characteristics of the Memory Tube make it useful for many applications, including electronic computation. The purpose of this paper is to review the basic principles of operation of the Memory Tube and to describe a special form suitable for use as a memory device in an electronic computer.

The Memory Tube resembles a conventional cathode-ray tube. At one end of an elongated envelope are placed one or more electron guns. At the other end is placed a dielectric target, which ordinarily consists of a glass plate coated with a suitable material, such as phosphor. In front of the target a fine-mesh metal screen is placed at a distance of a few thousandths of an inch from the target. The screen serves to control the electric field at the 